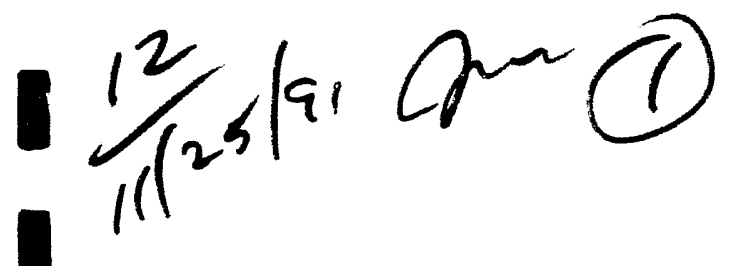

\title{
Fort Lewis Electric Energy Baseline and Efficiency Resource Assessment
}

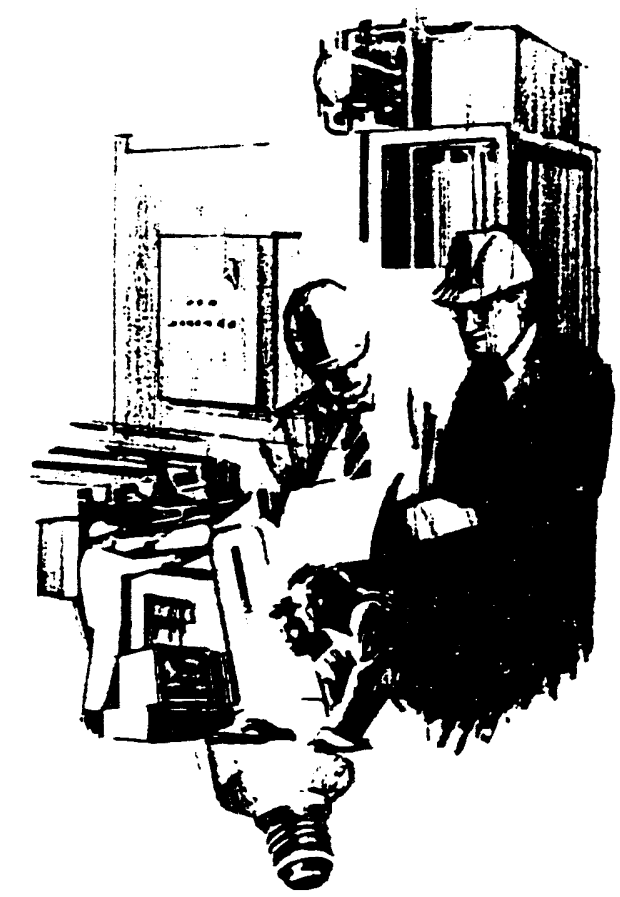

October 1991

Prepared for the U.S. Department of Energy

Federal Energy Management Program

under Contract DE-AC06-76RLO 1830

Pacific Northwest Laboratory

Operated for the U.S. Department of Energy

by Battelle Memorial Institute

\section{Battelle}




\title{
DISCLAIMER
}

This report was prepared as an account of work sponsored by an agency of the United States Government. Neither the United States Government nor any agency thereof, nor Battelle Memorial Institute, nor any of their employees, makes any warranty, expressed or implied, or assumes any legal liability or responsibility for the accuracy, completeness, or usefulness of any information, apparatus, product, or process disclosed, or represents that its use would not infringe privately owned rights. Reference herein to any specific commercial product, process, or service by trade name, trademark, manufacturer, or otherwise does not necessarily constitute or imply its endorsement, recommendation, or favoring by the United States Government or any agency thereof, or Battelle Memorial Institute. The views and opinions of authors expressed herein do not necessarily state or reflect those of the United States Government or any agency thereof.

\author{
PACIFIC NORTHWEST LABORATORY \\ operated by \\ BATTELLE MEMORIAL INSTITUTE \\ for the \\ UNITED STATES DEPARTMENT OF ENERGY \\ under Contract DE-ACO6-76RLO 1830
}

Printed in the United S/ates of America

Available to DOE and DOE contr Ictors from the

Office of Scientific and Technical Information, P.O. Box 62, Oak Ridge, TN 37831: prices available from (615) 576-8401. FTS 626-8401.

Available to the public from the National Technical Information Service,

U.S. Department of Commerce, 5235 Port Royal Rd., Springfield, VA 22161. 

T. J. Secrest
T. J. Marseille
J. W. Currie
G. B. Parker
J. G. DeSteese
E. E. Richman
J. A. Dirks
S. A. Shankle

October 1991

Prepared for

the U.S. Department of Energy

Federal Energy Management Program under Contract DE-AC06-76RLO 1830

Pacific Northwest Laboratory

Richland, Washington 99352 
In support of the U.S. Department of Energy Federal Energy Management Program, the Pacific Northwest Laboratory is developing a fuel-neutral approach for identifying, evaluating, and acquiring all cost-effective energy projects at federal installations. Fort Lewis, a U.S. Army installation near Tacoma, Washington, was selected as the pilot site for developing this approach. This site was chosen in conjunction with the interests of the Bonneville Power Administration to develop programs for its federal sector customers and the Army Forces Command to develop an in-house program to upgrade the energy efficiency of its installations.

This report documents the electricity assessment portion of the approach, providing an estimate of the electricity use baseline and efficiency improvement potential for major sectors and end uses at the Fort. Although the assessment did not identify all possible efficiency improvement opportunities, it is estimated that electricity use can be reduced by at 1 east $20 \%$ costeffectively at the $\$ 0.045 / \mathrm{kWh}$ marginal cost of electricity in the Pacific Northwest. 


\section{SUMMARY}

The mission of the U.S. Department of Energy (DOE) Federal Energy Management Program (FEMP) is to lead the improvement of energy efficiency and fuel flexibility within the federal sector. Through Pacific Northwest Laboratory, FEMP is developing a fuel-neutral approach for identifying, evaluating, and acquiring all cost-effective energy projects at federal installations. FEMP believes that the Bonneville Power Administration (Bonneville), as part of the federal sector and DOE, can actively support the identification, characterization, and procurement of electric energy efficiency resources from federal customers within the Bonneville service territory. For this reason, FEMP approached Bonneville with the proposal to develop a pilot program with a large federal customer in Bonneville's service territory. The purposes of that program would be to identify and acquire all cost-effective electric energy efficiency resources within the customer's infrastructure. FEMP emphasized that, to the extent possible, the pilot program should not require the federal customer to either procure an energy services contractor or provide capital funds. FEMP has identified these two requirements as major obstacles in the path of federal agencies/installations attempting to aggressively pursue energy efficiency programs. Bonneville agreed that significant energy efficiency resources existed within the federal customer base, that a pilot program was warranted, and that it should be designed to overcome these obstacles. FEMP and Bonneville agreed to fund the Pacific Northwest Laboratory (PNL), FEMP's lead laboratory, to identify and recruit a federal customer and to conduct a fuel-neutral efficiency assessment at the federal facility.

It was agreed that the pilot program should be designed to be transferable to other federal customers within the Bonneville service territory. To have maximum impact, the program should also be transferable to federal customers outside of Bonneville's service territory. This condition meant that the program would likely have greater transferability if the federal customer were not served directly by Bonneville but by a utility that purchased power from Bonneville. This would give the program maximum credibility when FEMP/PNL transfer the "lessons learned" to other utility service territories and other states. 
The conditions just described dictated the criteria that PNL used to identify the most appropriate federal customer to participate in the program. First, we knew from our experiences at over 20 large federal installations that a necessary condition for the program to be successful was that the federal customer be thoroughly committed to working through the process. We also knew that the federal customer needed to be served by a utility committed to inrovative approaches in demand-side management programs--ideally, a utility that had demonstrated commitment to the fundamental principles of least-cost planning.

Fortunately, all conditions were quickly met. FEMP has a cooperative program with the Army Forces Command (FORSCOM) for providing technical as istance to FORSCOM installations. FEMP and FORSCOM have agreed to cost-share activities in developing innovative approaches to energy efficiency at the latter's installations. One of those installations is Fort Lewis (near Tacoma, Washington), with whose key staff PNL had already developed a working relationship. In addition, Fort Lewis is served by Tacoma Public Utilities (TPU), which has demonstrated a commitment to energy efficiency programs over the years and enthusiastically embraced the concept. All these parties became involved in the pilot program.

The overall goals of the pilot program are

- to demonstrate a model approach for identifying and characterizing al1 cost-effective energy efficiency at Fort Lewis such that the approach can be transferred to other federal installations

- to acquire all cost-effective energy efficiency identified and characterized at Fort Lewis

- to acquire all cost-effective electric energy efficiency at Fort Lewis through a TPU/Bonneville agreement that would not require the Fort to either procure energy service contractors or provide any up-front capital.

The latiar goal can be accomplished through the Targeted Resources Acquisition Program offered by Bonneville. This program enables utilities that purchase power from Bonneville to identify and buy electric energy efficiency resources from the utilities' customers, then sell those resources back to Bonneville for use elsewhere in its service area. However, to take full 
advantage of this program, utilities such as TPU must prepare a proposal to Bonneville that tells the agency where and what the potential resources are, and how the utility plans to evaluate those estimated resources to determine their actual extent. The federal installation whose potential resources are being estimated also needs this information so it can decide whether or not to commit its share of the cost of the recommended retrofits.

In this report, we describe PNL's assessment of the electric energy efficiency resource potential at Fort Lewis. Through this assessment, we developed an estimate of the electricity use baseline and efficiency improvement potential for major sectors and end uses at the Fort. Developing the baseline was essential to segment the end uses that are targets for broad-based efficiency improvement programs and to provide TPU with the basis for its proposal to Bonneville. An estimate of the efficiency resource is presented to reflect the available quantity of resource for three electricity price ranges. The baseline and efficiency resource estimates did not identify all possible areas of opportunity, but instead identified the majority of the resource; areas of additional opportunity are noted, to encourage further effort.

\section{BASELINE ELECTRICITY USE}

Fort Lewis houses approximately 25,000 full-time residents. The Fort has a daytime population of approximately 35,000 persons. The annual fuel consumption is about 2.5 trillion Btu, of which $26 \%$ is in the form of electricity (annual average of 195,000 MWh). The annual cost of energy supplied to the Fort is over $\$ 12$ million, of which about $\$ 4.5$ million is for electricity.

In developing the baseline electricity use, we segmented the Fort into sectors, subsectors, and end uses to reflect major areas of consumption and efficiency potential. The four sectors identified were buildings, pumps/ motors, distribution, and exterior lights. The sectors were further segmented into subsectors and, in the case of buildings, end uses (interior lighting, domestic hot water [DHW], refrigeration, and other).

An estimated 4457 buildings with floorspace of 23.9 million $\mathrm{ft}^{2}$ are on the installation. We segmented the buildings sector into 16 subsectors (building types) based upon function and uniqueness of operation. Nine of the 
building types account for over $90 \%$ of the total floorspace. Principal contributions are family housing at nearly $25 \%$, barracks at nearly $20 \%$, office/ administration and warehouse each at over $12 \%$, other at nearly $9 \%$, the New Madigan Hospital at over $8 \%$, and motor pools with $8 \%$ of the total floorspace.

End uses identified in the buildings sector include five lighting type categories, domestic hot water supplied by residential-type water heaters, refrigeration supplied by residential-type refrigerators, and all other uses. The other category contains heating, ventilating, and air-conditioning (HVAC) energy end uses that are specific to each building type. HVAC energy use was not separated because almost all heating energy is supplied by fossil fuel and few buildings are cooled; electricity use for HVAC is primarily for fans and pumps.

The pumps/motors sector reflects electricity use for large pumps and motors (10 to 250 horsepower) used for the water supply and sewage treatment subsectors. The distribution sector accounts for the losses incurred for electricity distribution through the transformer and feeder subsectors. We segmented the exterior lights sector into three subsectors: residential, nonresidential (building exterior and parking lot lighting), and street lighting.

The limited availability of metered data created a challenge in developing the baseline electricity use. The Fort is served by three substations, designated as Madigan, South, and Central. Each is metered separately by TPU for both demand and power use. Aside from the commercial (nonappropriated) buildings on the Fort, these are the only sites where electricity use for the installation is metered. Seventeen feeder lines from these three substations provide all electrical power to the fort.

We metered each of the substations and feeders separately and collected time-series data for 4 consecutive months. The primary purpose of the metering was to measure the electric demand profile of the Fort and determine the relative contributions to that demand of each of the three substations and 17 feeders. The secondary purpose was to provide the only metered data for an accurate assessment of the electrical energy use intensities of the building stock. 
We used the metered data to ascertain and pinpoint the potential for energy efficiency opportunities in the various sectors of the site served by the 17 feeders, for both demand and baseload savings. The data were also used to more accurately determine the estimated energy use and energy use intensities of each of the major building and facility types at the Fort. Without these feeder-level metered data, we would have had to perform the analysis using TPU's billing data from the three substations. Thus, much more uncertainty would have been associated with this foundational analysis.

The metering results showed that the Fort has an annual baseload demand of 15,000 to $17,000 \mathrm{~kW}$, and that the peak demand of 27,000 to $30,000 \mathrm{~kW}$ usually occurs before noon, depending upon the season. The Central substation accounted for nearly $50 \%$ of the total Fort demand. From the data, we also determined that most of the $16^{\text {(a) }}$ feeder loads were not temperaturedependent; therefore, opportunities for electrical energy savings (kilowatthours) exceed the opportunities for demand savings (kilowatts).

The bas:line electricity use displayed in Table S.I was developed for the buildings sector end uses and estimated subsector consumption or losses for the oiner three sectors. The estimates were developed using limited primary energy use data for the Fort, other studies conducted to identify efficiency improvements at the Fort, input from installation staff, and other published studies. The estimated annual energy use of $197,000 \mathrm{MWh}$ was not adjusted to match the average actual of 195,000 MWh from billing data.

The buildings sector accounts for over $85 \%$ of the electricity use. Four of the building types account for over $46 \%$ of the total; these were singlefamily at $12.9 \%$, multifamily at $10.7 \%$, concrete barracks at $11.4 \%$, and office/ administration at $11.5 \%$. Pumps/motors consume an estimated $2.4 \%$ of the total, distribution 10 sses $7.6 \%$, and exterior lighting nearly $4 \%$.

(a) One of the feeders was a switching alternate and no load was measured
during the monitoring period. 
TABLE S.1. Estimated Baseline Electricity Use Per Year by Sector, Subsectur, and End Use

\section{Sector}

Building

Single-Family
Multifamily
Concrete Barracks
Wood Barracks
Office/Administration
Warehouse
Motor Pool
Hangar
Dining Halls
Clubs
Old Madigan Hospital
New Madigan Hospital
Commissary
Computer Center
Simulators
Other
Subtotal

Pumps/Motors Water Supply

Sewage Treatment

Subtotal

Distribution

Transformer Loss

Line Loss

Subtotal

Exterior Lights

Residential

Other Building

Street

Subtotal

Total

$\%$ of Total
Estimated Baseline Electricity Use (MWh)

\begin{tabular}{|c|c|c|c|c|}
\hline ighting & $\mathrm{DHW}$ & Ref & other & Total \\
\hline $\begin{array}{r}4,210 \\
3,713 \\
10,431 \\
1,088 \\
10,368 \\
6,025 \\
5,122 \\
1,084 \\
1,252 \\
1,154 \\
4,502 \\
5,959 \\
735 \\
118 \\
230 \\
4,873 \\
60,867\end{array}$ & $\begin{array}{r}9,287 \\
7,650 \\
\\
1,817 \\
26 \\
1,140 \\
92\end{array}$ & $\begin{array}{l}2,477 \\
2,0<, 0\end{array}$ & $\begin{array}{r}9,339 \\
7,707 \\
12,064 \\
982 \\
10,478 \\
4,990 \\
3,682 \\
912 \\
5,955 \\
2,410 \\
8,807 \\
2,023 \\
4,515 \\
376 \\
4,564 \\
4,249 \\
83,053\end{array}$ & $\begin{array}{r}25,313 \\
21,110 \\
22,495 \\
2,071 \\
22,663 \\
11,041 \\
9,944 \\
2,088 \\
7,207 \\
3,565 \\
13,309 \\
7,982 \\
5,250 \\
494 \\
4,797 \\
9,759 \\
169,088\end{array}$ \\
\hline
\end{tabular}

$$
\begin{array}{ll}
3,600 & 3,600 \\
1,160 & 1,160 \\
4,760 & 4,760
\end{array}
$$

13,000

2,000

13,000

2,000

15,000

15,000

1,290

2,453

4,000

7,744

1,290

2,453

4,000

7,744

68,611

20,653

4,517

102,813

196,591

34.9

10.5

2.3

52.3

100.00 
of the total consumption, nearly $35 \%$ is accounted for by lighting, over $10 \%$ by domestic hot water, over $2 \%$ by refrigeration, and the balance of $52 \%$ by other uses. Within the lighting end use, approximately $22 \%$ of total electricity is fluorescent lighting energy, of which most is consumed in fixtures with 4-ft F-40 type tubes. Incandescent and high-intensity-discharge (HID) 1 ighting account for $8.7 \%$ and $4.4 \%$, respectively, of the remainder of total electricity consumption.

\section{ELECTRIC EFFICIENCY RESOURCE SUPPLY}

The supply of the electric efficiency resource was estimated for all subsectors and end uses except the other category in the building subsectors. The quantity of energy resuurce available was estimated for three electricity price ranges: \$0 through \$0.023/kilowatt-hour (kWh), \$0.024 through $\$ 0.045 / \mathrm{kWh}$, and $\$ 0.046$ through $\$ 0.075 / \mathrm{kWh}$. The endpoint of the first price range chosen is the approximate price that Fort Lewis currently pays for electricity (including demand charges), the endpoint of the second price range is the approximate avoided cost for new electricity generation in the Pacific Northwest, and the endpoint of the last cost range is chosen as an arbitrary point beyond which there is clearly no cost-effective technology options.

The potential menu of efficiency measures considered by sector and end use was as follows:

\section{Buildings}

\section{Interior Lighting}

- Replace incandescent bulbs with compact fluorescent in $15 \%$ of the indoor residential fixtures, $75 \%$ of the indoor fixtures in other buildings, and $100 \%$ of the exterior fixtures.

- Replace standard magnetic ballasts with energy-efficient magnetic ballasts in two-tube fluorescent fixtures using 34-, 40-, and 75-W tubes.

- Replace standard magnetic ballasts with electronic ballasts in two-tube fluorescent fixtures using $34-, 40-$, and 75-W tubes.

- Replace standard magnetic ballasts with tunable electronic ballasts in two-tube fluorescent fixtures using 34-, 40-, and 75-W tubes. 
- Add parabolic reflectors to two-tube fluorescent fixtures using 34-, $40-$, and $75-W$ tubes.

- Replace two-tube fluorescent fixtures using 34-, 40-, and 75-W tubes with new fixtures with reflectors and electronic ballasts.

- Replace two-tube fluorescent fixtures using 75-W tubes with 150-W highpressure sodium lamps.

- Replace two-tube fluorescent fixtures using 75-W tubes with single-tube 75-W very-high-output (VHO) fixtures.

- Replace two-tube fluorescent fixtures using 34- and 40-W tubes with F-30 T-8 fixtures.

Lighting replacements were made on a constant level of service basis.

That is, if a replacement put out twice the level of light (measured in lumens), a one-for-two replacement was used.

\section{Domestic Hot Water}

- Increase the insulation level of the tanks by wrapping all of the water heaters with insulation.

- Wrap only new water heaters (less than 2 years old) with insulation.

- Replace $100 \%$ of existing water heaters with high-efficiency water heaters with nonmetallic or lined tanks. Information from the Fort Lewis staff indicates that life expectancy for water heaters is less than 5 years due to tank corrosion caused by carbonic acid. In addition, TPU staff encouraged consideration of a water heater replacement program with high-efficiency models, as that utility has experienced greater success with a replacement program than with wrap programs.

- Replace water heaters upon failure with high-efficiency water heaters with nonmetallic or lined tanks.

Refrigeration

- Replace $100 \%$ of existing residential-type refrigerators.

Replacing refrigerators with high-efficiency models as the. wear out rather than implementing a straight replacement program as above was not considered because it is understood that all models now available are of the "efficient" variety. Consequently, there is little differential between replacement options. 


\section{Pumps/Motors}

\section{Water Supply}

- Total'y replace well pump motors with high-efficiency motors.

- Replace well pump motors with high-efficiency motors upon failure.

\section{Sewage Treatment}

- Totally replace sewage treatment pump motors with high-efficiency motors.

- Replace sewage treatment pump motors with high-efficiency motors upon failure.

For both the water supply and sewage treatment subsectors, existing motors were assessed individually for replacement because the number of operating hours varied significantly, which has a large effect on the leve1ized energy cost. The cost and efficiency improvement also varies with motor size.

\section{Distribution}

\section{Transformer Loss}

- Replace existing transformers with high-efficiency units. Existing transformers were assessed by size category for replacement.

\section{Line Loss}

- Regulate the voltage of the distribution system so that the most distant point on individual feeders meets minimum voltage requirements uiider all load conditions. Although insufficient information to quantify the resource is available for this measure, it is estimated to provide a reduction of $1 \%$ to $3.5 \%$ in total baseload at a very iow cost (up to $\$ 0.01 / \mathrm{kWh}$ ).

\section{Exterior Lighting}

Residential

- Replace $100 \%$ of incandescent bulbs with compact fluorescent bulbs.

The levelized energy cost (LEC), net present value (NPV), and annual efficiency resource availability of each messure considered are displayed in 
Table 5.2. The regional power planning perspective using LEC shows the cost of the measures ranging from $\$ 0.0056$ to over $\$ 0.158 / \mathrm{kWh}$. The federal sector perspective using NPV is shown for the Fort paying $15 \%$ of the capital cost and $100 \%$ of the operations and maintenance (08M) cost.

The data developed and displayed in Table S.2 will allow the utility and Fort to choose the electric energy efficiency measures to install in the sitewide retrofit. The choices will hinge on the firal cost-sharing agreement as well as the agreement on the LEC ceiling value and NPV criteria. A federal agency is required to select energy efficiency options based on the NPV. The option with the highest NPV is selected. The decision criteria for a utility to choose among energy efficiency measures is based on the LEC.

Using the LEC values, efficiency measures up to the cost of the marginal supply resource for Bonnevilie (\$0.045/kWh) may be considered cost-effective. Using the NPV approach, measures with the highest NPV may be considered costeffective by the Fort. The choice is generally options that are below the utility's avoided cost (long-run marginal cost) of supplying electricity.

All options that are not part of mutually exclusive sets that have an LEC less than the avoided cost should be selected. Options that are part of mutually exclusive sets should be chosen if they have the LEC closest to the avoided cost of energy, but not exceeding it.

For example, based on NPV, the best choice for retrofitting fluorescent lighting fixtures having $40-W$ tubes was determined to be a total new fixture with electronic ballast and reflector (the choice shown in Table S.2). This choice also shows a LEC of $\$ 0.0166 / k$ Wh which will also be acceptable to the utility. Another viable choice for fixture replacement may be retrofitting with a higher efficiency type T-8 fixture. The NPV (shown in Table S.2) is near that of the high efficiency fixture and the LEC is $\$ 0.0245 / \mathrm{kWh}$, below the Bonneville avoided cost. However, the marginal LEC for this retrofit is $\$ 3.7801 / \mathrm{kWh}$ which is well above the long-term avoided cost. Based on these data, this technology may not be selected.

Other choices analyzed included ballast replacement (only) or adding reflectors for replacement (not shown in Table S.2). These had a lower NPV, a 


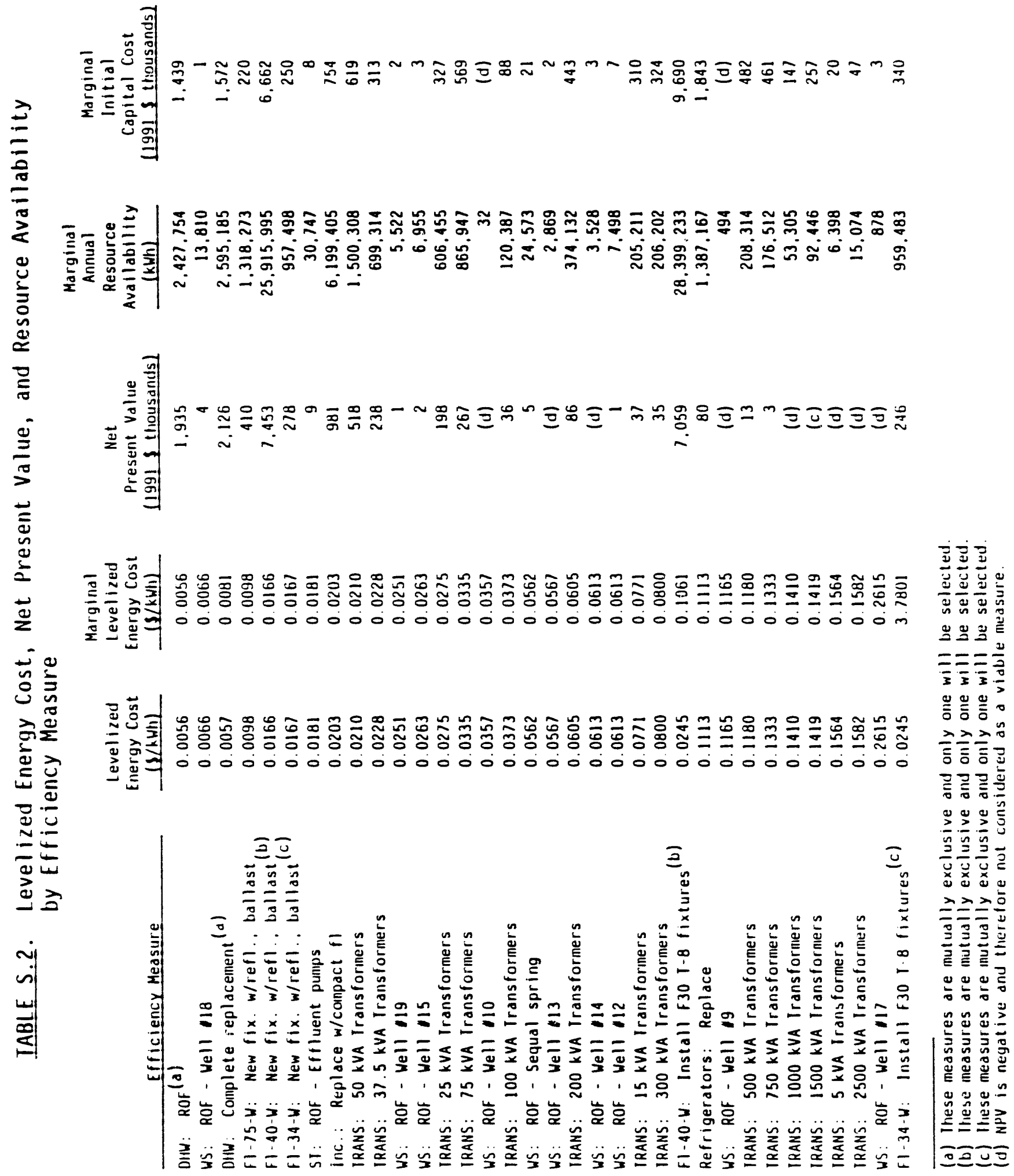


negative marginal energy savings compared to complete fi::ture replacement. These technologies also had higher LECS compared to the complete fixture repl acement.

Examination of the results of the analysis with the estimated costsharing split in Table S.2 shows that the choice of criteria (LEC or NPV) will not significantly affect the ultimate choice of energy efficiency measures to be installed at the Fort. The most desirable measures, in terms of both overall energy savings and in terms of NPV, couid be selected and implemented using either criteria.

The LEC and resource availability are displayed in Figure S.1 in the form of a supply curve. This shows availability of about 43,000 average annual MWh of electric efficiency at a cost of less than $\$ 0.037 / \mathrm{kWh}$. Above $\$ 0.037 / \mathrm{kWh}$, less than an additional 1,500 MWh are available.

Figure S.2 shows the resource availability by end use for LEC cost ranges of $\$ 0$ to $\$ 0.023 / \mathrm{kWh}, \$ 0.024$ to $\$ 0.045 / \mathrm{kWh}$, and $\$ 0.046$ to $\$ 0.075 / \mathrm{kWh}$. In the lowest cost range, over 37,000 average annual MWh (equivalent to over 4 average annual MW of capacity) are provided by efficiency improvements to water heaters, water supply pumps, interior lighting, exterior lighting, water treatment pumps, and voltage regulation at an estimated initial capital cost of about $\$ 9$ million. Other transformer and water supply pump replacements, in addition to a different set of lighting and water heating improvement;, contribute another 5,907 MWh to the resource potential for the mid-range cost. The upper cost range contains another 412 MWh provided by additional water supply pump and transformer replacements. Lighting measures account for over $90 \%$ of the efficiency resource available in the lowest cost range and nearly $85 \%$ of the resource of the total available up to a cost of $\$ 0.075 / \mathrm{kWh}$.

\section{ADDITIONAL RESOURCE OPPORTUNITIES}

A number of additional resource opportunities were identified in the assessment. Their potential contribution was not quantified because they are 


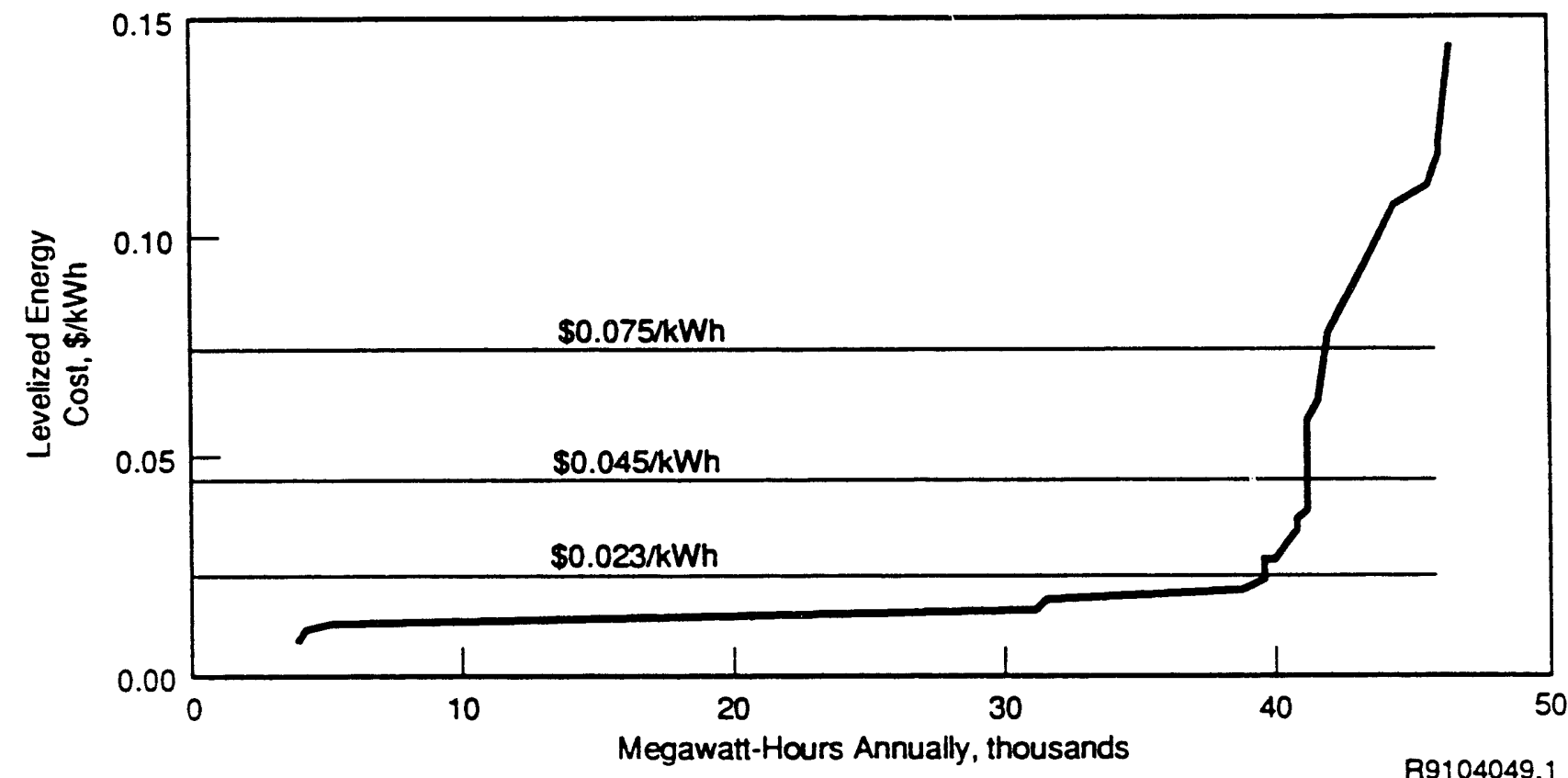

FIGURE S.1. Electric Efficiency Supply Curve

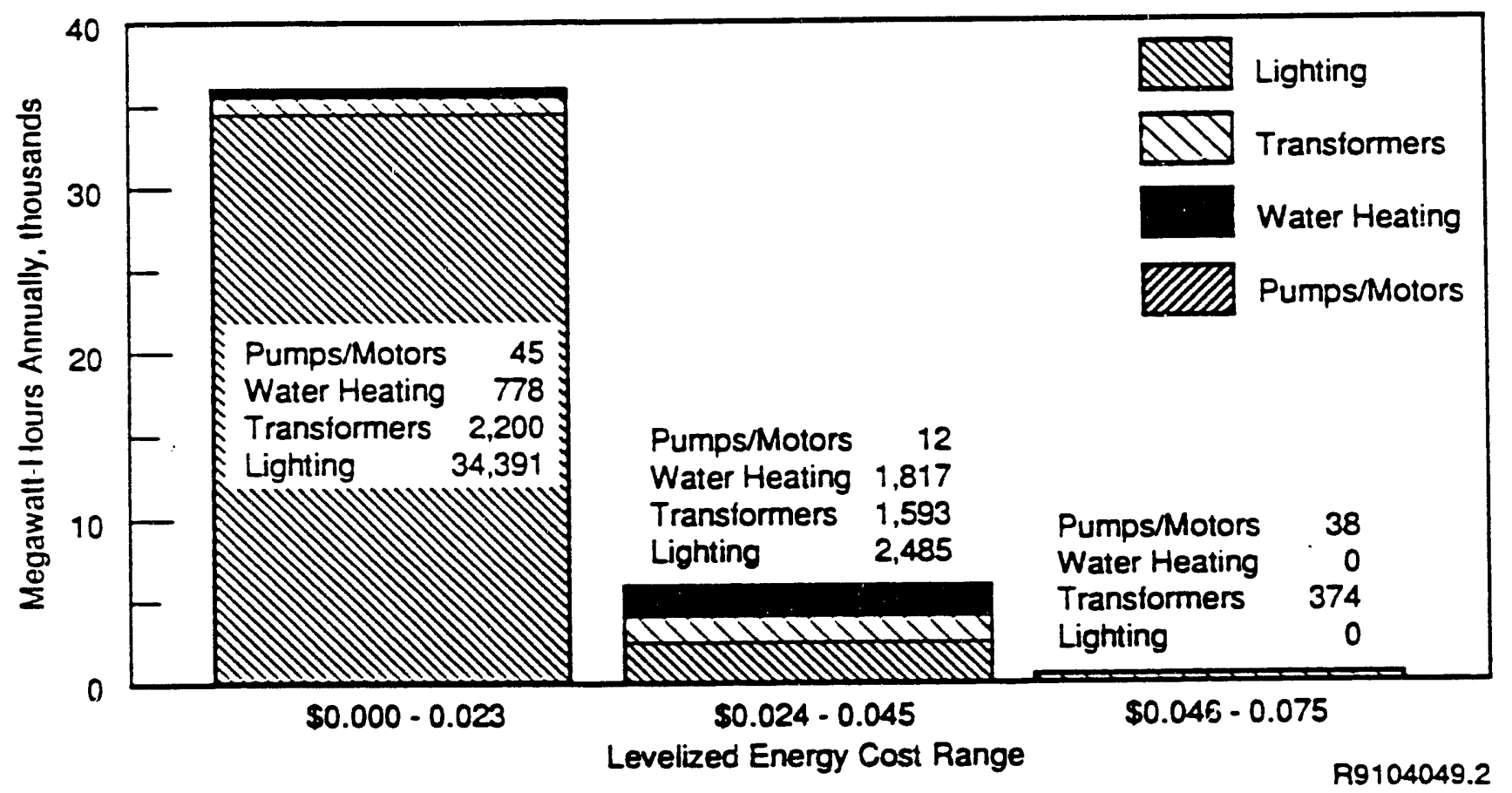

FIGURE S.2. Electric Efficiency Resource by End Use and Cost Category 
addressable only through more focused data collection efforts, which are beyond the scope of this initial effort. A listing of these resource opportunities by sector follows.

\section{Buildings}

- incandescent lighting - Replace those fixtures currently unable to accommodate compact fluorescent lamps to increase the penetration levels in addition to replacing bulbs in fixtures that will accept them.

- lighting controls - Implement controls to adjust for daylighting and/or occupancy. Daylighting controls are reportedly in operation in Building 3670 .

- HVAC - Improve heating and/or cooling efficiencies in buildings having electric heating and/or cooling equipment through a combination of higher-efficiency equipment, improving the building envelope thermal integrity, and/or improving operation and maintenance practices.

- heat recovery - Recover heat from exhaust airstreams in building types such as dining halls and clubs.

- low-flow shower heads - This measure is reported to be in place in most, if not all, applications.

\section{Pumps/Motors}

- replacement of motors less than 10 horsepower - This option would likely have high potential for motors that operate nearly continuous $7 y$. However, an inventory of the stock and operating schedules of small motors was not available, nor was an estimate developed.

- modification of related systems - One example would be to increase pipe size to reduce horsepower required to maintain pressure.

- implementation of operation and control practices - This provides for automated operation of the water supply system.

\section{Distribution}

- replacement of existing transformers as they fail with high-efficiency units, which may improve the cost-effectiveness of this measure

- the value of other distribution improvements, such as reconductoring feeders and adding capacitors, will reduce line losses and improve power factors. 


\section{Exterior Lighting}

- installation of new, and replacement of faulty, photocells to reduce or eliminate exterior lighting during daylight hours

- replacement of existing low-efficiency HID lighting with high-efficiency units

- replacement of incandescent lamps that are greater than $200 \mathrm{~W}$ with HID or other suitable high-efficiency alternative.

\section{RECOMMENDATION}

Our analysis indicates that significant cost-effective energy efficiency potential exists at Fort Lewis. At $\$ 0.023 / \mathrm{kWh}$, about 37,000 annual MWh of energy efficiency are available at an estimated capital cost of $\$ 9$ million. The Fort's electrical utility, TPU, has available several demand-side program options through its supplier, Bonneville. The most likely option appears to be the Bonneville Targeted Acquisition Program under which TPU purchases the efficiency from Fort Lewis and sells it to Bonneville at Bonneville's avoided cost of electricity, which is about $\$ 0.045 / \mathrm{kWh}$. The terms of the arrangement being discussed would have Fort Lewis contribute $15 \%$ of the capital investment, with the balance funded by TPU and Bonneville. Provided that there are no unresolvable contractual and technical issues, the potential exists for Fort Lewis to enter into an agreement with TPU for the approximately 37,000 annual MWh (4 annual average MW) of cost-effective energy efficiency resources identified.

The PNL assessment is a first cut at estimating the electrical energy efficiency potential at Fort Lewis. As such, the results should be useful to the Fort in determining if an aggressive energy efficiency program is warranted and, if so, which options should be implemented. Our results should not be used to draw conclusions regarding the cost-effectiveness of marginal technologies or specific end-use products. These refinements require more detailed analyses. 


\section{CONTENTS}

ABSTRACT

i i i

SUMMARY

v

ABBREVIATIONS AND ACRONYMS .................... . xxii

1.0 INTRODUCTION . . . . . . . . . . . . . . . . . 1.1

1.1 ASSESSMENT SCOPE .................... 1.1

1.2 REPORT ORGANIZATION . . . . . . . . . . . . . . 1.3

1.3 REFERENCES . . . . . . . . . . . . . . . 1.3

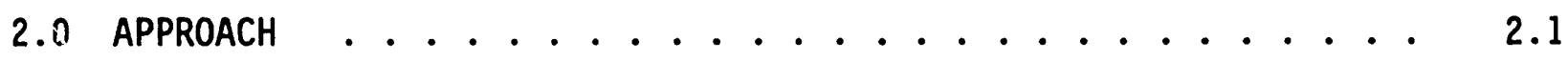

2.1 BASELINE DEVELOPMENT .................. 2.1

2.1.1 Sector Segmentation ............. 2.1

2.1.2 End'-Use Intensity and Baseline Development . . . 2.4

2.2 ANALYSIS APPROACHES ................. 2.5

2.2.1 Supply Curve ................. 2.5

2.2.2 Life Cycle Cost and Net Present Value . . . . . 2.6

2.3 SUPPLY CURVE DEVELOPMENT . . . . . . . . . . . . . . 2.7

2.3.1 Process ................... 2.7

2.3.2 Efficiency Measures . . . . . . . . . . 2.8

2.4 REFERENCE ...................... 2.12

3.0 BASELINE AND EFFICIENCY ESTIMATES . . . . . . . . . . . . . . 3.1

3.1 BUILDINGS SECTOR PROFILE . . . . . . . . . . . . . 3.1

3.2 ELECTRICITY USE BASELINE . . . . . . . . . . . . 3.2

3.3 ELECTRIC EFFICIENCY SUPPLY CURVE . . . . . . . . . . 3.6

3.4 Net PRESENT VAlUe . . . . . . . . . . . . . . . 3.11

3.5 CHOOSING ENERGY EFFICIENCY MEASURES . . . . . . . . . . . 3.11 
3.5.1 Criteria................. 3.11

3.5.2 Example ................. 3.14

APPENDIX A - DATA SOURCES . . . . . . . . . . . . . A.1

APPENDIX B - BUILDINGS SECTOR BASELINE AND EFFICIENCY ASSESSMENT • • B.1

APPENDIX C - MOTOR BASELINE AND EFFICIENCY ASSESSMENT . . • . . . c c.l

APPENDIX D - TRANSFORMER LOSS AND VOLTAGE REGULATION EFFICIENCY

ASSESSMENT ....................... D.1

APPENDIX E - EXTERIOR LIGHTING SECTOR BASELINE AND EFFICIENCY

ASSESSMENT ..................... E.1 


\section{FIGURES}

S.1 Electric Efficiency Supply Curve . . . . . . . . . . . xvi

S.2 Electric Efficiency Resource by End Use and Cost Category . . . xvi

3.1 Electric Efficiency Supply Curve . . . . . . . . . . . . 3.9

\section{TABLES}

S.1 Estimated Baseline Electricity Use Per Year by Sector,

Subsector, and End Use ................... $x$

S.2 Levelized Energy Cost, Net Present Value, and Resource Availability by Efficiency Measure . . . . . . . . . . . x xv

3.1 Fort Lewis Building Stock Description . . . . . . . . . 3.2

3.2 Substations and Feeders Serving Fort Lewis . . . . . . . . 3.4

3.3 Buildings Sector Electricity End-Use Intensities . . . . . . 3.5

3.4 Estimated Electric Baseline by Sector, Subsector, and End Use . 3.7

3.5 Levelized Energy Cost and Efficiency Resource by Measure and Cumulative Efficiency Resources . . . . . . . . . . 3.8

3.6 Electric Efficiency Resource Availability by End Use and Cost Range....................... 3.10

3.7 Net Present Value of Efficiency Measures by End Use for Measures with Highest NPV .............. 3.12 
AACE

Bonneville

CAD

CVR

DHW

DOE

DSM

ECO

eff

EIA

ELCAP

EMCS

EPA

EUI

FEDS

FEMP

f1

FORSCOM

HID

hp

HPS

HVAC

inc

kVA

$\mathrm{kW}$

kWh

LCC

LEC

MW

MWh

$N / A$

NIST

NPV
American Association of Cost Engineers

Bonneville Power Administration

computer-aided design

conservation voltage regulation

domestic hot water

U.S. Department of Energy

demand-side management

energy conservation opportunity

efficient

Energy Information Administration

End-Use Load and Corisumer Assessment Program

emergency manag'sment control system

U.S. Environmerital Protection Agency

end-use intensity

Facility Energy Decision Screening

Federal Energy Management Program

fluorescent

Army Forces Command

high-intensity discharge

horsepower

high-pressure sodium

heating, ventilating, and air conditioning

incandescent

kilovolt-ampere

kilowatt

kilowatt-hour

life cycle cost

levelized energy cost

megawatt

megawatt-hour

not applicable

National Institute of Standards and Technology

net present value 


$\begin{array}{ll}\text { NWPPC } & \text { Northwest Power Planning Council } \\ \text { O\&M } & \text { operations and maintenance } \\ \text { PNL } & \text { Pacific Northwest Laboratory } \\ \text { ref } & \text { refrigeration } \\ \text { ROF } & \text { replace on failure } \\ \text { SES } & \text { shared energy savings } \\ \text { TPU } & \text { Tacoma Public Utilities } \\ \text { trans } & \text { transformer } \\ \text { VHO } & \text { very-high-output } \\ \text { W } & \text { watt } \\ \text { WS } & \text { water supply }\end{array}$




\subsection{INTRODUCTION}

Under the National Energy Conservation Policy Act (as ammended 1988), the federal government is required to reduce energy use in its facilities $10 \%$ per square foot from 1985 levels by 1995. A new Executive Order on federal energy management (56 FR 12759) was signed in April 1991, which sets a goal of $20 \%$ reduction in federal facility energy use, and $20 \%$ industrial process efficiency improvements by the year 2000 (from 1985 levels). These goals are to be achieved by the implementation of life cycle cost-effective energy end-use technologies, utilizing utility demand-side management (DSM) programs, and shared energy savings (SES), to provide a significant portion of the funding for efficiency improvements.

A major obstacle to reducing energy use in large federal installations is the current inability to characterize energy consumption by major sector and end use in detail sufficient to enable more than limited efficiency acquisition efforts. These installations are typically the size of small cities, and, for the most part, energy use is not metered except at the installation level. The Fort Lewis Electric Energy Baseline and Efficiency Resource Assessment is being conducted by the Pacific Northwest Laboratory (PNL)(a) under the direction of the Department of Energy (DOE) Federal Energy Management Program (FEMP), the Bonneville Power Administration (Bonneville), and the Army Forces Command (FORSCOM) to develop a systematic approach with which to identify energy efficiency potential in large federal installations. This approach will be used to support energy efficiency acquisition programs in other major federal sector installations in the United States and abroad.

\subsection{ASSESSMENT SCOPE}

The Fort Lewis Electric Energy Baseline and Efficiency Resource Assessment characterizes baseline energy use at Fort Lewis by major sector and end use and develops an estimate of the major areas of electric energy efficiency potential. The purposes of this assessment are to support the development of

(a) Operated by Battelle Memorial Institute for the U.S. Department of Energy under Contract DE-AC06-76RLO 1830. 
a methodology that will enable replication of the process at other installations with less effort and to provide baseline information in support of electric efficiency acquisition activities at the Fort Lewis installation. Specific recommendations and technologies for improving facility electricityuse efficiency are not within the scope of this effort.

Two objectives are supported in this multiagency effort:

- to demonstrate the Facility Energy Decision Screening (FEDS) approach for identifying and characterizing the cost-effective energy efficiency resource at a large federal installation, which can be transferred to other installations

- to support the acquisition of the Fort Lewis electric energy efficiency resource by Tacoma Public Utilities (TPU) and Bonneville.

FEMP and other federal agencies are cofunding the developmerit of the FEDS methodology, which will enable federal installation energy managers to define the baseline facility energy use and identify the combination of energy supply and efficiency resources that meet installation mission requirements at least cost. The electricity resource assessment contained in this report supports that aspect of the FEDS methodology development. A separate but similar assessment is under way for energy supplied to Fort Lewis by natural gas and fuel $0 i 1$.

FORSCOM and Bonneville have cofunded the assessment of baseline electricity use at Fort Lewis and of major areas for electric energy efficiency improvement. This assessment is to support the acquisition of electric energy efficiency through a financial partnership among Fort Lewis, Bonneville, and TPU. This utility is the Fort's supplier of electricity. Under the terms of this partnership, Fort Lewis will contribute 15\% of the capital investment for the efficiency improvements. The balance will be funded by TPU and Bonneville through Bonneville's Targeted Acquisition Program. This program enables electric utilities to identify and buy energy efficiency resources from the utilities' customers and then sell those resources back to Bonneville for use elsewhere. Bonneville may also use the assessment process in implementing efficiency resource acquisition programs at other major federal facilities within its service area in the Pacific Northwest. 
The product of this assessment is a characterization of electric energy consumption at Fort Lewis by major use sector and major end use within each sector where significant efficiency potential can be accessed with a broadbased efficiency acquisition program. End-use consumption within a sector is not characterized in sufficient detail to identify the efficiency potential that may be obtainable through more focused acquisition activities. However, PNL has identified those additional opnortunities where focused activities may provide for the acquisition of efficiency beyond that identified in the major end uses.

\subsection{REPORT ORGANIZATION}

The text of this report provides an overview of the assessment. In Section 2.0, the approach used to develop the baseline electricity use characterization for Fort Lewis and the levelized cost methodology to develop the efficiency resource supply curve are described. Section 3.0 presents the electricity use baseline and efficiency resource supply curve.

The appendixes provide a detailed discussion of the derivation of the electricity use baseline and efficiency resource. Appendix A presents the data sources used to support the assessment. The buildings sector baseline and efficiency assessment are contiined in Appendix B. The motors sector, covered in Appendix $C$, addresses water supply and sewage treatment. Appendix $D$ provides the treatment of transformers and voltage regulation for the distribution system. The exterior lighting energy baseline and efficiency resource are presented in Appendix E.

\subsection{REFERENCES}

56 FR 12759. April 19, 1991. "Federal Energy Management." Federal Register. National Energy Conservation Policy Act, Public Law 95-619, 42 USC 8253. 


\subsection{APPROACH}

This section explains the approach we used to characterize the baseline electric energy use at soic Lewis and to develop a bottom-line estimate of the efficiency resource available. The approach is similar to those used by many electric utilities for developing load forecasts and assessing the energy efficiency potential available through various acquisition programs.

The first step is to identify the major energy-using sectors, subsectors, and end uses and to develop an energy consumption baseline. The second step develops two cost measures for depicting the financial attractiveness of the efficiency resources. Utilities typically use a levelized cost measure to express the cost of supply-and demand-side resources on a dollars per kilowatt-hour basis to develop a supply curve relating the quantity of resource available at a schedule of prices. Federal agencies are required by 10 CFR 436 to evaluate cost-effectiveness using a life cycle cost (LCC), net present value (NPV) measure.

The approach used to develop the Fort Lewis electricity use baseline is described in Section 2.1. This discussion contains the breakdown \&f sectors, subsectors, and end uses, and the development of the end-use intensities (EUIs). The two cost approaches and supply curve concept are presented in Section 2.2. Additional detail for each of the identified sectors is contained in its corresponding appendix.

\subsection{BASELINE DEVELOPMENT}

We developed the electricity baseline through a two-step process. In the first step, the energy use was segmented into identifiable sectors, subsectors, and end uses. The second step entailed estimating baseline consumption through the development of subsector consumption and EUIs for subsectors in which end uses are identified.

\subsubsection{Sector Segmentation}

Our review of the stock of electricity-using facilities at Fort Lewis led to the identification of four principal sectors for the assessment: 
- buildings

- pumps/motors
- distribution

- exterior lighting.

Each of these sectors was further segmented into subsectors; a discussion of each follows.

\section{Buildings}

The buildings sector was segmented into 16 building subsector categories based upon identifiable function or uniqueness in terms of size or energy use.

The residential building stock was segmented into

- single-family - detached housing

- multifamily - ranging from duplexes to eight-unit complexes.

The stock of barracks was segmented into

- concrete - typically three-story barracks constructed of concrete, brick, or masonry, and housing unaccompanied enlisted personnel

- wood - typically one- or two-story barracks constructed of wood and housing unaccompanied en 1 isted personnel.

The remaining stock of buildings was segmented into the following categories:

- motor pool - all maintenance and production facilities for vehicles and stationary equipment

- hangar - aircraft maintenance

- office/administration - houses administrative, headquarters, training, traffic control, and airfield communications functions

- warehouse - dry and refrigerated storage facilities, including fuel storage

- dining hall - unaccompanied personnel dining facilities

- clubs - officer, enlisted, and noncommissioned officer dining facilities

- 01d Madigan Hospital - all hospital, clinic, dental, and other medical facilities contained primarily in the 0ld Madigan complex, excluding the New Madigan Hospital 
- New Madigan Hospital - new hospital and health care facility scheduled to be in operation by mid-1993

- commissary - grocery

- computer center - housing central mainframe computer equipment

- simulators - helicopter simulator

- other - all other buildings such as private food service (e.g., commercial restaurant, bowling), base personnel support (e.g., craft shop, Taundry), goif course, and boat docks.

The end uses selected for the buildings sector were identifiable areas of energy efficiency potential where broad-based acquisition programs would apply. The end uses identified are

- interior lighting - segmented into five categories by fluorescent (F-34, F-40, and F-96 tube fixtures), incandescent lighting (bulb size less than $200 \mathrm{~W}$ ), and high-intensity-discharge (HID) lighting

- hot water - domestic hot water supplied by residential-type water heaters

- refrigeration - food and other refrigeration supplied by residential-type refrigerators

- other - all other end uses not specified above, such as HVAC energy and specialized energy requirements of specific building types, such as office equipment, booster heaters for the dining hall hot water supply, and refrigeration for walk-in refrigerator/freezers.

It is recognized that efficiency potential may exist in the other category in specific building types. However, that potential is not quantifiable without significant additional information and effort.

\section{Pumps/Motors}

Electricity use for pumps and motors was segmented into two subsectors:

- water supply - pumps used for drawing water from wells and providing water distribution

- sewage treatment - effluent pumps used at the central sewage treatment plant.

The pumps and motors analyzed in this category tend to be large, with horsepower ranging from 10 to 250. No attempt was made to estimate the number 
of smaller motors distributed around Fort Lewis that provide a range of services from air-handling to machine work, although Fort Lewis staff estimate the number of smaller motors to be in the thousands.

The end uses for the pumps/motors sector are identical to the two identified subsectors.

\section{Distribution}

Electricity "use" for distribution was segmented into two subsectors:

- transformer - load and no-load losses of all transformers used to step down voltage for energy-using equipment

- voltage regulation - potential reduction in end-use energy consumption provided by regulation of feeder voltage so that the most distant load from the substation is maintained at the minimum acceptable voltage under all load conditions on the circuit.

The end uses for the distribution sector are identical to the two identified subsectors.

\section{Exterior Lighting}

Exterior lighting was segmented into three subsectors as follows:

- residential - porch and other residential exterior lighting served primarily by incandescent bulbs

- other building - all other building exterior lighting served by a mixture of incandescent and HID fixtures

- street - all street lighting served by HID fixtures.

The end uses in the exterior lighting category are identical to the three subsectors identified.

\subsubsection{End-Use Intensity and Baseline Development}

The estimated baseline electricity consumption was developed through a combination of EUIs developed for the buildings sector end uses and estimated subsector consumption for the other three sectors. The EUIs developed provide the intensity of energy use measured in kilowatt-hours per square foot per year for a specific end use and building type. EUIs are a commonly used 
measure to enable aggregate estimates of energy use to be developed using estimates of the total floorspace for their respective building types.

These estimates were developed using primary data for energy use at Font Lewis, other studies conducted to identify efficiency improvements at Fort Lewis, input from Fort Lewis staff, and secondary information from other studies conducted for the Pacific Northwest region.

The major focus of the development of the EUI and baseline development is the buildings sector, because it is the major energy-consuming sector of the four. We used an iterative process to develop the baseline and refine the buildings sector EUIs as follows:

- Buildings sector EUIs were estimated using the available primary and secondary data by each of the four end uses expressed in kilowatthours per square foot per year $\left(\mathrm{kWh} / \mathrm{ft}^{2}-\mathrm{yr}\right)$.

- Electricity consumption (or loss) was estimated by subsector within each of the other three sectors.

- Metered data from each of 17 electricity distribution (feeder) points aggregated to 7 points was used to provide control totals to check the estimated load developed from the buildings sector EUIs and subsector consumption associated with that feeder. In cases where the estimated $10 a d$ deviated by more that $20 \%$ from the control total, adjustments were made to the buildings sector EUIs.

\subsection{ANALYSIS APPROACHES}

Two distinct analysis approaches are used to evaluate the desirability of the efficiency alternatives.

\subsubsection{Supply Curve}

The concept of the supply curve is employed to evaluate options from the point of view of the utility and the energy planners in the Pacific Northwest region. This is discussed in detail in the Section 2.3, but, in brief, the supply curve approach allows the costs and availability of the potential efficiency alternatives to be compared with other electricity resources (either other efficiency resources or generating resource), based on the real levelized energy cost (LEC) of the resource. The LEC is the cost per unit of energy saved and is expressed in dollars per kilowatt-hour (\$/kWh). The LEC 
of an efficiency resource is calculated as the annualized total cost divided by the annual energy savings and allows comparison with the cost of a generating resource calculated in the same manner.

\subsubsection{Life Cycle Cost and Net Present Value}

The second analysis approach required by federal agencies to screen investments is the determination of the LCC and NPV of each alternative. Federal agencies are required by 10 CFR 436 to select alternatives with the lowest LCC and maximum positive NPV. Each alternative has an associated initial capital cost, as well as a stream of costs over the term of analysis. In additica, each alternative saves some amount of energy, which translates into savings on the Fort's utility bill. The NPV employs the concept of the present value of a stream of savings or costs that will be enjoyed or incurred in the future. The present value of a stream is the amount that could be invested now at a given interest rate that could generate the stream.

For all energy efficiency options that are not part of a mutually exclusive set, one should choose those that have positive NPVs. A positive NPV implies that the LCC is less than the alternative of no action. For alternatives that are part of a mutually exclusive set, the efficiency alternative with the highest NPV should be selected.

This analysis is complicated somewhat by three factors 1) the costsharing between Fort Lewis and TPU, 2) the interest (or discount) rate to use in the analysis, and 3) assumptions about future electricity prices.

Currently, it is expected that Fort Lewis will pay $15 \%$ of the initial capital costs of an energy efficiency measure alternative and pay $100 \%$ of the operations and maintenance (O\&M) cost from the start of the project.

The discount rate is a complicating issue because regional power planners typically use the rate developed by the Northwest Power Planning Council (NWPPC) (3\% rea1), while Fort Lewis is required to use the rate established by DOE for federal energy conservation ( $4.7 \%$ rea $)$. For this reason, the LEC calculations for the supply curve construction (discussed in the following section) use the $3 \%$ rate, while the NPV calculations use the $4.7 \%$ rate. 
In a similar vein, NWPPC forecasts in its medium-high scenario that electricity prices will increase $0.3 \%$ annually over the next 20 years. The Energy Information Administration (EIA) of DOE makes forecasts of real energy price changes that must be used with the National Institute of Standards and Technology (NIST) energy conservation project evaluation methodology. These forecasts vary year to year and show a significantly greater rate of fuel price escalation than the NWPPC forecast. Fuel price does not enter directly into the LEC calculation and, hence, does not directly influence the supply curve construction. The NIST escalation rate used in the NPV calculations ranges from $0.9 \%$ to $1.24 \%$ annually over the 20 -year analysis period. The NPV analysis results are discussed in detail in Section 3.4.

\subsection{SUPPLY CURVE DEVELOPMENT}

The concept of supply curves for comparing the cost-effectiveness of efficiency resources with energy supply alternatives is described, as are the efficiency measures that were and were not considered within this assessment. Section 2.3.1 details the concept and the assumptions used to derive the supply curves. The efficiency measures that were and were not considered are provided in Section 2.3.2.

\subsubsection{Process}

Supply curves are developed to relate the quantity of a resource available at a schedule of prices. In this assessment, the efficiency resource is expressed in terms of real LEC. This provides a dollars-per-kilowatt-hour equivalent that enables comparison with electricity prices to provide an estimate of the quantity of cost-effective electric energy efficiency available at Fort Lewis, from the perspective of the regional energy planners.

The process for developing the total supply curve starts with estimating the energy-efficiency improvements that can be obtained by applying specific measures to each of the identified sector and subsector end uses (see Section 2.3.2). Given each measure's cost, operating life, and capital recovery factors given earlier, the quantity of energy efficiency is translated into a LEC basis. 
Each of the measures is then sorted in ascending order by LEC. Those measures that are mutually exclusive, such as adding reflectors to all $40-W$ fixtures versus adding reflectors and electronic ballasts to all 40-W fixtures versus replacing all 40-W fixtures with high efficiency T-8 fixtures are identified. These mutually exclusive options are then incorporated into the supply curve as follows:

- re-sort all LEC measures of the mutually exclusive set (lowest to highest LEC)

- calculate the additional energy (kWh) savings obtained by implementing the next lowest LEC in the list instead of the minimum LEC measure (the measure above), i.e., calculate the marginal energy savings

- delete the next lowest LEC from the list and supply curve development if the marginal savings are negative. (Note--a negative marginal savings indicates that the measure is dominated by lower LEC option - it saves less energy at a higher cost per unit.)

- calculate the incremental (marginal) annualized total cost of implementing each of the remaining measures

- calculate the marginal LEC as: marginal annualized total cost/marginal savings

- sort all measures in ascending order by marginal LEC

- calculate the cumulative savings as the sum of the marginal savings

- plot the cumulative savings on the $x$-axis versus the marginal LEC on the $y$-axis for all the measures.

Breakpoints in the price schedule that were considered important are at $\$ 0.023 / \mathrm{kWh}, \$ 0.045 / \mathrm{kWh}$, and $\$ 0.075 / \mathrm{kWh}$. The lower breakpoint is the approximate price that Fort Lewis currently pays for electricity. The middle breakpoint is the approximate avoided cost for new electricity generating facilities in the Pacific Northwest, and the upper breakpoint is chosen arbitrarily as clearly not cost-effective for resources above that level.

\subsubsection{Efficiency Measures}

The classes of potential electrical efficiency measures were jointly developed by PNL and TPU. These classes were then segmented into two categories for each of the major sectors 1) those that were most likely to be 
implemented and 2) those that were not considered in the analysis, but may add to the efficiency resource potential. The cost performance (energy use) data for each of the measures was developed by PNL.

\section{Buildings Sector}

Measures considered for the buildings sector were in the areas of lighting, hot water, and refrigeration.

\section{Lighting}

- replacing incandescent bulbs with compact fluorescent in $15 \%$ of the indoor residential fixtures, $75 \%$ of the indoor fixtures in other buildings, and $100 \%$ of the exterior fixtures

- adding energy-efficient magnetic ballasts to two-tube fluorescent fixtures using 34-, 40-, and 75-W tubes

- adding electronic ballasts to two-tube fluorescent fixtures using $34-, 40-$, and 75-W tubes

- adding tunable electronic ballasts to two-tube fluorescent fixtures using $34-, 40-$, and $75-W$ tubes

- adding parabolic reflectors to two-tube fluorescent fixtures using $34-, 40-$, and 75-W tubes

- replacing two-tube fluorescent fixtures using 34-, 40-, and 75-W tubes with new fixtures with reflectors and electronic ballasts

- replacing two-tube fluorescent fixtures using 75-W tubes with 150-W high-pressure sodium lamps

- replacing two-tube fluorescent fixtures using 75-W tubes with single-tube 75-W very-high-output (VHO) fixtures

- replacing two-tube fluorescent fixtures using 34 - and 40-W tubes with F-30 T-8 fixtures.

Lighting replacements were made on a constant level of service basis. That is, if a replacement put out twice the level of light (measured in lumens), a one-for-two replacement was used. 


\section{Hot Water}

- increasing the insulation level of the tanks by wrapping all of the water heaters with insulation

- wrapping only new water heaters with insulation

- replacing $100 \%$ of the water heaters with high-efficiency water heaters with nonmetallic or lined tanks - Information from the Ft. Lewis staff indicates that life expectancy for water heaters is less than 5 years because of tank corrosion caused by carbonic acid. In addition, TPU staff encouraged consideration of a water heater replacement program with high-efficiency models, as that utility has experienced greater success with a replacement program than with wrap programs.

- replacing water heaters upon failure with high-efficiency water heaters with nonmetallic or lined tanks.

\section{Refrigeration}

- Replacing $100 \%$ of existing residential-type refrigerators.

Replacing refrigerators with high-efficiency models as they wear out rather than implementing a straight replacement program as above was not considered because it is understood that all models now available are of the "efficient" variety. Consequently, there is little to no differential between replacement ontions.

Items not considered in the buildings sector that may add to the efficiency resource potential are

- incandescent lighting - Replace fixtures to accommodate compact fluorescent to increase the penetration levels in addition to replacing bulbs in fixtures that will accept them.

- lighting controls - Implement controls to adjust for daylighting and/or occupancy. Daylighting controls are reportedly in operation in Building 3670 .

- HVAC - Improve heating and/or cooling efficiencies in buildings having electric heating and/or cooling equipment through a combination of higher-efficiency equipment, improving the building envelope thermal integrity, and/or improving operation practices.

- heat recovery - Recover heat from exhaust airstreams in building types such as dining halls and clubs. 
- low-flow shower heads - This measure is reported to be in place in most, if not all, applications.

\section{Pumps/Motors}

Measures considered for the pumps/motors sector were motor replacements, as follows:

- water supply - Replace well pump motors with high-efficiency motors.

- water supply - Replace well pump motors with high-efficiency motors upon failure.

- sewage treatment - Replace sewage treatment effluent pump motors with high-efficiency motors.

- sewage treatment - Replace sewage treatment effluent pump motors with high-efficiency motors upon failure.

For both water supply and sewage treatment subsectors, existing motors were assessed individually for replacement because the number of operating hours varied significantly, which has a large effect on the LEC. Also, given the range of costs and efficiency improvement by motor size, the reader is referred to Appendix $C$ for additional detail.

Items that were not considered in the pumps/motors sector that may add to the efficiency resource potential are

- replacement of motors less than 10 horsepower - This option would likely have high potential for motors that operate nearly continuously. However, an inventory of the stock and operating schedules was not available, nor was an estimate developed.

- modification of related systems - One example would be to increase pipe size to reduce horsepower required to maintain pressure.

- implementation of operation and control practices - This option provides for automated operation of the water supply system.

\section{Distribution}

Measures considered for the distribution sector were transformer replacement and voltage regulation:

- Replace existing transformers with high-efficiency units. Existing transformers were assessed by size category for replacement. Given 
that the cost and efficiency improvement vary by size category, the reader is referred to Appendix D for additional detail.

- Regulate the voltage of the distribution system so that the most distant point on individual feeders meets minimum voltage requirements under all loading conditions of the feeder. Although insufficient information is available to quantify this resource, it is estimated to provide a reduction of $1 \%$ to $3.5 \%$ in total baseload at a cost up to $\$ 0.01 / \mathrm{kWh}$.

Items that were not considered in the distribution sector that may add to the efficiency resource potential are

- replacement of existing transformers as they fail with highefficiency units, which may improve the cost-effectiveness of this measure

- the value of other distribution improvements, such as reconductoring feeders and adding capacitors to reduce line losses and improve power factors.

\section{Exterior Lighting}

The only measure considered for this sector was the replacement of $100 \%$ of the existing incandescent lighting that is less than $200 \mathrm{~W}$ in residential applications with compact fluorescent.

Items that were not considered in the exterior lighting sector that may add to the efficiency resource potential are

- installation of new, and replacement of faulty, photocells to reduce or eliminate exterior lighting during daylight hours

- replacement of existing low-efficiency HID with lighting with highefficiency units

- replacement of incandescent lighting that is greater than $200 \mathrm{~W}$ with HID or other suitable high-efficiency alternative.

\subsection{REFERENCE}

10 CFR 436. November 20, 1990, "Federal Energy Management and Planning Program; Life Cycle Cost Methodologies and Procedures." Code of Federal Regulations. 


\subsection{BASELINE AND EFFICIENCY ESTIMATES}

The estimated electricity use baseline and the supply curve relating the efficiency resource potential are discussed in this section. Section 3.1 provides an overview of the building stock to show numbers of buildings and amount of floorspace by building type. The estimated energy use baselines by sector, subsector, and end use are presented in Section 3.2. The supply curve of estimated electric energy efficiency is contained in Section 3.3, the net present value is discussed in Section 3.4, and the criteria for choosing efficiency measures are given in Section 3.5 .

For background, Fort Lewis houses approximately 25,000 full-time residents, which include military personnel and dependents, and has a daytime population of approximately 35,000 persons. In 1989, total facility energy consumption was approximately 2.5 trillion Btu, of which $43 \%$ was provided by natural gas, $31 \%$ by 011 , and $26 \%$ by electricity. The fuel cost of over $\$ 12$ million comprised $37 \%$ electricity, $37 \%$ natural gas, and $26 \% 011$.

During the period 1986 through 1987, annual electricity consumption ranged from 181,000 MWh to 197,000 MWh at a cost ranging from $\$ 3.5$ to $\$ 4.5$ million. In 1989 , electricity consumption was approximately 193,000 MWh and cost $\$ 4.5$ million, at an average price of $\$ 0.023 / \mathrm{kWh}$ (including demand charges).

\subsection{BUILDINGS SECTOR PROFILE}

The estimated 4457 buildings on the post have approximately 23.9 million square feet of floorspace. Table 3.1 summarizes the buildings sector in terms of floorspace, number of buildings, and average floorspace by building type.

Nine of the 16 identified building types account for over $90 \%$ of the total square footage. Family housing comprises the largest share of floorspace, accounting for nearly $25 \%$ of the total. This is followed by barracks housing for unaccompanied personnel, accounting for nearly $20 \%$ of the total. 
TABLE 3.1. Fort Lewis Building Stock Description

\begin{tabular}{|c|c|c|c|c|}
\hline Building Type & $\begin{array}{c}\text { Floorspace } \\
\left(\mathrm{ft}^{2}\right)^{2}\end{array}$ & $\begin{array}{c}\text { Percentage } \\
\text { of Total } \\
\text { Floorspace }\end{array}$ & $\begin{array}{l}\text { Number of } \\
\text { Buildings }\end{array}$ & $\begin{array}{c}\text { Average } \\
\text { Floorspace } \\
\left(\mathrm{ft}^{2}\right)\end{array}$ \\
\hline Single-Family & $3,207,801$ & 13.4 & 1,811 & 1,721 \\
\hline Multifamily & $2,675,095$ & 11.2 & $394^{(a)}$ & $1,579^{(b)}$ \\
\hline Concrete Barracks & $3,209,566$ & 13.4 & 79 & 40,627 \\
\hline Wood Barracks & $1,461,523$ & 6.1 & 291 & 5,022 \\
\hline Office/Administration & $2,892,262$ & 12.1 & 715 & 4,045 \\
\hline Warehouse & $2,933,673$ & 12.3 & 446 & 6,578 \\
\hline Motor Po: : & $1,926,594$ & 8.0 & 252 & 7,645 \\
\hline Hangar & 366,005 & 1.5 & 8 & 45,751 \\
\hline Dining Halls & 124,377 & 0.5 & 24 & 5,182 \\
\hline Clubs & 112,168 & 0.5 & 8 & 14,021 \\
\hline 01d Madigan Hospital & 736,651 & 3.1 & 79 & 9,325 \\
\hline New Madigan Hospital & $2,000,000$ & 8.4 & 1 & $2,000,000$ \\
\hline Commissary & 105,000 & 0.4 & 1 & 105,000 \\
\hline Computer Center & 15,398 & 0.1 & 1 & 15,398 \\
\hline Simulators & 54,200 & 0.2 & 2 & 27,100 \\
\hline Other & $\underline{2,116,933}$ & 8.8 & 345 & 6,136 \\
\hline Total & $23,937,246$ & & 4,457 & \\
\hline
\end{tabular}

(a) Contains 1694 living units.

(b) Average floorspace per living unit.

Office/administration buildings and warehouses comprise the next largest shares with over $12 \%$ each. These are followed by other with nearly $9 \%$, the New Madigan Hospital with over $8 \%$, and motor pools with $8 \%$ of the total floorspace.

\subsection{ELECTRICITY USE BASELINE}

The limited availability of metered data created a challenge in developing the baseline electricity use. The Fort is served by three substations, designated as Madigan, South, and Central. Each substation is metered 
separately by TPU for both demand and power use. Aside from the commercial (nonappropriated) buildings on the Fort, these are the only sites where electricity use for the installation is metered. A total of 17 feeder 1 ines from these three substations provide all electrical power to the Fort.

We metered each substation and feeder separately and collected timeseries data for 4 consecutive months. The metering was done primarily to measure the electric demand profile for the Fort and to determine the relative contributions to that demand of each of the three substations and 17 feeders. The secondary purpose was to provide the only metered data for an accurate assessment of the electrical energy use intensities of the building stcck.

The areas and primary boildings at the Fort serviced by each of the feeders is given in Table 3.2. The percentage of the total load served by each substation and the percentage of the substation load served by each feeder are shown. The areas or primary buildings served are also displayed in descending order of electrical load on the feeder.

We used this information $t_{i j}$ ascertain and pinpoint the potential for energy efficiency opportunities in the various sectors of the Fort served by the 17 feeders, for both demand and baseload savings. The data were also used to more accurately determine t'ic estimated energy use and energy use intensities of each of the defined building types at the Fort. Without this metered information, we would have performed the analysis using billing data from the three substations; thus, much more uncertainty would be associated with this foundational analysis. The feeder-level metered data give a more reliable, accurate indicator of the electrical energy use for individual facilities and groups of facilities and more accurately portray the efficiency potential at the Fort.

The resuits of the metering study showed that the Fort has a daily baseload of 15,000 to $17,000 \mathrm{~kW}$, and that the peak demand of 27,000 to $30,000 \mathrm{~kW}$ usually occurs before noon, depending upon the season. The data revealed that the Central substation acc.sunted for nearly $50 \%$ of the total Fort demand. 
TABLE 3.2. Substations and Feeders Serving Fort Lewis

\begin{tabular}{|c|c|c|c|}
\hline Substation & $\begin{array}{l}\text { \% Total } \\
\text { Load } \\
\end{array}$ & $\begin{array}{l}\text { Feeder No. (\% } \\
\text { Substation Load) }\end{array}$ & Areas/Building Served \\
\hline Madigan & 13 & $\begin{array}{lr}\text { M1 } & (3) \\
\text { M2 } & (32) \\
\text { M3 } & (65)\end{array}$ & $\begin{array}{l}\text { Residential/Warehouse } \\
\text { New Madigan Hospital } \\
\text { Warehouse/Motor Pool/Office }\end{array}$ \\
\hline South & 34 & $\begin{array}{ll}\text { S2 } & (14) \\
\text { S3 } & (17) \\
\text { S4 } & (32) \\
\text { S5 } & (37)\end{array}$ & $\begin{array}{l}\text { Residential/Warehouse/Office/Dining } \\
\text { Barracks/Office/Motor Pool/Warehouse } \\
\text { Residential/Clubs } \\
\text { Office/Barracks/Motor Pool/Hangar }\end{array}$ \\
\hline Central & 53 & $\begin{array}{l}\text { A1 }(5) \\
\text { A2 }(14) \\
\text { A3 }(10) \\
\text { A4 }(16) \\
\text { A5 }(18) \\
\text { A6 }(18) \\
\text { A7 }(<1) \\
\text { A8 }(2) \\
\text { A9 }(12) \\
\text { A10 }(5)\end{array}$ & $\begin{array}{l}\text { Switching Alternate } \\
\text { Barracks/Office/Warehouse } \\
\text { Clubs/Warehouse } \\
\text { Office/Barracks } \\
\text { Barracks/Motor Pool/Office/Hangar } \\
\text { Office/Motor Pool/Warehouse } \\
\text { Switching Alternate } \\
\text { New Madigan Hospital } \\
\text { School/Logistics Center } \\
\text { Old Madigan/Office/Barracks/Resid. }\end{array}$ \\
\hline
\end{tabular}

Total $\quad 100$

From the data, we also determined that most of the $16^{(\mathrm{a})}$ feeder loads were not temperature-dependent; therefore, opportunities for electrical energy savings (kilowatt-hours) exceed the opportunities for demand savings (kilowatts).

These data are pivotal for pointing out the areas of the Fort served by the feeders for further detailed evaluation of electrical use reduction potential. For example, it was evident that the Central substation load would have the most potential for reducing both demand and energy use. Feeders A5, A6, and $A 9$ all showed significant peak demand of greater than $2500 \mathrm{~kW}$ during

(a) One of the feeders was a switching alternate and no load was measured during the monitoring period. 
the monitoring period. These feeders serve barracks, offices, motor pools, warehouses, and the logistics center, facilities where both demand and energy savings potential are greatest.

Estimates indicate that the buildings sector accounts for over $80 \%$ of the electricity use at Fort Lewis. Given this, and the number of building types that comprise the buildings sector use, the estimated EUIs developed for the sector by building type are discussed before the baseline profile; these are displayed in Table 3.3. The estimated EUIs provide the intensity of energy use by the four end uses (lighting, domestic hot water, refrigeration, and other) and for the building total. Detail on the development of the buildings sector EUIs is contained in Appendix B; the baseline development for the other three sectors is discussed in their respective appendixes.

\section{TABLE 3.3. Buildings Sector Electricity End-Use Intensities}

\begin{tabular}{l} 
Building Type \\
\hline Single Family \\
Multifamily \\
Concrete Barracks \\
Wood Barracks \\
Office/Admin. \\
Warehouse \\
Motor Pool \\
Hangar \\
Dining Halls \\
Clubs \\
Old Madigan Hospital \\
New Madigan Hospital \\
Commissary \\
Computer Center \\
Simulators \\
Other
\end{tabular}

\begin{tabular}{cc}
\hline Lighting & DHW \\
1.31 & 2.90 \\
1.39 & 2.86 \\
3.25 & \\
0.74 & \\
3.58 & 0.54 \\
2.05 & 0.01 \\
2.66 & 0.60 \\
2.97 & 0.25 \\
10.00 & \\
10.29 & \\
6.11 & \\
3.00 & \\
7.00 & \\
7.64 & \\
4.24 & 0.06 \\
2.30 & 0.30
\end{tabular}

EUI $\left(\mathrm{kWh} / \mathrm{ft}^{2}-\mathrm{yr}\right)$

\begin{tabular}{|c|c|c|}
\hline Refrigeration & Other & Total \\
\hline 0.77 & 2.91 & 7.89 \\
\hline \multirow[t]{15}{*}{0.76} & 2.88 & 7.89 \\
\hline & 3.75 & 7.00 \\
\hline & 0.67 & 1.41 \\
\hline & 3.71 & 7.83 \\
\hline & 1.70 & 3.76 \\
\hline & 1.91 & 5.17 \\
\hline & 2.50 & 5.72 \\
\hline & 48.00 & 58.00 \\
\hline & 21.50 & 31.79 \\
\hline & 11.95 & 18.06 \\
\hline & 1.00 & 4.00 \\
\hline & 43.00 & 50.00 \\
\hline & 24.43 & 32.07 \\
\hline & 84.20 & 88.50 \\
\hline & 2.00 & 4.60 \\
\hline
\end{tabular}


Other than family housing, most domestic hot water was supplied through an onsite fossil-fueled boiler or through a district heating system, which results in a low or no electrical EUI for that end use. Similarly, residential types of refrigerators were not present in most building types other than family housing. A significant note is the low EUIs for the New Madigan Hospital; these are expected to increase markedly once the hospital is commissioned and in full operation in mid-1993.

The estimated baseline by sector, subsector, and end use is shown in Table 3.4.

The estimated total consumption of 197,000 MWh compares well with actual levels of approximately 195,000 MWh. Therefore, it is felt that the estimated consumption provides a reasonable approximation of the actual. Within this total, the buildings sector accounts for $86 \%$, pumps/motors for over $2 \%$, distribution for nearly $8 \%$, and exterior lighting for nearly $4 \%$.

From an end-use standpoint, total lighting energy is estimated to account for nearly $35 \%$ of the total, hot water for over $10 \%$, refrigeration for over $2 \%$, and the remaining $52 \%$ by all other uses. Fluorescent lighting is estimated to comprise about two-thirds of the total lighting energy.

Four building types (single-family, multifamily, concrete barracks, and office/administration) each account for over $10 \%$ of total consumption and, combined, are estimated to account for over $45 \%$ of total annual electricity consumption. Only three other building types (warehouse, motor pool, and the 01d Madigan Hospital) are estimated to consume more than $5 \%$ of the total, although the New Madigan Hospital share of the total is expected to increase significantly when it is in full operation.

\subsection{ELECTRIC EFFICIENCY SUPPLY CURVE}

The LEC and efficiency resource by each of the measures considered (see Section 2.3.2) and the cumulative efficiency resource are shown in Table 3.5. The levelized cost ranges from $\$ 0.0022 / \mathrm{kWh}$ for replacing domestic hot water heaters on failure with high-efficiency nonmetallic units to over $\$ 0.26 / \mathrm{kWh}$ for replacing a seldom-used well pump on failure with a high-efficiency unit. 


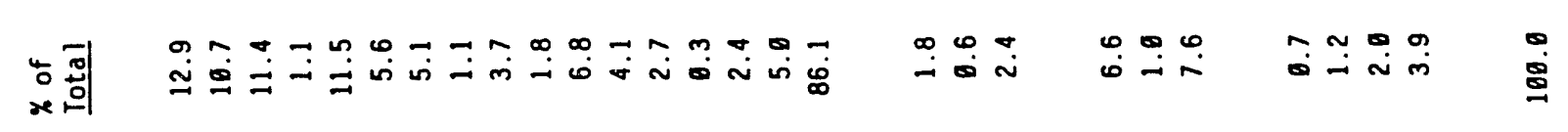

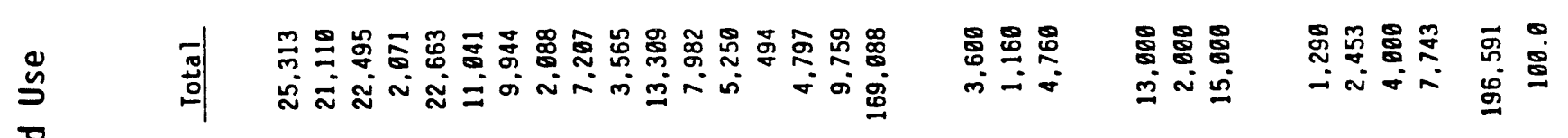
롬 1 通

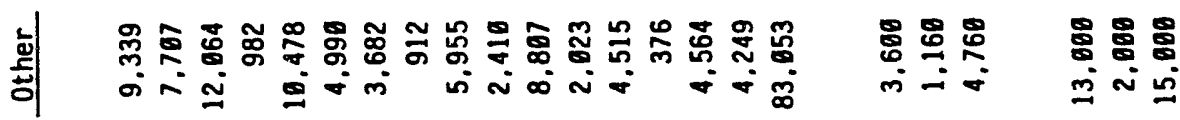

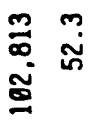

荠 量

$\underset{5}{+}$

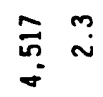

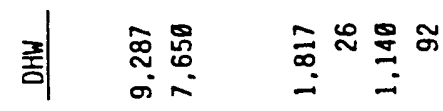

กิ

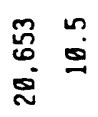

章

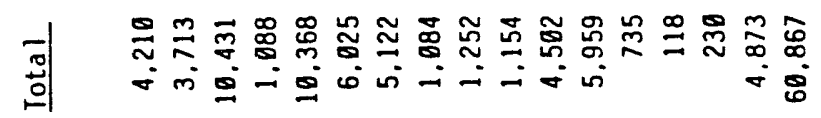

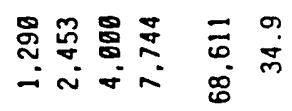

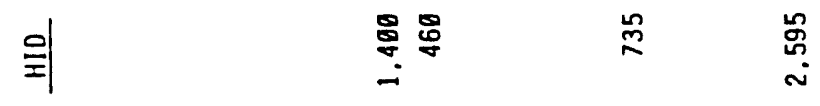

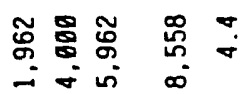

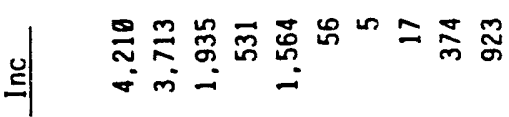

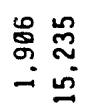

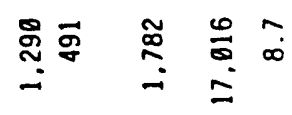

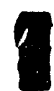

|숭

$\underset{\sim}{\infty}$

$\stackrel{\infty}{i} \underset{\sim}{\infty}$

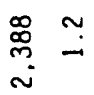

|

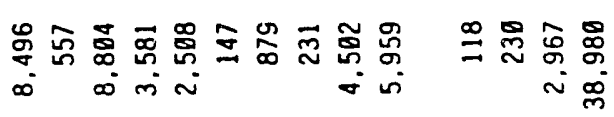

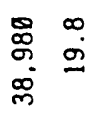

冚:

$\stackrel{\circ}{\circ}$

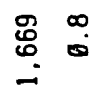

:

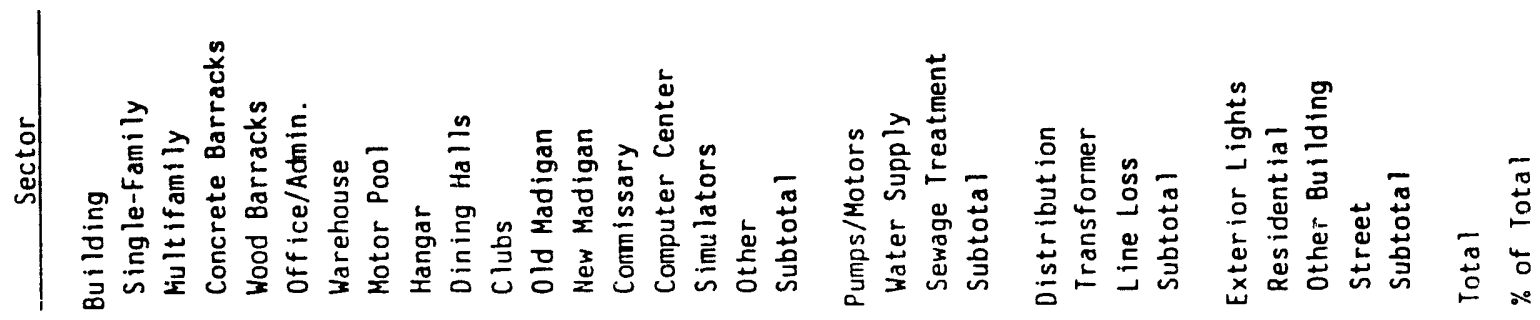


TABLE 3.5. Levelized Energy Cost and Efficiency Resource by Measure and Cumulative Efficiency Resources

\begin{tabular}{|c|c|c|c|c|}
\hline Measure & $\begin{array}{l}\text { Marginal } \\
\text { Levelized } \\
\text { Rea I Cost } \\
(\$ / \mathrm{kWh}) \\
\end{array}$ & $\begin{array}{l}\text { Marginal } \\
\text { Annual } \\
\text { Energy } \\
\text { Use } \\
\text { Decrease } \\
\text { (kWh) } \\
\end{array}$ & $\begin{array}{c}\text { Cumulat ive } \\
\text { Annual } \\
\text { Energy } \\
\text { Use } \\
\text { Decrease } \\
\text { (kWh) } \\
\end{array}$ & $\begin{array}{c}\text { Initial } \\
\text { Capital Cost } \\
\text { (1991 \$ } \\
\text { thousands) } \\
\end{array}$ \\
\hline DHW: $\operatorname{ROF}^{(a)}$ & 0.0056 & $2,427,754$ & 2.427 .754 & 1,439 \\
\hline WS: ROF - Well 18 & 0.0066 & 13.810 & $2,441,564$ & 1 \\
\hline DHW: Complete replacement (a) & 0.0081 & 167,431 & $2,608,995$ & 1,572 \\
\hline F $7-75-w:$ New fix. w/ref $1 .$, ballast & 0.0098 & $1,318,273$ & $3,927,268$ & 220 \\
\hline F1-4b-W: New fix. w/ref 1. , ballast $(b)$ & 0.0166 & $25,915,995$ & $29,843,263$ & 6.662 \\
\hline F1-34-W: New fix. w/refl., ballast ${ }^{(c)}$ & 0.0167 & 957,498 & $30,800.761$ & 250 \\
\hline ST: ROF - Eff luent pumps & 0.0181 & 30.747 & $30,831,508$ & 8 \\
\hline Inc.: Replace $w /$ compact $f$ l & 0.0203 & $6,199,465$ & 37.030 .913 & 754 \\
\hline TRANS: 50 kVA Transformers & 0.0210 & $1,500.308$ & $38,531,221$ & 619 \\
\hline TRANS: $37.5 \mathrm{kVA}$ Transformers & 0.0228 & 699,314 & $39,230.535$ & 313 \\
\hline WS: ROF - We 11 19 & 0.0251 & 5,522 & $39,236,057$ & 2 \\
\hline WS: ROF - We $11 \neq 15$ & 0.0263 & 6,955 & $39,243,012$ & 3 \\
\hline TRANS: 25 kVA Transformers & 0.0275 & 606,455 & $39,849,467$ & 327 \\
\hline TRANS: 75 kVA Transformers & 0.0335 & 865,947 & $40,715,414$ & 569 \\
\hline WS: ROF - We $11 \neq 10$ & 0.0357 & 32 & $40,715,446$ & $<1$ \\
\hline TRANS: $100 \mathrm{kVA}$ Transformers & 0.0373 & 120,387 & $40,835,833$ & 88 \\
\hline WS: ROF - Sequal spring & 0.0562 & 24,573 & $40,860,406$ & 21 \\
\hline WS: ROF - Well 13 & 0.6567 & 2,869 & $40,863,275$ & 2 \\
\hline T?ANS: $200 \mathrm{kVA}$ Transformers & 0.0605 & 374,132 & 41.237 .487 & 443 \\
\hline WS: ROF - We11 14 & 0.8613 & 3,528 & 41.240 .935 & 3 \\
\hline WS: ROF - We11 12 & 0.0613 & 7,498 & $41,248,433$ & 7 \\
\hline TRANS: 15 kVA Transformers & 0.8771 & 205.211 & $41,453,644$ & 310 \\
\hline TRANS: 300 kVA Transformers & 0.0800 & 206,202 & $41,659,846$ & 324 \\
\hline Fl-40-W: Install F30 T-8 fixtures $(\mathrm{b})$ & 0.1061 & $2,483,238$ & $44,143,084$ & 9.690 \\
\hline Refrigerators: Replace & 0.1113 & 1.387 .167 & $45,530,251$ & 1,843 \\
\hline WS: ROF - Well $\$ 9$ & 0.1165 & 494 & $45,530,745$ & $<1$ \\
\hline TRANS: 500 kVA Transformers & 0.1180 & 208,314 & $45,739,059$ & 482 \\
\hline TRANS: $750 \mathrm{kVA}$ Transformers & 0.1333 & 176.512 & $45,915,571$ & 461 \\
\hline TRANS: 1000 kVA Transformers & 0.1410 & 53.385 & $45,968,876$ & 147 \\
\hline TRANS: $1500 \mathrm{kVA}$ Transformers & 0.1419 & 92,446 & $46,861,322$ & 257 \\
\hline TRANS: 5 kVA Transformers & 0.1564 & 6,398 & $46,067,729$ & 20 \\
\hline TRANS: 2500 kVA Transformers & 0.1582 & 15,074 & $46,082,794$ & 47 \\
\hline WS: ROF - Well 17 & 0.2615 & 878 & $46,083,672$ & 3 \\
\hline F 1-34-W: Insta11 F3E T-8 fixtures $(c)$ & 3.7801 & 1,985 & $46,085,657$ & 340 \\
\hline
\end{tabular}

$(a, b, c)$ These measures are mutually exclusive and only one will be selected. 
The cumulative efficiency resource column provides the total resource available as successive measures are considered, adding in the marginal contribution by measure. In cases where the measures are not mutually exclusive, such as transformer and motor replacement on failure, the annual resource is added to ihe cumulative total. In cases where the measures are mutually exclusive, such as lighting and water heater measures, only the marginal increment provided by the successive measure is added to the cumulative total. For example, in the case of retrofitting fluorescent fixtures having 40-W tubes with reflectors and ballasts that provide 25,916 MWh of resource or replacing these fixtures with T-8 fixtures having 30-W tubes that provide 28,399 MWh of resource, the additional resource provided by the latter measure is 2,483 MWh.

The levelized cost and annual efficiency resource columns are displayed graphically in Figure 3.1. The supply curve is relatively flat through a levelized cost of about $\$ 0.026 / \mathrm{kWh}$, providing over 42,000 MWh of efficiency resource. At costs above $\$ 0.026 / \mathrm{kWh}$, the slope increases significantly and the additional resource available becomes negligible by comparison.

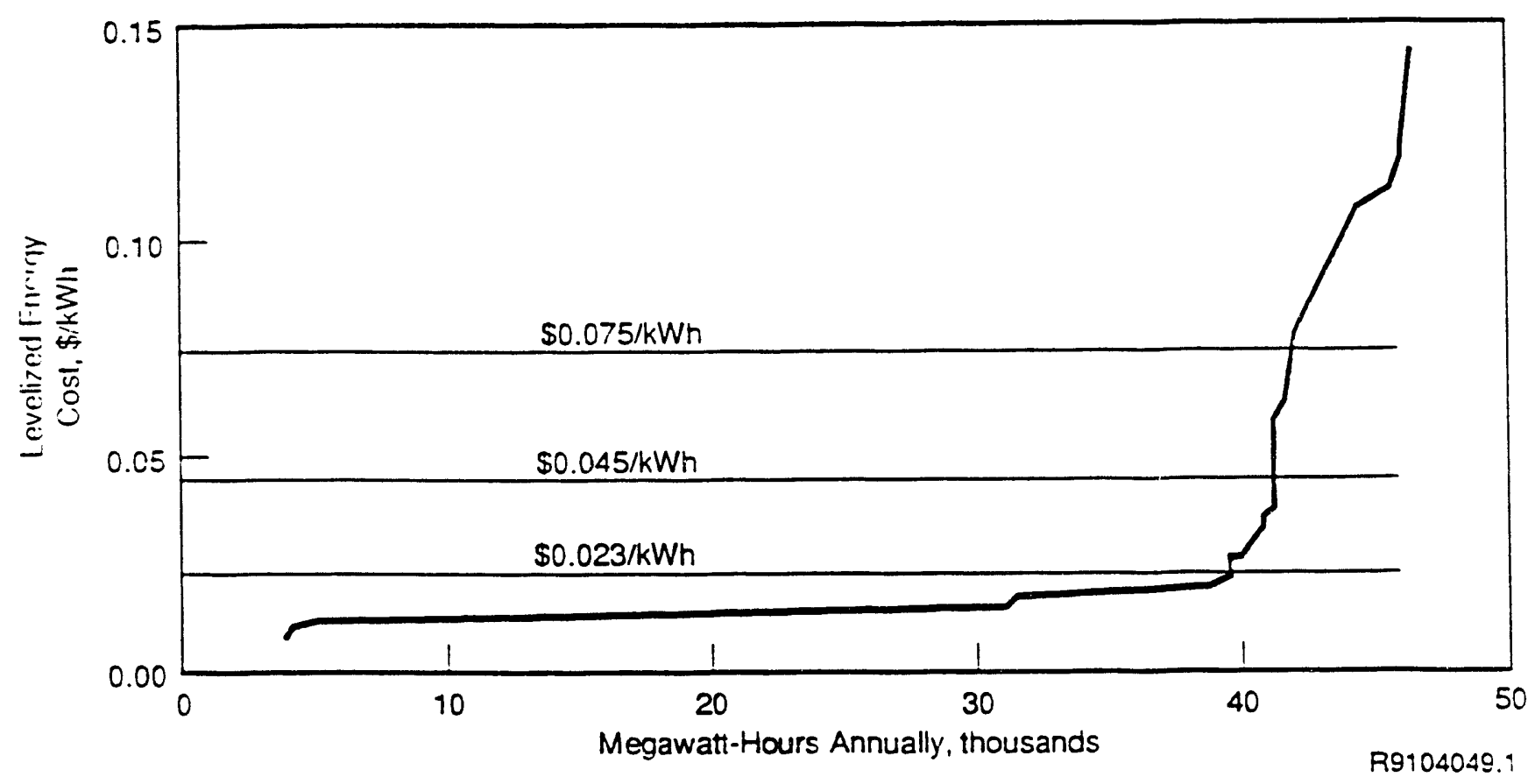

FIGURE 3.1. Electric Efficiency Supply Curve 
For the efficiency measures selected, the estimated electric efficiency resource by sector and end use are presented in Table 3.6 for the three cost categories.

The total estimated electric efficiency resource available at a cost of $\$ 0.075 / \mathrm{kWh}$ and less is 43,733 average annual MWh, representing 4.99 average annual MW of capacity. Of this, $86 \%$ is available at less than $\$ 0.023 / \mathrm{kWh}$, with another $13 \%$ available at between $\$ 0.024$ and $\$ 0.045 / \mathrm{kWh}$, and the remaining $1 \%$ at a cost of $\$ 0.046$ to $\$ 0.075 / \mathrm{kWh}$.

In the lower cost range, over 37,000 average annual MWh are provided by efficiency improvements to water heaters, water supply pumps, interior lighting, exterior lighting, water treatment pumps, and voltage regulation. This represents over 4 average annual MW of capacity. Additional transformer and water supply pump replacements, in aúuition to a different set of lighting and water heating improvements, contribute another 5,907 MWh (0.7 average MW capacity) to the resource potential for the mid-range cost. The upper cost range contains another 412 MWh provided by additional replacements of water supply pumps and transformers. Lighting measures account for over $90 \%$ of the efficiency resource available in the lower cost range and nearly $85 \%$ of the resource of the total resource available up to a cost of $\$ 0.075 / \mathrm{kWh}$.

TABLE 3.6. Electric Efficiency Resource Availability by End Use and Cost Range

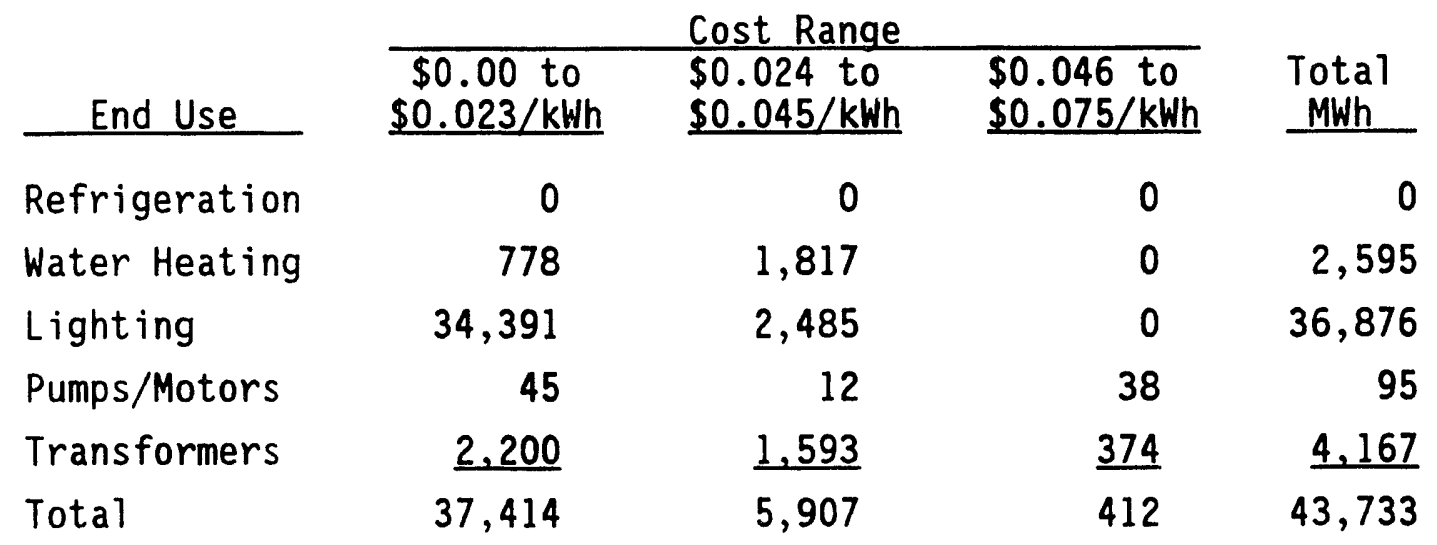




\subsection{NET PRESENT VALUE}

As discussed in Section 2.0, in addition to the supply curve methodology, the NPV of each energy efficiency measure alternative was calculated. The results are given in Table 3.7. This approach, required of federal agencies, is designed to allow evaluation of each alternative as an investment. A positive NPV indicates that the benefits of an alternative outweigh its costs, and the higher the NPV of an alternative, the more attractive it is. In the absence of subsidies (cost-sharing or rebates), and real energy price escalation, the maximum NPV option from a set of mutually exclusive options will be the one that has a marginal LEC closest to the federal facility's cost of energy without exceeding the cost.

\subsection{CHOOSING ENERGY EFFICIENCY MEASURES}

The information developed in Section 3.0 will allow the utility and Fort to choose the electric energy efficiency measures to install in the site-wide retrofit. The choices will hinge on the final cost-sharing agreement as well as agreement on the LEC "cutoff" and NPV criteria. These are discussed below.

\subsubsection{Criteria}

Using the LEC values, efficiency measures up to the cost of the marginal supply resource for Bonneville $(\$ 0.045 / \mathrm{kWh})$ may be considered cost-effective. A11 options that are not part of mutually exclusive sets that have LECs less than the avoided cost should be selected. Options that are part of mutually exclusive sets should be chosen if they have the LEC closest to the avoided cost of energy, while not exceeding the avoided cost. A federal agency is required to select energy efficiency options based on the NPV. Therefore, the option with the highest NPV should be considered cost-effective by the Fort.

These two criteria can lead to identical choices of options under the following conditions:

1. The installation bears the full cost of installing the measure.

2. The is no real energy price escalation.

3. The price the utility charges the installation is equal to the utility's avoided cost. 
TABLE 3.7. Net Present Value of Efficiency Measures by End Use for Measures with Highest NPV (a)

\begin{tabular}{|c|c|c|c|}
\hline End Use & Option & $\begin{array}{c}\text { NPV } \\
(1991 \$) \\
\end{array}$ & $\begin{array}{c}\text { Marginal } \\
\text { Annual } \\
\text { Energy } \\
\text { Decrease } \\
\text { (MWh) } \\
\end{array}$ \\
\hline Refrigeration & $\begin{array}{l}\text { Replace with high efficiency } \\
\text { models }\end{array}$ & 80,358 & 1,387 \\
\hline Water heating & $\begin{array}{l}\text { Immediate replacement with } \\
\text { high efficiency models }\end{array}$ & $2,125,959$ & $2,595,185$ \\
\hline $\begin{array}{l}\text { Lighting } \\
\text { Incandescent }\end{array}$ & $\begin{array}{l}\text { Replace with compact } \\
\text { fluorescent }\end{array}$ & 927,856 & 6,199 \\
\hline $34-W f 1$ & $\begin{array}{l}\text { Replace with new fixt. with } \\
\text { standard electronic ballast }\end{array}$ & 277,917 & 957 \\
\hline $40-W f 1$ & $\begin{array}{l}\text { Replace with new fixt. with } \\
\text { standard electronic ballast } \\
\text { and parabolic reflector }\end{array}$ & $7,454,913$ & 25,916 \\
\hline $75-W f 7$ & $\begin{array}{l}\text { Replace with new fixt. with } \\
\text { standard electronic ballast } \\
\text { and parabolic reflector }\end{array}$ & 410,348 & 1,318 \\
\hline $\begin{array}{l}\text { Water Supply Pumps } \\
\text { Sequal Spring }\end{array}$ & Replace upon failure & 4,739 & 25 \\
\hline We11 \#9 & Replace upon failure & 29 & 0.50 \\
\hline We11 \#10 & Replace upon failure & 8 & 0.03 \\
\hline We11 \#12 & Replace upon failure & 1,362 & 7 \\
\hline We11 \#13 & Replace upon failure & 550 & 3 \\
\hline We11 \#14 & Replace upon failure & 641 & 4 \\
\hline We11 \#15 & Replace upon failure & 1,806 & 7 \\
\hline We11 \#18 & Replace upon failure & 4,192 & 14 \\
\hline We11 \#19 & Replace upon failure & 1,448 & 6 \\
\hline $\begin{array}{l}\text { Water Treatment Pumps } \\
\text { Effluent Pumps }\end{array}$ & Replace upon failure & 8,544 & 31 \\
\hline
\end{tabular}


TABLE 3.7. (contd)

\begin{tabular}{|c|c|c|c|}
\hline End Use & Option & $\begin{array}{c}\text { NPV } \\
(1991 \$)\end{array}$ & $\begin{array}{c}\text { Marginal } \\
\text { Annual } \\
\text { Energy } \\
\text { Decrease } \\
\text { (MWh) } \\
\end{array}$ \\
\hline $\begin{array}{l}\text { Transformers } \\
15 \mathrm{kVA}\end{array}$ & Replace with high efficiency & 37,004 & 205 \\
\hline 25 kVA & Replace with high efficiency & 197,780 & 606 \\
\hline $37.5 \mathrm{kVA}$ & Replace with high efficiency & 237,665 & 699 \\
\hline $50 \mathrm{kVA}$ & Replace with high efficiency & 517,748 & 1,500 \\
\hline 75 kVA & Replace with high efficiency & 267,148 & 866 \\
\hline $100 \mathrm{kVA}$ & Replace with high efficiency & 35,792 & 120 \\
\hline $200 \mathrm{kVA}$ & Replace with high efficiency & 85,771 & 374 \\
\hline $300 \mathrm{kVA}$ & Replace with high efficiency & 35,395 & 206 \\
\hline $500 \mathrm{kVA}$ & Replace with high efficiency & 12,517 & 208 \\
\hline 750 kVA & Replace with high efficiency & 2,672 & 177 \\
\hline
\end{tabular}

(a) Discount Rate: $4.7 \%$.

Fuel Escalation: NIST.

Fort pays $15 \%$ of capital costs.

Fort pays all O\&M costs for all years.

If the capital cost of a measure is cost-shared, the measure may be selected on the NPV basis even though its LEC is above the installation's cost of energy. This occurs because the LEC is intended to reflect the true cost of the energy conserved, and therefore includes the entire cost of the measure, regardless of who pays for it. The NPV, on the other hand, is a measure of the attractiveness of an investment from the installation's point of view, and hence only includes the installation's portion of the cost (capital cost).

If the installation pays for only $15 \%$ of the cost of the measure $185 \%$ utility cost-share), measures with marginal LECS many times higher than cost 
of electricity have positive NPVs. Most of the measures that would be chosen on the basis of a positive NPV (those shown in Table 3.7) would not be chosen on the basis of LEC assuming an avoided cost equal to the price of electricity paid by the installation.

\subsubsection{Example}

For example, based on NPV data, the best choice for retrofitting fluorescent lighting fixtures having $40-W$ tubes is a new fixture with electronic ballast and reflector. This choice also shows a LEC of $\$ 0.0166 / \mathrm{kWh}$ which will also be acceptable to the utility. Another viable choice for fixture replacement may be retrofitting with a higher efficiency type T-8 fixture. The NPV is near that of the high-efficiency fixture and the LEC is $\$ 0.0245 / \mathrm{kWh}$, below the Bonneville avoided cost. However, the marginal LEC for this retrofit is $\$ 0.0378 / \mathrm{kWh}$ which is well above long-term avoided cost. Based on these data, this technology may not be selected.

Other choices analyzed (shown in Appendix B) inciuded ballast replacment (only) or adding reflectors for replacement. These choices had a lower NPV, a negative marginal energy savings compared to complete fixture replacement. These technologies also had higher LECs compared to the complete fixture replacement.

In conclusion, examination of the results of the analysis conducted in this assessment (with the above cost-sharing split) show that the choice of criteria (LEC or NPV) will not significantly affect the ultimate choice of energy efficiency measures to be installed at the Fort. The most desirable measures, in terms of both overall energy savings and in terms of NPV could be selected and implemented using either criteria. If all positive NPV measures less than the Bonneville avoided cost were implemented, the combined NPV would be in excess of $\$ 10$ million. 
APPENDIX A

DATA SOURCES 


\section{DATA SOURCES}

Data sources used to characterize the baseline and electric energy efficiency resource include databases maintained by the Fort, energy studies conducted previously for the Fort, and information available from other sources. These sources are described in this appendix.

\section{A. 1 DATABASES}

\section{A.1.1 Building/Facility Database - Base Format (Fort Lewis - Electronic File)}

The database file provided by Fort Lewis contains information on 3399 non-family housing structures located on the main post, including all permanent and temporary buildings, and nonbuildings (e.g., sheds and shade covers, which are typically unconditioned). Virtually all of the buildings are a part of the regular Army and civilian contingent. A few (10 to 20) are a part of the Army Reserve function. Not included in this database are family housing units.

The database contains the following five columns of information for each structure:

- building number

- building use description by original function

- number of floors - Those with "0" floors are meant to be primarily nonbuilding structures (e.g., boat ramps, shade covers, latrines, other similar nonconditioned items). Some miscoding has occurred (e.g., "fire station" is "0," while several "overhead covers" are "1").

- "official" square footage of structure - This includes conditioned and unconditioned areas of structure and may include external areas (e.g., carports, shade roofs). Again, some miscoding is present in the form of enclosed structures with a " 0 " area.

- code indicating current use of structure - This is a five-digit category code; see Section A.1.2 below. 


\section{A.1.2 Building Type Coding List (Fort Lewis - Paper Copy)}

This list contains three-digit category codes used by the Army to categorize all buildings and facilities by their type (e.g., hangar, barracks) or area of use (e.g., airfield, shipyard).

\section{A.1.3 Building/Facility Database (IFS) (Fort Lewis - Paper Copy)}

This printout contains information on the breakdown of housing areas (e.g., size, number of units, age, location, construction type). This printout also appears to contain the same information on all other buildings on the post. No electronic copy was available at the time.

\section{A.1.4 Real Property Housing List (Fort Lewis - Paper Copy)}

This document includes a breakdown of single-family residential housing by area and quantity. It provides information not available el sewhere.

\section{A.1.5 Energy Use Spreadsheet (Fort Lewis - Electronic File)}

This spreadsheet presents various compilations of energy use for the post from 1986 to 1989. It includes monthly energy use for electricity, natural gas, and \#2 and \#6 fuel 0il. The use is displayed according to user: primary post, housing, and National Guard.

\section{A.1.6 Energy and Demand by Substation Feeder Spreadsheet (Fort Lewis - Electronic File)}

These spreadsheets provide monthly metered energy and demand levels for several years for the post.

\section{A.1.7 Housing and Water Pump Meter Reading Spreadsheet (Fort Lewis - Electronic File)}

This spreadsheet contains monthly meter reading values from the Fortowned meters in place at various housing areas and certain water pumping stations. Also included are similar readings for the various substation feeders throughout the Fort.

\section{A. 1.8 Post Maps (Fort Lewis)}

One set of maps includes building numbers for all identifiable buildings on the post. A second electric line feeder map was color-coded during a site 
visit to identify groups of buildings and facilities with their respective substation feeders.

\section{A.1.9 Computer-Aided Design (CAD) Drawings of Representative Post Buildings (Fort Lewis)}

The post CAD drawings provided no connected load, construction type, or occupancy information. Printouts of the CAD layouts were available for use in additional data-gathering by walk-through audits.

\section{A.1.10 Post Transformer Spreadsheet (Fort Lewis - Electronic File)}

The database file provided by Fort Lewis contains information on the 2059 pole and pad mount transformers, switches, and capacitors located on the main post. Approximately 2029 are actual transformers. According to Fort Lewis personnel, this file was very recently upgraded based on a survey required by the U.S. Environmental Protection Agency (EPA).

The following 14 columns of data are included in the database:

- item number (primarily sequential)

- manufacturer

- number of cycles

- impedance value (sometimes " 0 ")

- cooling medium (e.g., oil, air)

- manufacturer's serial number

- number of phases

- kVA rating (sometimes " 0 ")

- style (not usually indicated)

- type (not usually indicated)

- primary (high side) voltage

- secondary (low side) voltage

- service type (e.g., pole mount, pad mount)

- unit location (usually building number). 


\section{A.2 FORT LEWIS ENERGY STUDIES}

\section{A.2.1 Energy Resources Management Plan 1987 (Fort Lewis - Report)}

The Energy Resources Management Plan completed in January 1987 includes economic analyses of various building conservation projects involving insulation, infiltration, controls, reduced water flows, lighting, and storm windows. This study considered only nonfamily housing buildings on the post. Reevaluations of other Fort-wide energy projects are also included. Packaged projects that include floor, ceiling, and wall insulation, as well as infiltration sealing, controls, and other measures are estimated to save over $\$ 3$ million at a simple payback of less than 5 years. The report evaluated the consolidation of two central distribution plants along with a waste incinerator. The distribution plant consolidation is already in progress. The feasibility of an emergency management control system (EMCS) for the post was studied and found to be practical in only the North Fort area. The report provides only minimal information on the building stock on the post.

\section{A.2.2. Fort Lewis Energy Savings Opportunity Survey 1987 (Fort Lewis - Report)}

In this two-volume report with appendixes, potential energy conservation opportunities (ECOs) in the building stock are examined and other ECOs studied previously are reviewed. For the building stock, 91 buildings were surveyed to estimate the energy conservation potential in approximately 1400 buildings on the post from a list of 49 energy conservation measures.

\section{A.2.3 Energy Survey of Army Dining Facilities at Fort Lewis, Washington (United Industries Corporation - Report UIC-8601)}

This 1986 survey reports on an energy audit and analysis of 38 dining facilities on the post to identify retrofit and operation opportunities for improving energy efficiency.

\section{A.2.4 Electric Substation Monitoring 1990 (Fort Lewis - Report)}

This test report describes monitoring conducted to measure the electric demand profile of the Fort and to determine the contribution to the total demand by each of the three substations and associated feeder lines. 


\section{A.2.5 Commissary Electric Profile 1990 (Fort Lewis - Report)}

This test report documents measurements of the total energy consumption in the commissary to determine energy use and demand per square foot and to determine whether energy conservation opportunities exist in the commissary.

\section{A.3 SECONDARY INFORMATION}

Secondary sources of information were also useful in characterizing the baseline and energy efficiency resource of the Fort. These included the following documents:

\section{A.3.1 Conservation Resources Supply Document, Draft 1990 (Bonneville)}

Report providing technical documentation of information used to develop the Bonneville Draft 1990 Conservation Supply Document.

\section{A.3.2 Technical Appendix to Conservation Supply for the 1990 Power Plan 1989 (Northwest Power Planning Council)}

Report providing technical documentation of information used to develop the Northwest Power Planning Council (NWPPC) estimate of electric energy efficiency resources in the Pacific Northwest.

\section{A.3.3 Description of Electric Energy Use in Single-Family Residences in the Pacific Northwest, July 1989 (Bonneville, DOE/BP-13795-21)}

Report providing summary information on end-use metered consumption of electricity in 499 residences in the Pacific Northwest during the period September 1984 through May 1988.

\section{A.3.4 Description of Electric Energy Use in Commercial Buildings in the Pacific Northwest, December 1989 (Bonneville, DOE/BP-13795-22)}

Report providing summary information on end-use metered consumption of electricity in nearly 100 commercial buildings in the Pacific Northwest during the period September 1984 through October 1988. 


\section{APPENDIX $\mathrm{B}$}

\section{BUILDINGS SECTOR BASELINE AND EFFICIENCY ASSESSMENT}




\section{BUILDINGS SECTOR BASELINE AND EFFICIENCY ASSESSMENT}

To assess total building energy use and conservation potential at Fort Lewis, a complete picture of the Fort's building stock and typical energy use was developed through a three-step process. The entire post building stock was categorized by basic building type or function, and total square footages of conditioned space for each type were derived. End-use intensities (EUI) ( $k W h / \mathrm{ft}^{2} \mathrm{yr}$ ) for the various energy uses (end uses) for each building type were estimated and applied to the square footage of each building type to arrive at a total energy use value for each end use for all buildings on the post. These values were then used in assessing potential post-wide energy savings for specific conservation measures.

\section{B.1 BUILOING STOCK CATEGORIZATION}

The building database provided by Fort Lewis contained information on all Fort nonresidential facilities. This includes all nonbuilding facilities (e.g., sheds, bus stop shelters, flagpoles, walkways). The database is generally set up to use a "number of floors" value of " 0 " to identify nonbuilding-type structures. Therefore, the original sorts (by three-digit code) of the database were based on all buildings with one or more floors. This led to the omission of many obvious conditioned buildings (apparently miscoded with " 0 " floor). In addition, many facilities are coded under specific operational categories, e.g., "airfield" or "maintenance, " rather than cateyories that closely match the chosen prototypes.

For these reasons, the remainder of the database was manually searched, and additional five-digit categories were identified as fitting with the prototypes. These buildings, as well as any obvious conditioned facilities with " 0 " floor codings, were added to the original database sort totals. Still remaining was a small subset of buildings with one or more floors but " 0 " square footage. For these buildings, the square footage was obtained from Fort personnel and added to the appropriate category totals. 
For residential buildings not included in the above database, different data sources were used. The Real Property Housing List and Resources Management $\mathrm{Pl}$ an were used to arrive at total unit numbers for each housing area, as well as associated building numbers. The Building/Facility Database - (IFS) type contained square footage values for each unit and an indication of building age and type, e.g., single, duplex. Because these data existed only in paper form, they were manually transferred from the printout to arrive at square footage totals for each type and vintage (year of construction) of housing units.

The building type values derived from the various sources are summarized in Table B.1.

TABLE B.1. Fort Lewis Building Stock Summary

\begin{tabular}{|c|c|c|c|}
\hline Building Type & $\begin{array}{c}\text { Total Area } \\
\left(\mathrm{ft}^{2}\right)^{-1}\end{array}$ & Building Count & $\frac{\text { Average Size/Unit }}{\left(\mathrm{ft}^{2}\right)}$ \\
\hline Single Residence & $3,207,801$ & 1,811 & 1,771 \\
\hline Multiple Residence & $2,675,095$ & 394 & $1,579^{(a)}$ \\
\hline TOTAL & $5,882,896$ & 2,205 & N/A \\
\hline
\end{tabular}

The vintage of all the residential units ranges from the early 1940 s to the 1980s; most were constructed in the 1950s to 1960s.

Barracks

$\begin{array}{llll}\text { Three-story concrete } & 3,209,566 & 79 & 40,627\end{array}$

Includes all three-story facilities in Army code groups 721, 724 (none), and 725 (none): unaccompanied enlisted personnel barracks-type structures with or without dining areas and associated latrine and other facilities (construction type not identified in database, but virtually all threestory units are known to be concrete/brick/masonry).

Barracks

$\begin{array}{llll}\text { Two-story wood } & 1,461,532 & 29 & 15,022\end{array}$

Includes all two-story or less facilities in Army code groups 721, 74032, 724 (none), and 725 (none): unaccompanied enlisted personnel barrackstype structures with or without dining areas and associated latrine and other facilities (construction type not identified in database, but virtually all two- and fewer-story units are known to be wood frame). 
TABLE B.1. (contd)

$\frac{\text { Building Type }}{\text { Motor Pool }} \frac{\begin{array}{c}\text { Total Area } \\ \left(\mathrm{ft}^{2}\right)\end{array}}{1,926,594} \frac{\text { Building Count }}{252} \frac{\begin{array}{c}\text { Average Size/Unit } \\ \left(\mathrm{ft}^{2}\right)\end{array}}{7,645}$

Includes all facilities in Army code groups 210 through 229, plus 123 and 1212: all maintenance and production facilities for vehicles and stationary equipment of a 17 kinds.
Dining Hall
124,377
24
5,182
Includes all facilities in Army code group 722 and 74062: unaccompanied personnel dining facilities.
$\begin{array}{llll}\text { Office/Administration } & 2,892,262 & 715 & 4,045\end{array}$
Includes all facilities in Army code groups $131,133,171,610,620,730$ (none), $14131,14182,14183,14185,72330,72360$, and 73072 : airfield communications, traffic control, training, headquarters, and administrative.
Warehouse
$2,933,673$
446
6,577
Includes all facilities in Army code groups 124 (none), 143 (none), and 410 through 442: all supply and storage facilities including fuel, dry, and refrigerated.
01d Madigan
736,651
79
9,324
Includes all facilities in Army code groups 510 through 550 and 73045 - all hospital, clinic, dental, and other medical facilities (not including the New Madigan Hospital). This includes facilities at the 0ld Madigan area and elsewhere on the post.

$\begin{array}{lrrr}\text { Hangar } & 333,005 & 8 & 45,750 \\ \begin{array}{l}\text { New Madigan } \\ \text { Hospita7 (approximate) }\end{array} & 2,000,000 & 1 & 2,000,000 \\ \text { Commissary } & 105,000 & 1 & 105,000 \\ \text { Computer Center } & 15,398 & 1 & 15,398 \\ \text { Simulator(s) } & 54,200 & 2 & 27,100 \\ \text { Club(s) } & 112,168 & 8 & 14,021\end{array}$

These values are based on information from site personnel and manual searches in the building database. 
IABLE B.1. (contd)

\begin{tabular}{|c|c|c|c|}
\hline Buil & $\begin{array}{l}\text { Total Area } \\
\left(\mathrm{ft}^{2}\right) \\
\end{array}$ & Building Count & $\frac{\text { Average Size/Unit }}{\left(\mathrm{ft}^{2}\right)}$ \\
\hline her & $2,116,933$ & $345^{(b)}$ & $6,136^{(b)}$ \\
\hline FORT LEWIS GRAI & $23,937,346^{(b)}$ & $4,457^{(b)}$ & $N / A$ \\
\hline
\end{tabular}

(a) These 394 multiple residence buildings contain a total of 1694 units and vary from duplexes to eight-unit complexes.

(b) Grand total includes all buildings with number of floors greater than " 0, " plus major facilities not yet in database and buildings with " 0 " floors identified as valid conditioned facilities. This value and "other" may be high or low due to database errors, as some buildings have incorrectly identified numbers of floors and missing sqliare footages.

General Notes: It appears that many facilities are coded under specific operational categories, e.g., "airfield" or "maintenance," rather than the building types that we are used to. The accuracy of matches of these Army building categories to identified building prototypes will vary. The use of some five-digit categories provided additional detail. Sorting based on the more detailed building descriptions may be more useful. This would, however, require much more effort in scanning the entire database to identify the various building acronyms used for each type and may still be widely inaccurate.

\section{B.2 END-USE INTENSITY AND BASELINE ESTIMATION}

\section{B.2.1 End-Use Intensity Development}

EUIs can be very specific to certain buildings in any area. However, for large groups of similarly operated buildings, an average EUI can be used to estimate energy consumption for a specific end use. Several sources were consulted in estimating EUIs for the various end uses and building types represented. In some cases, an established EUI from regional forecasting documents (Bonneville and NWPPC) and actual measurements (collected in the End-Use Load and Consumer Assessment Program [ELCAP]) was used and/or modified if the building type and use was a good match. Other EUIs were derived by applying rated equipment capacities to an estimated operation schedule. Still others were derived based on a combination of the two methods. 
The EUIs were developed with the focus on identifying electricity consumption within major end uses with significant efficiency improvement potential; they were not developed to provide a detailed accounting of end-use electricity consumption. The major end uses identified within the buildings sector are

- interior lighting provided by incandescent lighting, fluorescent lighting by fixtures with F-96 tubes, F-40 tubes and F-34 tubes, and high-intensity-discharge (HID) lighting

- hot water provided by residential-type electric water heaters

- refrigeration provided by residential-type and-sized units.

All other electricity consumption is combined into the other category. The composition of the consumption in this category is determined by the stock of electricity-using equipment in each of the building types and the use intensity. Although efficiency potential likely exists within this category, it is building-type dependent and is not amenable to capture in a facilitywide efficiency improvement program supported by this assessment.

Electricity used for heating, ventilating, and air conditioning (HVAC) was not identified separately because few buildings have air-conditioning equipment. In addition, most HVAC electricity use is for pumps and fans, which are not believed to have the level of efficiency resource potential sought in this assessment.

The development of the EUIs is described on the worksheets included in this section of the appendix. The worksheets provide the EUI development notes for each building type on the post. 


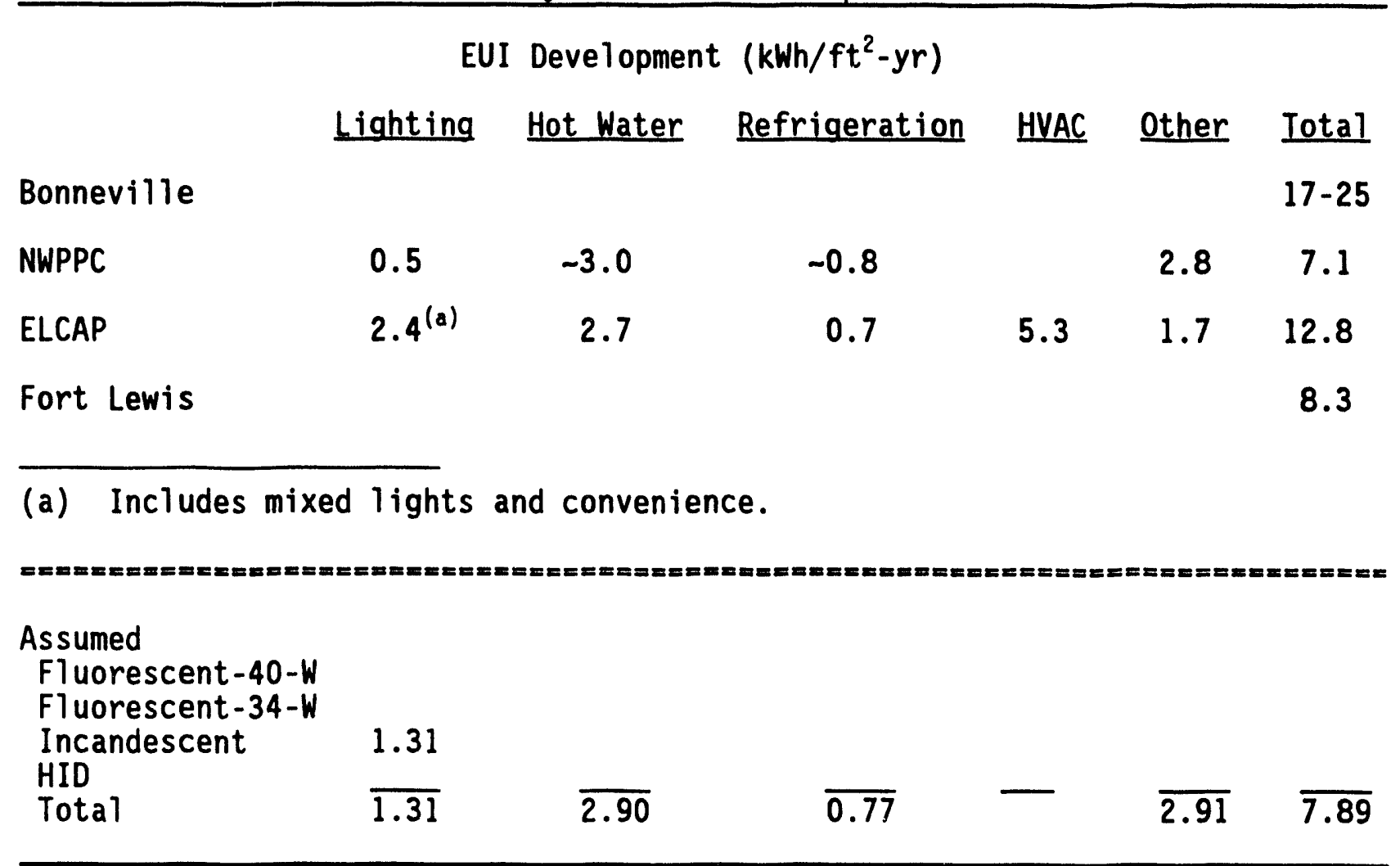

End-use intensities were developed using information on the amount of electricity delivered to family housing combined with secondary information. During the period July 1989 through June 1990, 48,484,626 kWh of electricity were delivered to family housing. This was reduced by $2 \%$ to reflect assumed street lighting requirements and by 1,291,000 kWh for assumed exterior 1ighting energy to provide energy used directly to serve occupant needs. This adjusted total provides an annual per square foot consumption of $7.89 \mathrm{kWh}$, which serves as the control total for applying the secondary information in allocating among end uses.

NWPPC End-Use Estimates (excludes heating and cooling)

kWh/yr $\quad k W h / f t^{2}-y r$

Lighting

Internal

External

Hot Water

Refrigeration

Dryer

Television

other

620

70

5000

1156

950

200

2730

0.45

0.05

3.0

0.83

0.68

0.14

1.95

\section{B. 6}


Fort Lewis Consumption Data by Housing Area

The following data are for the period July 1989 - June 1990.

$k W h / f t^{2}-y r$

Beachwood
Madigan
Clarksdale
Davis Hill/Parkway
Evergreen
Broadmoor
Greenwood
Hillside
Average

12.2

9.3

10.0

5.9

3.9

4.0

3.1

12.6

8.3

Other Assumptions

Water heat $90 \%$ electric, $10 \%$ gas

Cooking $100 \%$ electric

$100 \%$ occupancy year round

Space heat $100 \%$ gas 
Residential Multi-Unit

Electricity Basel ine Development Notes

EUI Development (kWh/ft $\left.{ }^{2}-y r\right)$

Lighting Hot Water Refrigeration HVAC other Total

Bonneville

$10-12$

NWPPC

0.5

$-3.0$

$-0.8$

$2.8 \quad 7.1$

ELCAP

$2.4^{(a)}$

2.7

0.7

5.3

$1.7 \quad 12.8$

Fort Lewis

8.5

(a) Includes mixed lights and convenience.

Assumed

Fluorescent - 40-W

Fluorescent-34-W

Incandescent

HID

Total

1.39

$\overline{1.39}$

$\overline{2.86}$

$\overline{0.76}$

$\overline{2.88}$

$\overline{7.89}$

See notes for Single Family Attached/Detached worksheet. Slight differences in assumed EUIs result from adjustments made for square footage and remainders. 
EUI Development (kilh/ft $\left.{ }^{2}-y r\right)$

Lighting Hot Water Refrigeration HVAC other Total

Bonneville

$10-12$

NWPPC

0.5

$-3.0$

$-0.8$

2.8

7.1

ELCAP

$2.4^{(a)}$

2.7

0.7

5.3

1.7

12.8

Fort Lewis

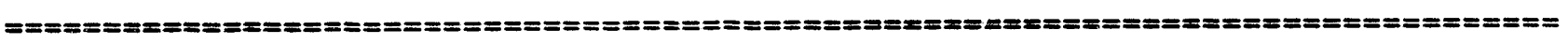

Assumed

Fluorescent -40-W

4.24

Fluorescent-34-W

Incandescent

HID

Total

$\overline{4.24}$

$\overline{0.06}$

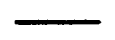

$\overline{84.20} \overline{88.50}$

No secondary data were available for this category. The total EUI of $88.50 \mathrm{kWh}$ was based upon an annualized estimate of simulator electricity consumption from metering of the helicopter simulator for a 2-week period. Lighting energy consumption is assumed to be about the same as the new administration category and one electric hot water heater per simulator is assumed. Energy use in the other category would be accounted for primarily by the simulator equipment, along with cooling energy and office and miscellaneous equipment.
\end{abstract}


Lighting Hot Water Refrigeration HVAC Other Total

Bonneville

30-105

NWPPC

ELCAP

$12.8^{(a)}$

2.5

$11.5^{(b)}$

$8.5^{(c)}$

5.9

43.4

Fort Lewis

8.6

18.2

26.8

(a) Includes exterior lighting of 2.5.

(b) Includes food preparation.

(c) Heating and cooling energy of 4.4 and fans and auxiliaries of 4.1 .

\section{Assumed \\ Fluorescent $-40-W$ \\ Fiuorescent-34-W \\ Incandescent \\ HID \\ Total}

2.06

8.23

$\overline{10.29}$

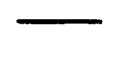

EUIs were developed using the NWPPC and ELCAP data and the portion of the dining hall survey conducted for Fort Lewis that dealt with the clubs. The total EUI is assumed to be an average of the ELCAP and Fort Lewis totals, with the ELCAP total reduced by its exterior lighting and heating and cooling energy requirements $(36.78 \mathrm{kWh})$. The interior lighting EUI was assumed to be similar to the ELCAP estimate and shared between fiuorescent and incandescent by $20 \%$ and $80 \%$, respectively. 
Computer Center

Electricity Baseline Development Notes

EUI Development ( $\left.k W h / \mathrm{ft}^{2}-\mathrm{yr}\right)$

Lighting Hot Water Refrigeration HVAC other Total

Bonneville

NWPPC

ELCAP

Fort Lewis

Assumed

Fluorescent $-40-W$

7.64

Fluorescent-34-W

Incandescent

HID

Total

8.23

$\overline{7.64}$

$\overline{1.70} \quad \overline{22.73} \quad \overline{32.07}$

The EUI for the new administration category is assumed as the baseline, with the following adjustments:

- Lighting is assumed to be about $50 \%$ higher than that of the new administration category.

- An air-conditioning EUI of $1.7 \mathrm{kWh}$ is based on the ELCAP Office EUI (this may be low) in place of the new administration HVAC EUI.

- The other category is assumed to be largely computer loads, which may range from 5 to $40 \mathrm{kWh} / \mathrm{ft}^{2}-\mathrm{yr}$, so a value of $20 \mathrm{kWh}$ was assumed in addition to the new administration other category EUI. 
01d Madigan Hospital

Electricity Basel ine Development Notes

EUI Development (kWh/ft $\left.{ }^{2}-\mathrm{yr}\right)$

Lighting Hot Water Refrigeration HVAC other Total

Bonneville

(health care) $\quad 4.8$

14.0

11.3

NWPPC

ELCAP

Fort Lewis

Other

DOE-EIA

Assumed

Fluorescent-40-W

Fluorescent-34-W

Incandescent

HID

Total

6.11

$\overline{6.11}$

$\overline{11.95} \overline{18.06}$

The total EUI of $18.06 \mathrm{kWh}$ is developed based upon actual consumption of $10,158,600 \mathrm{kWh}$ from October 1989 through October 1990. Lighting is assumed to be slightly higher than the new administration category because of extended operation hours in parts of the building. The other category contains cooling for approximately $10 \%$ to $15 \%$ of the floorspace. No attempt was made to identify refrigeration or electricity-fueled hot water within the other category. 
New Madigan Hospital

Electricity Baseline Development Notes

EUI Development (kWh/ft $\left.{ }^{2}-y r\right)$

Lighting Hot Water Refrigeration HVAC Other Total

Bonneville

(health care)

8.9

11.3

53.6

NWPPC

ELCAP

Fort Lewis

Other

DOE-EIA

Assumed

Fluorescent - 40-W

Fluorescent-34-W

3.00

Incandescent

HID

Total

$\overline{3.00}$

$\longrightarrow$

$\overline{1.00} \quad \overline{4.00}$

The total EUI of $4 \mathrm{kWh}$ is based upon actual reported consumption of about $8 \mathrm{million} \mathrm{kWh}$. Current consumption is assumed to be lighting-dominated; minimal other equipment is operating. It is expected that consumption will increase to at least $25 \mathrm{kWh} / \mathrm{ft}^{2}-\mathrm{yr}$ when the hospital is in full operation because of several factors including extended hours of operation, hospital equipment, operation of four chillers to supply cooling, and use of office and other miscellaneous equipment. 
EUI Development ( $\left.k W h / f t^{2}-y r\right)$

Lighting Hot Water Refrigeration HVAC Other Total

Bonneville

5.2

18.5

NWPPC

ELCAP

Fort Lewis

Assumed

Fluorescent-40-W

Fluorescent-34-W

Incandescent

HID

Total

1.4

0.9

$\overline{2.3}$

$\overline{0.3}$

$\overline{2.0}$

$\overline{4.6}$

In the other category it is assumed that $50 \%$ have

- fluorescent lighting with an EUI of 2.8 and high-wattage ( $>200 \mathrm{~W}$ ) incandescent with an EUI of 1.8

- hot water heating with an EUI of 0.6

- other equipment with an EUI of 4.0 .

The EUIs shown are adjusted for the $50 \%$ shares of fioorspace. 
Concrete Barracks

Electricity Baseline Development Notes

EUI Development (kWh/ft $\left.{ }^{2}-y r\right)$
Lighting Hot Water Refrigeration HVAC other Total

Bonneville

(hotel/motel) $\quad 3.6$

$14-21$

NWPPC (hotel/motel)

ELCAP

Fort Lewis

18

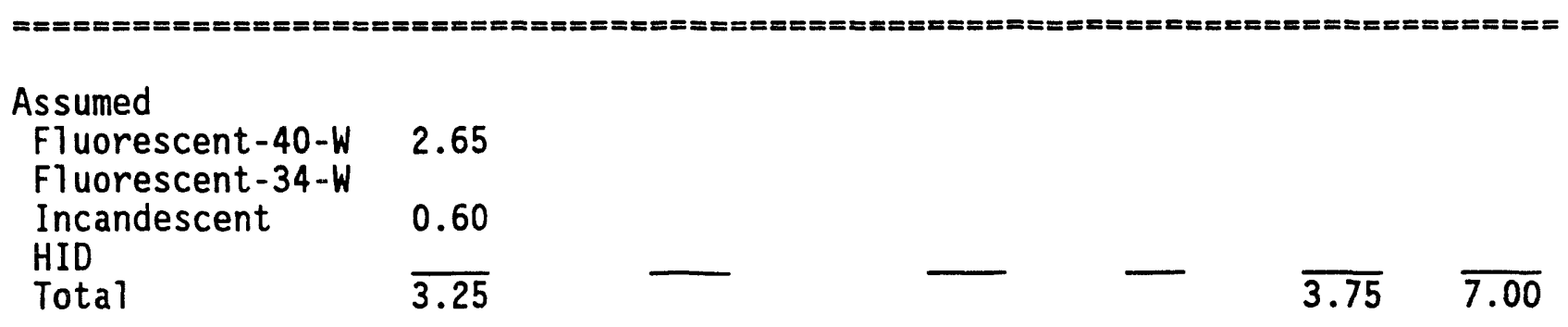

The EUIs were constructed from a survey of connected load and assumed operating schedules. The concrete barracks are also assumed to operate year round at $100 \%$ occupancy:

The other category includes these end uses:
Water cooler
Room refrigerator
Washer and dryer
Stereo and television
Central heat control
Room space heater
Other miscellaneous. 
EUI Development (kWh/ft $\left.{ }^{2}-\mathrm{yr}\right)$

\section{Lighting Hot Water Refrigeration HVAC Other Total}

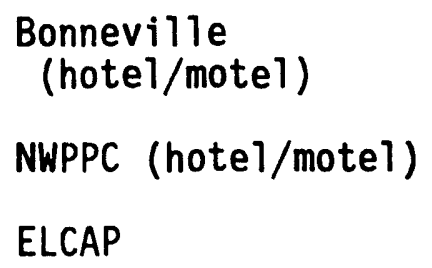

$14-21$

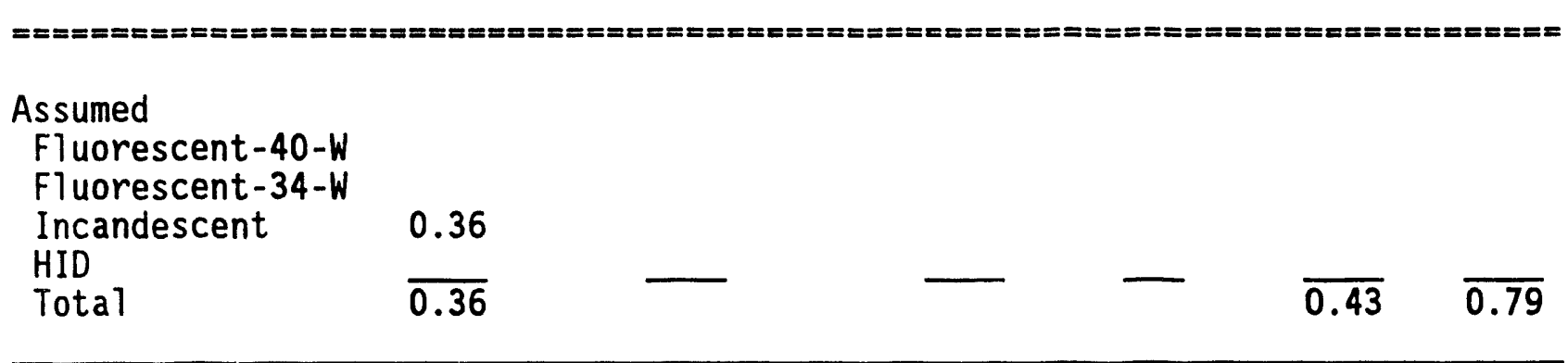

The EUI was based upon a survey of connected load and assumed operating schedules. The wood barracks -- not upgraded subcategory is assumed to be $30 \%$ occupied during the year. The not upgraded subcategory is assumed to account for $70 \%$ of wood barracks floorspace.

The other end-use category includes

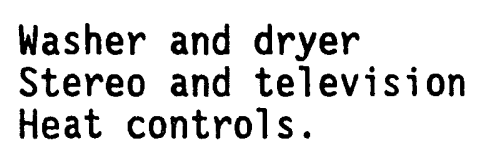

The connected load for this subcategory is assumed to be lower than other barracks as these have an open bay plan and serve primarily transient personnel. 
Wood Barracks -- Not Upgraded With Dayroom

Electricity Baseline Development Notes

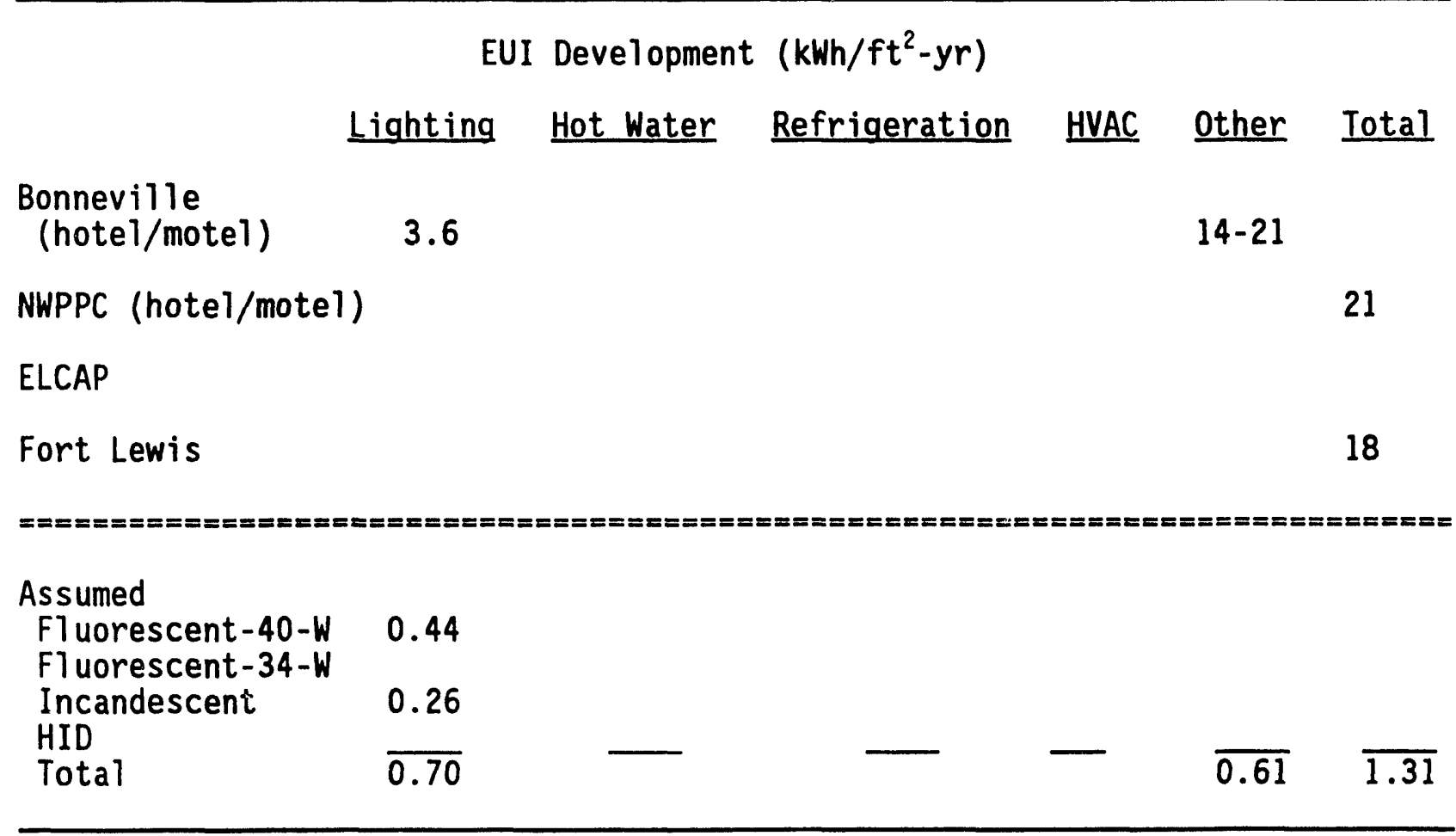

The EUIs were developed from a survey of connected load and assumed operating schedules. This subcategory is assumed to be $30 \%$ occupied during the year; it also is assumed to account for $10 \%$ of wood barracks floorspace. The EUI for lighting is higher than it is for the not upgraded subcategory because of extended operating hours.

Other includes

$$
\begin{aligned}
& \text { Washer and dryer } \\
& \text { Stereo and television } \\
& \text { Heat controls } \\
& \text { Other miscellaneous. }
\end{aligned}
$$


Wood Barracks -- Upgraded

Electricity Baseline Development Notes

\section{EUI Development ( $\left.k W h / \mathrm{ft}^{2}-\mathrm{yr}\right)$ \\ Lighting Hot Water Refrigeration HVAC other Total}

Bonneville

(hotel/motel) $\quad 3.6$

$14-21$

NWPPC (hotel/motel)

ELCAP

Fort Lewis

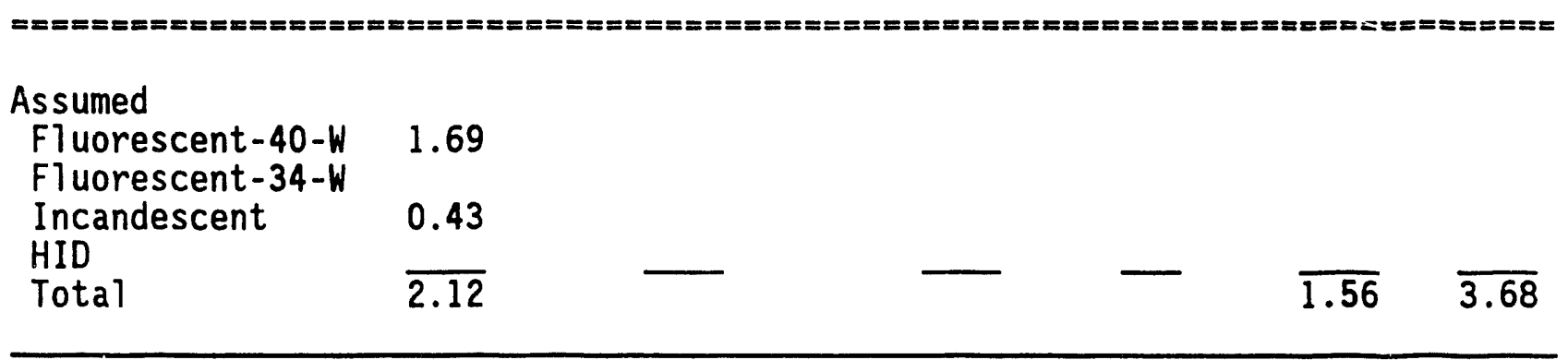

The EUIs are based on a survey of connected load and assumed operating schedules. The wood barracks -- upgraded subcategory is assumed to be $50 \%$ occupied all year. This subcategory has higher installed lighting capacity than the other wood barracks. This subcategory is assumed to account for $20 \%$ of wood barracks floorspace.

Other includes

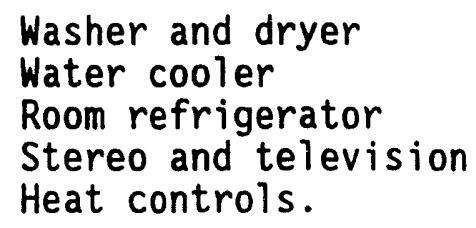

The connected load in the other category is higher than for the other wood barracks because the rooms are enclosed and house more permanent staff. 
New Administration

Electricity Baseline Development Notes

\begin{tabular}{|c|c|c|c|c|c|c|}
\hline & & Developmer & $t\left(k W h / f t^{2}-y r\right)$ & & & \\
\hline & Lighting & Hot Water & Refrigeration & HVAC & Other & Iotal \\
\hline Bonneville & $7-8.7$ & & & & 16.6 & \\
\hline $\begin{array}{l}\text { NWPPC (small } \\
\text { office) }\end{array}$ & 5.17 & 0.50 & & 13.5 & & \\
\hline ELCAP & $9.7^{(a)}$ & 0.4 & & $8.5^{(b)}$ & 2.4 & 21 \\
\hline Fort Lewis & & & & & & 18 \\
\hline $\begin{array}{l}\text { (a) } 7.6 \text { interior } \\
\text { (b) } 3.9 \text { heating } \\
=================\end{array}$ & $\begin{array}{l}2.1 \text { exte } \\
\text { and cool in }\end{array}$ & $\begin{array}{l}\text { or. } \\
4.6 \text { fans }\end{array}$ & and auxiliaries. & & & \\
\hline $\begin{array}{l}\text { Assumed } \\
\text { Fluorescent-40-W } \\
\text { Fluorescent-34-W } \\
\text { Incandescent } \\
\text { HID } \\
\text { Total }\end{array}$ & $\begin{array}{l}4.24 \\
0.18 \\
4.42\end{array}$ & & & $\overline{3.48}$ & $\overline{1.95}$ & $\overline{9.85}$ \\
\hline
\end{tabular}

The EUI is based upon a connected load survey and assumed operating schedules. HVAC energy is for fans and auxiliary equipment; no cooling energy is assumed for this category. The other EUI is lower than for the old administration category because of observed equipment loadings and the presence of nonoffice floorspace such as lobby, hallway, and auditorium. The new administration subcategory is assumed to account for $10 \%$ of overall administration floorspace. 


\section{EUI Development ( $\left.k W h / \mathrm{ft}^{2}-\mathrm{yr}\right)$ \\ Lighting Hot Water Refrigeration HVAC other Total}

Bonneville

NWPPC

ELCAP

Fort Lewis

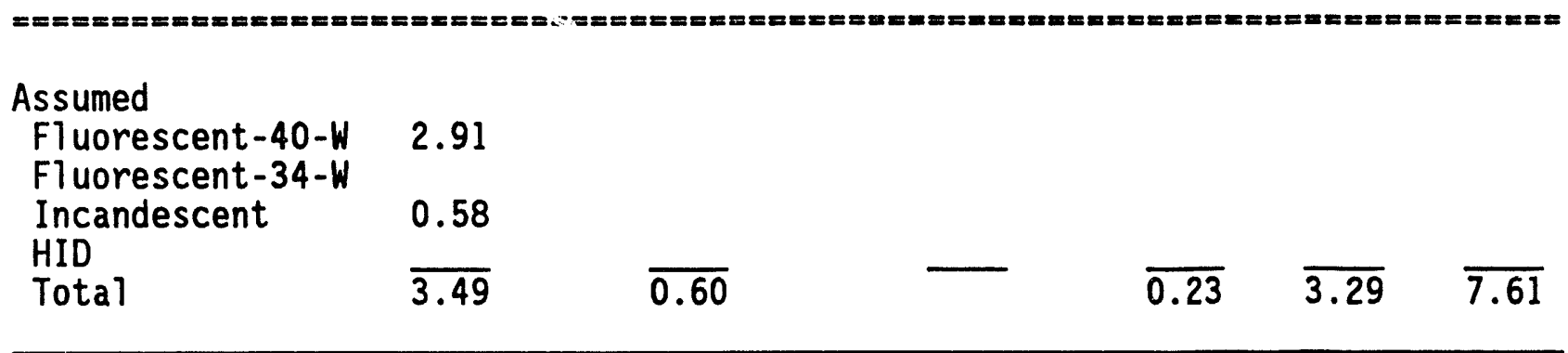

The EUI is based upon a connected load survey and assumed operating schedules. HVAC energy is for fans and auxiliary equipment; no cooling energy is assumed for this category. The other EUI is higher than for the new administration category because of observed equipment loadings. The space comprises hallway and offices, with no lobby, auditorium, or other nonoffice functional use areas. The old administration subcategory is assumed to account for $90 \%$ of overal1 administration floorspace. 
New Motor Pool

Electricity Baseline Development Notes

EUI Development (kWh/ft $\left.{ }^{2}-y r\right)$

Lighting Hot Water Refrigeration HVAC Other Total

Bonneville

NWPPC

ELCAP

Fort Lewis

Assumed

Fluorescent-40-W

Fluorescent - 34-W

Incandescent

HID

Total

1.57

$\frac{1.14}{2.71}$

$\overline{3.86}$

$\overline{6.57}$

The EUIs are based on a connected load survey and assumed operating schedules. The new motor pool subcategory is assumed to account for $40 \%$ of total motor pool floorspace.

Other includes

HVAC

fan coil

$2 \times$ air handler

furnace combustion motor

Hot Water

boiler control

dhw circulation

Shop Equipment

compressor

air dryer

door opener

crane

grinder

welder

exhaust fan

vehicle exhaust 
Other Miscellaneous

microfiche

water cooler

soft drink machine vending machine

radio. 
01d Motor Pool -- Upgraded

Electricity Basel ine Development Notes

EUI Development (kWh/ft $\left.{ }^{2}-\mathrm{yr}\right)$

Lighting Hot Water Refrigeration HVAC other Iotal

Bonneville

NWPPC

ELCAP

Fort Lewis

\section{Assumed}

Fluorescent - 40-W

Fluorescent $-34-W$

Incandescent

0.15

HID

Total

$\frac{2.70}{2.86}$

$\overline{0.99}$

$\overline{0.61} \quad \overline{4.46}$

The EUIs are based on a connected load survey and as jumed operating scheduies. The old motor pool -- upgraded subcategory is assumed to account for $10 \%$ of the total motor pool floorspace.

Other includes

HVAC

distribution fan

boiler combustion motor

Exhaust fan. 
01d Motor Pool -- Not Upgraded

Electricity Baseline Development Notes

\section{EUI Development (kWh/ft $\left.{ }^{2}-y r\right)$ \\ Lighting Hot Water Refrigeration HVAC Other Total}

Bonneville

NWPPC

ELCAP

Fort Lewis

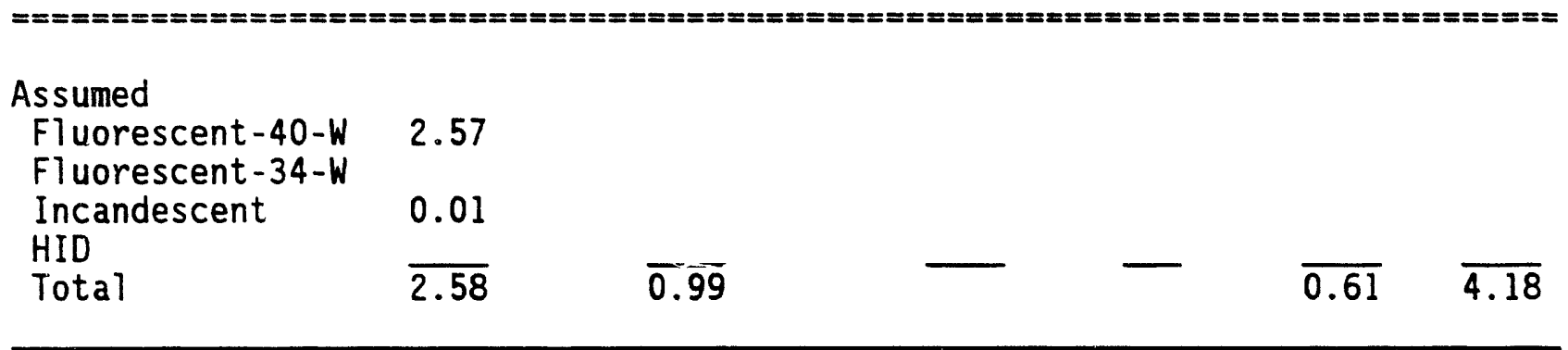

The EUIs are based on a connected load survey and assumed operating schedules. The old motor pool -- not upgraded subcategory is assumed to account for $50 \%$ of the total motor pool floorspace.

Other -- same as old motor pool -- upgraded. 


\section{Dining $\mathrm{Hall}$ \\ Electricity Baseline Development Notes}

EUI Development (kWh/ft $\left.\mathrm{ft}^{2} \mathrm{yr}\right)$

Lighting Hot Water Refrigeration HVAC other Total

Bonneville

NWPPC

ELCAP

Fort Lewis (audit) 10.2

$48.3 \quad 58.5$

Other (AF Study) 15

79

94

Assumed

Fluorescent-40-W $\quad 7.00$

Fluorescent-34-W

Incandescent

HID

Total

3.00

$\overline{10.00}$

The dining hall EUIs are based on a connected load survey, a dining hall audit conducted for Fort Lewis, and a dining hall study conducted for the Air Force by PNL. 
Hangar -- Full Service

Electricity Baseline Development Notes

\section{EUI Development (kWh/ft $\left.{ }^{2}-\mathrm{yr}\right)$}

Lighting Hot Water Refrigeration HVAC Other Total

Bonneville

NWPPC

ELCAP

Fort Lewis

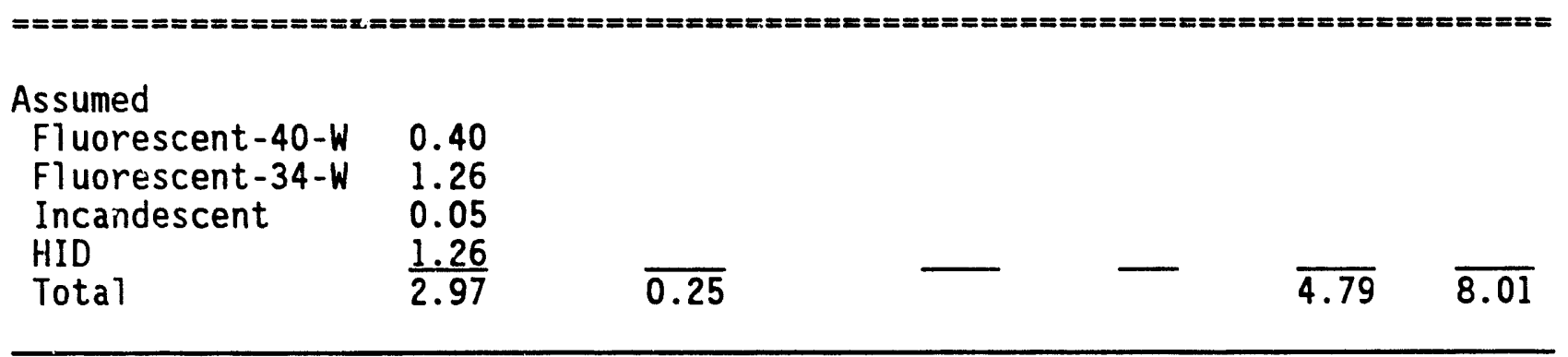

The hangar -- full service EUI is based on a connected load survey and an assumed operating schedule. 
EUI Development (kWh/ft $\left.\mathrm{ft}^{2}-\mathrm{yr}\right)$

Lighting Hot Water Refrigeration HVAC other Total

Bonneville

NWPPC

ELCAP

Fort Lewis

Assumed

Fluorescent-40-W $\quad 0.40$

Fluorescent-34-W $\quad 1.26$

Incandescent $\quad 0.05$

HID $\quad 1.26$

Total $\quad \frac{1.26}{2.97}$

$\overline{0.25}-\quad-\quad \overline{2.21} \quad \overline{5.43}$

The bases for the EUIs for hangar -- all other are the same as those for the hangar -- full service, except for less shop equipment in the other category. 
EUI Development (kWh/ft $\left.{ }^{2}-y r\right)$

Lighting Hot Water Refrigeration HVAC Other Total

Bonneville

NhiPPC
ELCAP
$2.7^{(a)}$
0.14
$3.35^{(b)} 0.91$
7.1

Fort Lewis

(a) 2.4 interior lighting, 0.34 exterior lighting.

(b) 2.8 heating and cooling, 0.55 ventilation and auxiliaries.

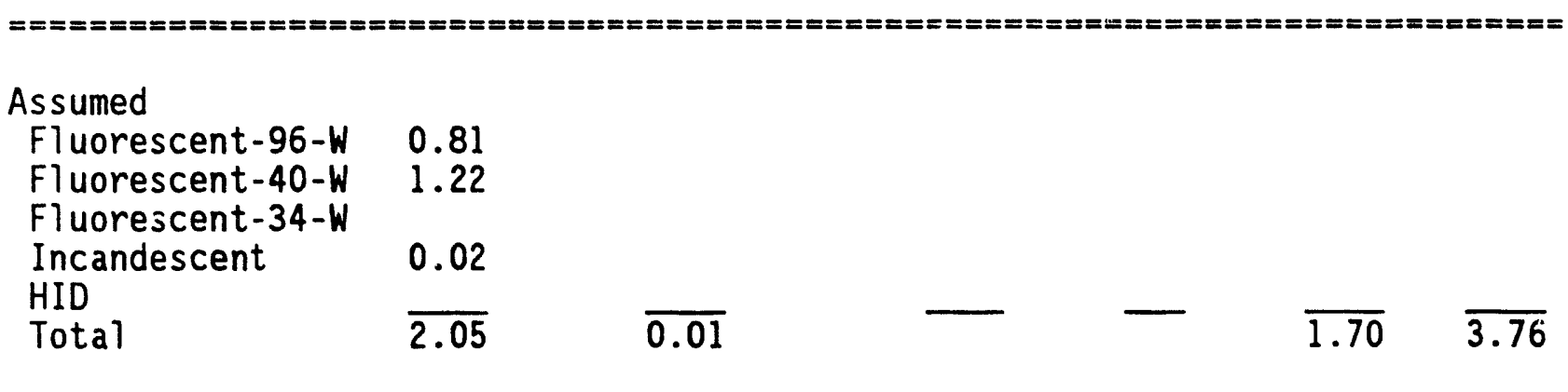

The warehouse EUIs are based on a connected load survey and the assumed operating schedules. ELCAP interior lighting and hot water data are judged to be high for this category because of observed operation and because this building category is not electrically heated or cooled. 


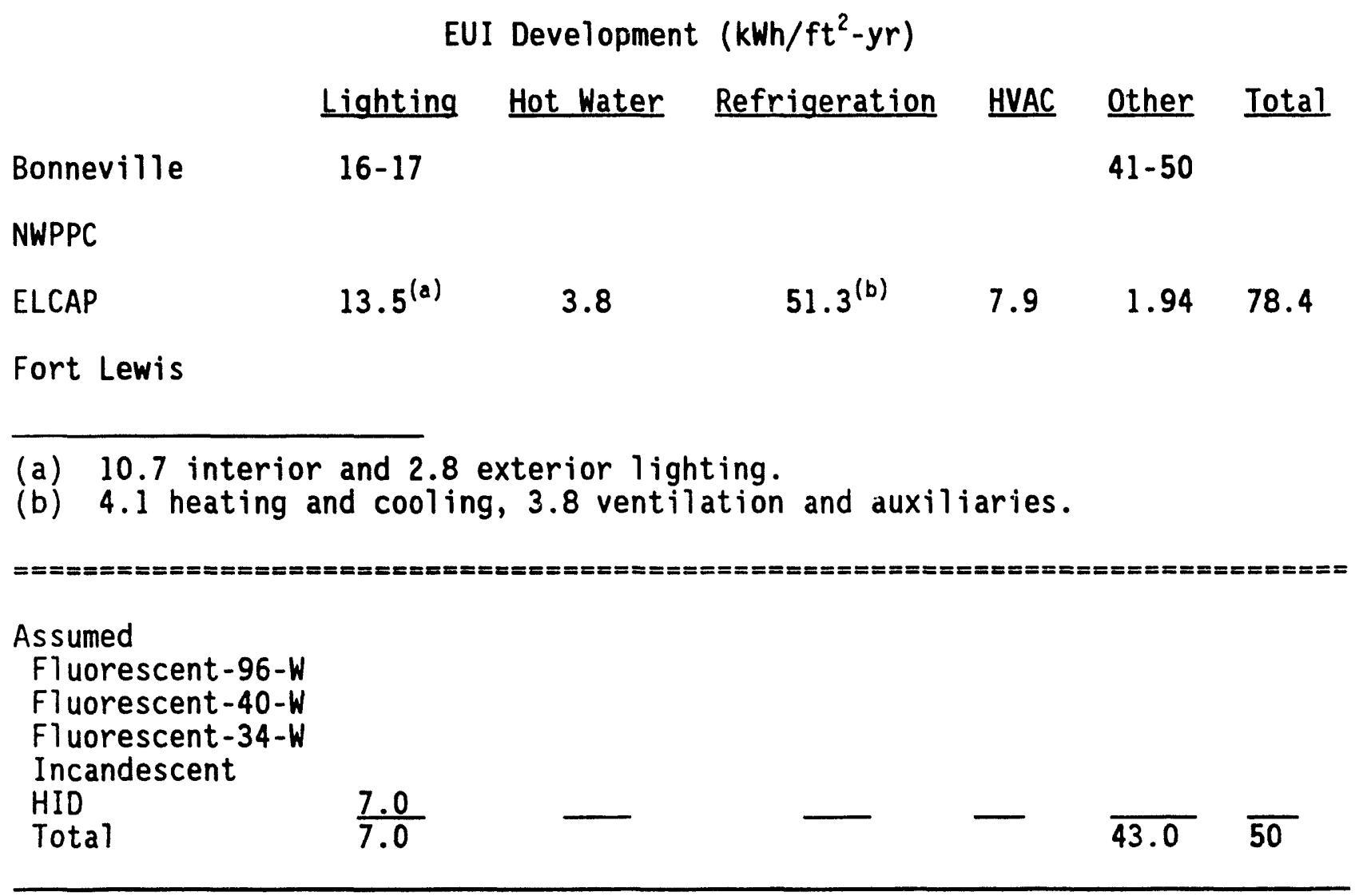

The total EUI is an annualized estimate based upon a 2-week period of metering. The interior lighting is of the HID type and is reportedly underlit, so the lighting EUI is assumed to be lower than the ELCAP grocery category reduced for exterior lighting. Energy consumption in the commissary is low compared to the ELCAP data because the commissary is a new facility that is felt to be energy-efficient and has shorter operating hours than a typical grocery. 


\section{B.2.2 Baseline Development}

The EUIs developed for each Fort Lewis sector were applied to their respective building type square footages to provide the estimated baseline energy use summarized in Table B.2.

\section{B.2.3 Electricity Distribution Point Aggregation}

In the process of developing the EUIs, the baseline estimates were compared to control points to identify areas for making adjustments to the EUIs and to lessen the likelihood of gross misestimation. Seventeen feeders exist that serve as electricity distribution points and for which meter readings were available. Given the distribution of buildings among the 17 feeders and potential for the feeders to be interconnected, these feeders were aggregated to nine points for checking the sector totals and building sector EUIs. The EUI adjustment process required inventorying the building stock and other subsectors by each of the nine checkpoints. The estimated building sector consumption was developed by building type for each checkpoint as the product of the building type total EUI multiplied by the square footage for respective checkpoints. The pumps/motors total sector estimate was added in on feeder A4, even though some water supply motors are located on other feeders, because the major water supply pumping station and sewage treatment plants are located on that feeder. Distribution sector 1 osses of $7.5 \%$ of the estinated feeder total were added in, and exterior lighting sector losses were estimated based upon the stock of buildings by type and estimated total electricity using the assumptions described in Appendix $E$. The estimated total electricity consumption for each feeder was then compared to the metered data to identify major discrepancies, and additional adjustments to the EUIs were made. The outcome of this process is displayed in Table B.3.

Overal1, the estimated electricity consumption is $5 \%$ higher than the metered consumption for the feeders, with all but two of the estimated consumption levels being within $20 \%$ of the respective checkpoint. It is felt that estimates within $20 \%$ of the metered level are reasonable, given the uncertainties that exist in developing the estimates. For feeders A2 and A4, where the estimates are more than $40 \%$ higher than the metered total, it is felt that the lower building utilization in the North Fort area led to the 


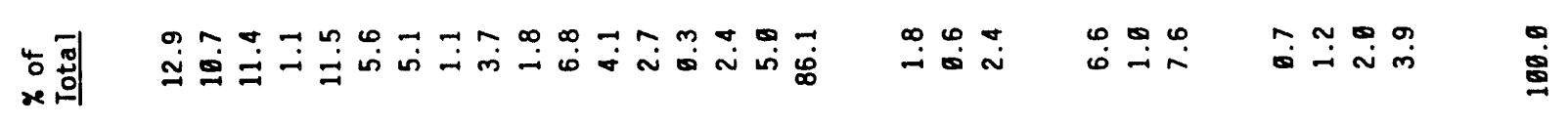

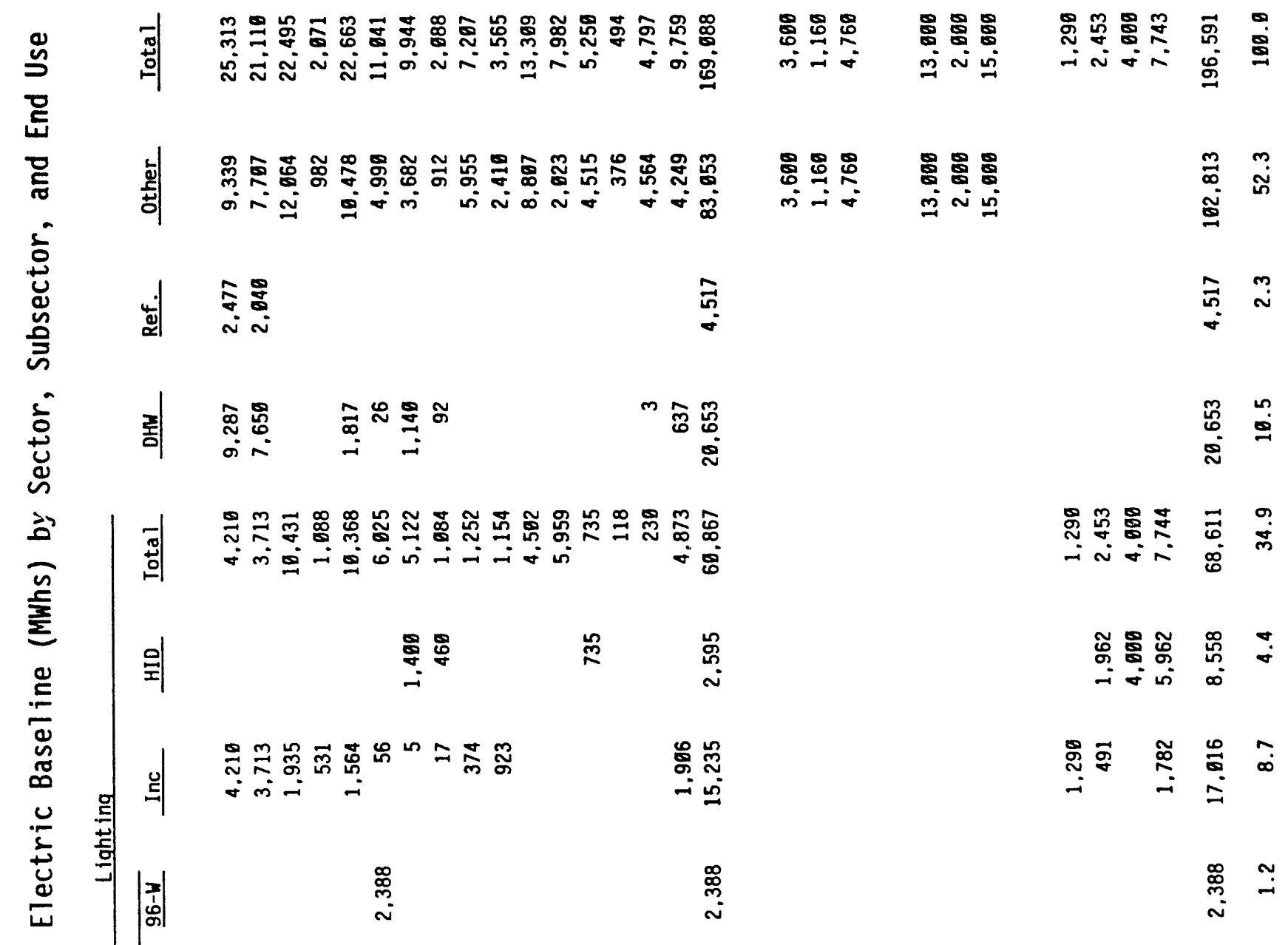

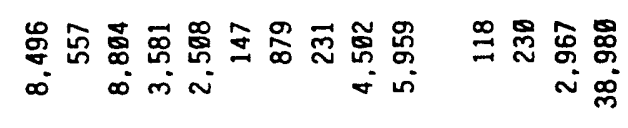
$\begin{array}{ll}\infty & \infty \\ \infty & 0 \\ \infty & 0\end{array}$

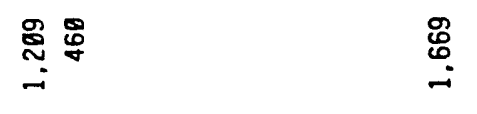

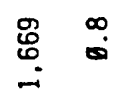

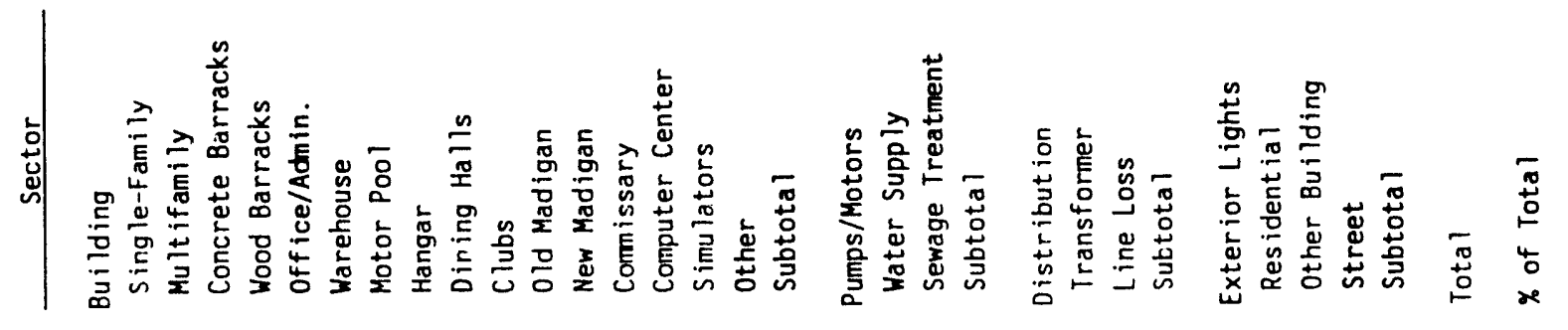




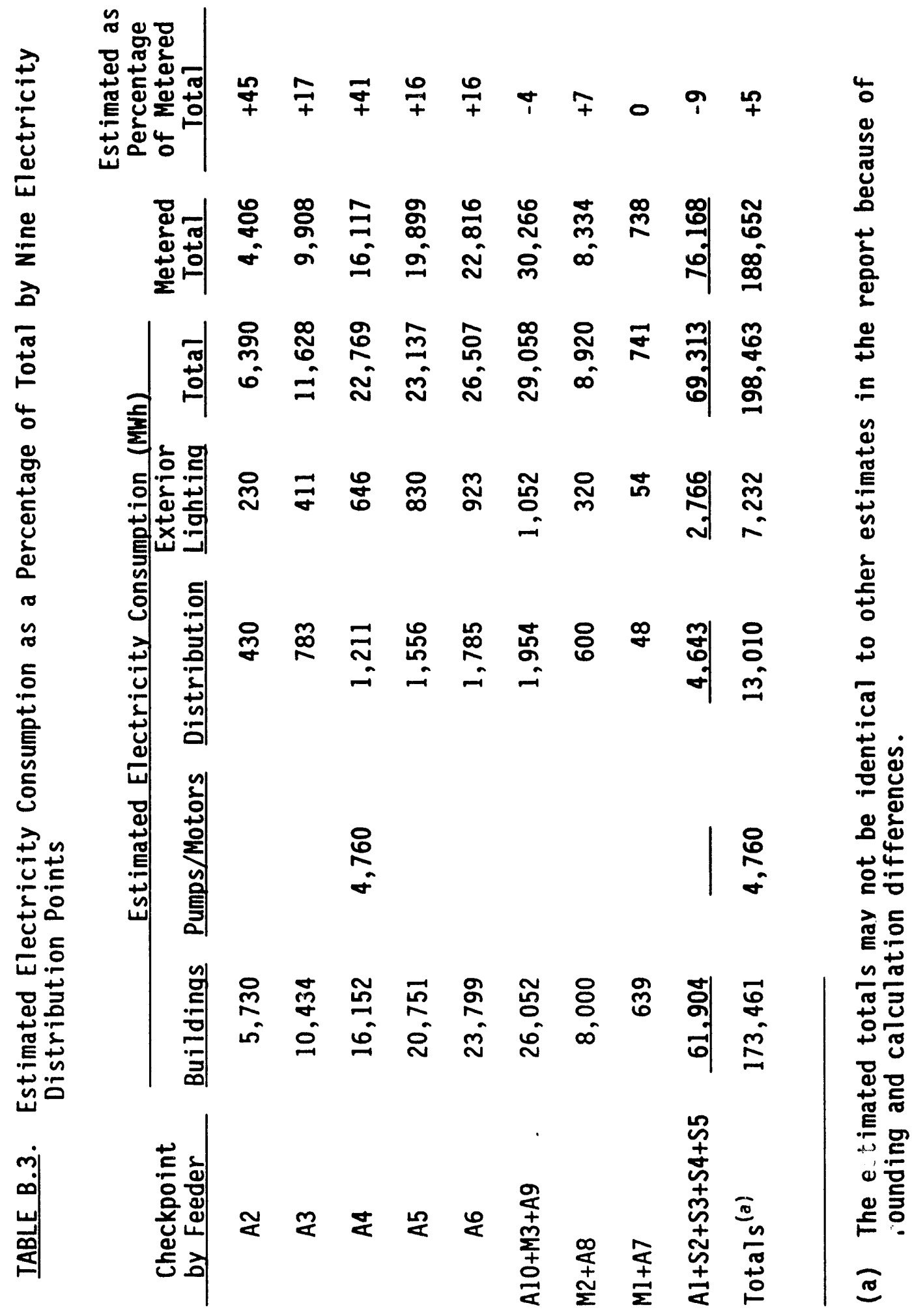


overestimate by using the average EUI. The converse of this is seen in the checkpoint consisting of feeder $\mathrm{Al}+\mathrm{S} 2+\mathrm{S} 3+\mathrm{S} 4+\mathrm{S} 5$, which supplies the Main Fort area where building utilization levels are higher, providing for the estimated total to be lower than the metered total using the average EUI.

\section{B.3 EFFICIENCY ASSESSMENT}

\section{B.3.1 Hot Water Heiter}

The efficiency potential, levelized cost, and net present value of wrapping water heaters and of replacing water heaters with nigh-efficiency models having nonmetallic tanks was examined. Two water heater wrap options and two water heater replacement options were examined:

- Option 1: Wrap all water heaters with R-11 insulating wrap.

- Option 2: Wrap the newest $30 \%$ of all water heaters.

- Option 3: Replace all water heaters with more efficient models.

- Option 4: Replace all water heaters upon failure.

One wrapping option is to wrap all existing heaters. The other is to wrap only the newest $30 \%$ of heaters. The second wrapping option is considerably more attractive because the existing domestic electric hot water heaters suffer from corrosion problems at Fort Lewis, significantly shortening the life of units with steel tanks. The replacement options are to replace all heaters at once with high-efficiency versions or to replace them with high-efficiency versions as they fail.

An estimate of the total number of electric water heaters at Fort Lewis was derived by using the baseline data, dividing the total sector water heater kilowatt-hours of a given building type by the total kilowatt-hours per water heater for that sector. No differentiation between $3000-\mathrm{W}$ and $4500-\mathrm{W}$ heaters was made here or in subsequent cost and energy savings calculations. Because only the total annual use in kilowatt-hours was available in the baseline data, the number and size of electric heaters in the other building category was estimated by using an average heater size of $4250 \mathrm{~W}$ and the operating schedule used for residential buildings. 
Standby loss reductions as the result of an $R-11$ wrap were estimated by the Northwest Power Planning Council (NWPPC 1986) at $817 \mathrm{kWh} / \mathrm{yr}$ for an electric water heater. However, more recent PNL metered data for actual electric water heaters being used in the Northwest for residential applications indicate that standby losses are reduced an average of $611-k W h / y r$. This more recent data was used for the analysis. The $611-\mathrm{kWh} / \mathrm{yr}$ figure was used as the annual savings from either wrapping an existing heater or replacing it with a high-efficiency heater.

The estimated installed cost of applying R-11 insulation wrap to electric water heaters used for this analysis is $\$ 45.00 /$ unit. This was taken from the NWPPC report cited above. The cost of replacing an existing heater with a high-efficiency version was assumed to be $\$ 370$, which was derived from a recent price list from the Marathon Water Heater Company for fiberglass water heaters (fiberglass is being used to overcome the corrosion problems mentioned previously). The cost of replacing a heater with a high-efficiency version upon failure was assumed to be $\$ 22.78$, the difference between the price of the $\$ 370$ efficient Marathon and the $\$ 347.22$ standard fiberglass version.

The time periods used for the levelized cost calculations vary over the options. The wrap of all existing heaters is assumed to have the life of the median Fort Lewis water heater, roughly 3 years. The $30 \%$ of the newest heaters wrapped in the second wrapping option are assumed to have 5-year lives. The option that consists of replacing all heaters immediately uses a 20-year term (the assumed life of a new, noncorroding water heater), while the option that replaces the heaters upon failure has a 24-year term, to allow the replacement and failure of all water heaters.

Using the data and assumptions described, a total of approximately 4247 domestic electric water heaters are located at Fort Lewis, two-thirds of which are located in the detached or multi-unit residential buildings. The results of the analysis are presented in Table B.4. The levelized energy cost is calculated using the NWPPC discount rate of $3 \%$, and the net present values are calculated using the Fort's share of the capital (15\%) and operations and maintenance (0\&M) costs $(100 \%)$. 
TABLE B.4. Hot Water Heater Option Analysis: Energy Savings, Levelized Energy Cost, and Net Present Value

\begin{tabular}{|c|c|c|c|c|}
\hline Action & $\begin{array}{l}\text { Annual Energy } \\
\text { Savings (kVh) }\end{array}$ & $\begin{array}{l}\text { Levelized Energy } \\
\text { Cost }(5 / \mathrm{kWh}) \\
\end{array}$ & $\begin{array}{l}\text { Net Present } \\
\text { Cost (1991 \$ })\end{array}$ & 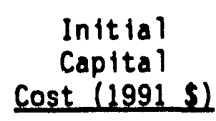 \\
\hline R-11 Wrap All Heaters & $2,595,185$ & 0.0260 & 133,732 & 191.135 \\
\hline Wrap $36 \%$ of Newest & 778,555 & 0.0161 & 69,538 & 57.340 \\
\hline Replace All Heaters & $2,595,185$ & 0.6057 & $2,125,959$ & $1,571,552$ \\
\hline Replace on Failure & $2,427,754$ & 0.6056 & $1,935.369$ & $1,439,450$ \\
\hline
\end{tabular}

\section{B.3.2 Refrigerators}

The efficiency potential and levelized cost were estimated for replacing existing refrigerators at Fort Lewis with DOE 1990 Standard efficiency units (as defined by the National Appliance Energy Conservation Act of 1987, Public Law 100-12). Domestic-type refrigerators were identified in the baseline data in residential (detached and multifamily) and administration (old and new) building types. An estimate of the total number of refrigerators in these buildings was derived by dividing the total refrigeration consumption for each building type by the estimated individual refrigerator consumption of $1314 \mathrm{kWh}$. The estimated number of refrigerators is 3780 units.

As calculated by the baseline data, the average annual energy use for each refrigerator at Fort Lewis is $1314 \mathrm{kWh}$. It has been estimated that the 1990 DOE Standard :yould lower average annual energy consumption of new 18- $\mathrm{ft}^{3}$ refrigerators to $947 \mathrm{kWh}$, a savings of $367 \mathrm{kWh}$ annually.

Average costs of new $18-\mathrm{ft}^{3}$ refrigerators used for this analys is were $\$ 488.0 \mathrm{C} /$ unit, or $\$ 1.8$ million total for all units. This price was obtained from a local retail store, with a 0.75 multiplier applied to help account for the discount generaliy afforded a volume purchase. For the levelized cost calculation, an appliance lifetime of 15 years was used. The results of the analys is are presented in Table B.5.

\section{B.3.3 Lighting}

Nine lighting efficiency improvements for Fort Lewis were examined using the baseline electricity consumption data. These include 
- Replace incandescent bulbs wit compact fluorescent in $15 \%$ of the indoor residential fixtures, $75 \%$ of the indoor fixtures in other buildings, and $100 \%$ of the exterior fixtures.

- Replace standard magnetic ballasts with energy-efficient magnetic ballasts in two-tube fluorescent fixtures using 34-, 40-, and 75-W tubes.

- Replace standard magnetic ballasts with electronic ballasts in two-tube fluorescent fixtures using 34-, 40-, and 75-W tubes.

- Replace standard magnetic ballasts with tunable electronic ballasts in two-tube fluorescent fixtures using 34-, 40-, and 75-W tubes.

- Add parabolic reflectors to two-tube fluorescent fixtures using 34-, 40-, and 75-W tubes.

- Replace two-tube fluorescent fixtures using 34-, 40-, and 75-W tubes with new fixtures with reflectors and electronic ballasts.

- Replace two-tube fluorescent fixtures using 75-W tubes with 150-W highpressure sodium lamps.

- Replace two-tube fluorescent fixtures using 75-W tubes with single-tube 75-W very-high-output (VHO) fixtures.

- Replace two-tube fluorescent fixtures using 34- and 40-W tubes with F-30 T-8 fixtures.

The assumptions, methodology, and analysis results for each of these improvements is described in the following subsections.

TABLE B.5. Refrigeration Option Analysis: Energy Savings, Lıvelized Energy Cost, and Net Present Value

\begin{tabular}{|c|c|c|c|c|}
\hline Action & $\begin{array}{l}\text { Annual Energy } \\
\text { Savings (kWh) }\end{array}$ & $\begin{array}{l}\text { Levelized Energy } \\
\text { Cost }(\$ / k W h) \\
\end{array}$ & $\begin{array}{c}\text { Net Present } \\
\text { Value }(1991 \text { S) } \\
\end{array}$ & $\begin{array}{c}\text { Initial } \\
\text { Capital } \\
\text { Cost }(1991 \$) \\
\end{array}$ \\
\hline $\begin{array}{l}\text { Replace All } \\
\text { Refrigerators }\end{array}$ & $1,387,167$ & 0.0113 & 80.358 & $1,842,627$ \\
\hline
\end{tabular}




\section{B.3.3.1 Fluorescent-Incandescent Replacement}

Many different types and styles of screw-in fluorescent replacements for existing incandescent are available. For this analysis, the desirability of replacing standard incandescent bulbs with "generic" integral fluorescent units $^{(a)}$ was examined.

To simplify the analysis and because of a lack of more detailed data, a11 incandescent lighting at Fort Lewis was assumed to be $75-W$ bulbs. Using this assumption, an estimate of the total number of incandescent light fixtures for each building sector could be obtained using the baseline data. This was accomplished by multiplying the total number of buildings in that sector (total $\mathrm{kWh} /$ prototype $\mathrm{kWh}$ ) by the baseline estimated incandescent watts per prototype building and then dividing by 75 . Summing these totals across each building sector, the Fort-wide total number of equivalent $75-\mathrm{W}$ incandescent fixtures was estimated to be 135,266 .

The lighting output of a $20-W$ integral fluorescent unit is about equal to that of a 75-W incandescent. This size was, therefore, considered the "equivalent" replacement for the entire Fort. Thus, a complete replacement would decrease what is now incandescent baseline energy usage by over $73 \%$, or approximately 12.4 million $\mathrm{kWh}$ annual savings. Penetration rates assumed are 15\% for residential interior applications, $75 \%$ in nonresidential interior applications, and 100\% for exterior applications. An additional option of replacing fixtures to accommodate compact f?uorescent bulbs to increase the penetration was not considered.

PNL-collected lighting data indicate that $20-W$ integral fluorescent units may be purchased in quantity for about $\$ 14$ each. Whereas the average life of 75-W incandescent bulbs is 750 hours, integral fluorescent units can last from 9 to 13 times as long. Thus, for the levelized energy cost analysis, a 7500-hour lamp-life was used for these units.

The results of the analysis for replacing 53,890 incandescent with fluorescent fixtures are presented in Table B.6.

(a) Integral fluorescent units are a combined 1amp, ballast, and adapter that is discarded when the lamp burns out and must be replaced. 
TABLE B.6. Incandescent Lamp Replacement Analysis: Energy Savings, Levelized Energy Cost, and Net Present Value

\begin{tabular}{|c|c|c|c|c|}
\hline Action & $\begin{array}{l}\text { Annual Energy } \\
\text { Savings (kWh) }\end{array}$ & $\begin{array}{l}\text { Levelized Energy } \\
\text { Cost (\$/kWh) } \\
\end{array}$ & $\begin{array}{c}\text { Net Present } \\
\text { Value }(1991 \quad \$)\end{array}$ & $\begin{array}{c}\text { Initial } \\
\text { Capital } \\
\text { Cost (1991 \$) } \\
\end{array}$ \\
\hline $\begin{array}{l}\text { Rep lace Incandescent } \\
w / F \text { luorescent }\end{array}$ & $6,199,465$ & 0.0203 & 927,856 & 754,454 \\
\hline
\end{tabular}

The financial calculations do not include 0\&M savings that would result from reduced ordering, storing, replacing and disposing requirements associated with incandescent lamps. If these savings were factored into the analysis, the replacement of incandescents with compact fluorescents would become more attractive. An alternative to screw-in compact fluorescents would be to use fixtures with permanently installed ballasts that use plug-in fluorescent lamps to prevent reversion to use of incandescents and thereby increase the probability of energy savings over the long term. It is expected that this alternative would also be comparable financially to the strategy examined because, in addition to the lower 0\&M costs, a ballast replacement would not be necessary every time a lamp failed.

\section{B.3.3.2 Fluorescent Lighting Ballast Replacements}

The second set of lighting conservation options examined (Options 2, 3 , and 4) looked at replacing standard magnetic core ballasts with efficient magnetic ballasts, electronic ballasts, or tunable electronic ballasts.

Cost estimates for the selected ballast options vary considerably. Table B.7 provides the ballast cost, including installation, chosen for this analysis.

TABLE B.7. Estimated Cost for Fluorescent Fixture Ballast Replacement

\begin{tabular}{|c|c|c|c|}
\hline Ba'last Option & 34-Watt & 40-Watt & 75-Watt \\
\hline Efficient Magnetic & $\$ 12.50$ & $\$ 12.50$ & $\$ 17.50$ \\
\hline Electronic & $\$ 32.50$ & $\$ 32.50$ & $\$ 40.00$ \\
\hline Tunable Electronic & $\$ 40.00$ & $\$ 40.00$ & $\$ 47.50$ \\
\hline
\end{tabular}


The number of fixtures involved in each option, as well as the initial capital cost of each, are displayed in Table B.8.

The Fort-wide total number of ballasts was estimated using a process similar to that used for computing the number of incandescent fixtures. First, each building sector's 34-W, 40-W, or 75-W fluorescent lighting total annual energy usage ( $(W h)$ was divided by the total 34-W, 40-W, or 75-W f1uorescent lighting consumption ( $k W h$ ) for the prototype building in that sector to determine the equivalent number of prototype buildings in the sector. This number was then multiplied by the total installed watts of fluorescent lighting for the prototype and divided by the watt rating for a two-lamp fluorescent fixture. Four building sectors (Other, Clubs, 01d Madigan, and Commissary) had no prototypical installed wattages, just total annual use in kilowatt-hours for the whole sector. For these building sectors, daily and yearly operation schedules were used to back out an approximate total kilowatt rating for the sector. This number could then be divided by the watt rating for a two-lamp fluorescent fixture to obtain an estimate of the number of ballasts for that sector.

Although electronic ballasts produce a higher quality light than their core counterparts, the reportedly poor existing quality lighting currently afforded by the fluorescent fixtures in these building sectors suggested that delamping opportunities are limited for this conservation option, as is the potential of dimmable (tunable) electronic ballasts. Thus, the estimated

\section{TABLE B.8. Fluorescent Lighting Ballast Replacement Analysis: Number of Replacement Fixtures and Initial Capital Cost}

\begin{tabular}{|c|c|c|c|c|c|c|}
\hline \multirow[b]{2}{*}{ Ballast Option } & \multicolumn{3}{|c|}{$\begin{array}{l}\text { Number of } \\
\text { cement Fixt }\end{array}$} & \multicolumn{3}{|c|}{ Initial Capital Cost (1991 \$) } \\
\hline & 34-Watt & 40 -Watt & $75-$ Watt & 34-Watt & 40 -Watt & 75-Watt \\
\hline int Magn & 7,252 & 192,397 & 5,606 & 90,644 & $2,404,960$ & 98,111 \\
\hline nic & 7,252 & 192,397 & 5,606 & 235,674 & $6,252,895$ & 224,255 \\
\hline Tunable Electronic & 7,252 & 192,397 & 5,606 & 290,060 & $7,695,871$ & 266,303 \\
\hline
\end{tabular}


energy savings that could be achieved by use of electronic ballasts is based solely on the lower operating power requirements on the ballast and the reduced energy use by the 'cubes.

Tunable electronic ballasts were included for completeness; however, the benefits of reduced energy consumption resulting from dimming (to keep the lighting level constant) were not considered. Thus, because tunable ballasts cost more than their nontunable counterparts, tunable ballasts will have higher levelized energy costs. A more detailed analysis could very likely show that tunable ballasts are the preferred technology in rooms with significant daylighting. The results of the analysis are provided in Table B.9.

\section{B.3.3.3 Fluorescent Lighting Reflectors}

The fifth lighting conservation measure that was analyzed using the Fort Lewis baseline data was to install parabolic reflectors on $34-W, 40-W$, and 75- $W$ fixtures. The population of replacement fixtures is shown in Table B.10. Although the reflectors do not reduce energy consumption, they do cause each fixture to produce more usable light, allowing the total number of fixtures in use to be reduced. This option was analyzed on a lumen-equivalent

TABLE B.9. Fluorescent Lighting Fixture Ballast Options Analysis: Energy Savings, Levelized Energy Cost, and Net Present Value

\begin{tabular}{|c|c|c|c|}
\hline Ballast Option & $\begin{array}{c}\text { Annual } \\
\text { Energy } \\
\text { Savings } \\
\text { (kWh) }\end{array}$ & $\begin{array}{c}\text { Levelized } \\
\text { Energy } \\
\text { Cost } \\
(\mathrm{s} / \mathrm{kWh}) \\
\end{array}$ & $\begin{array}{c}\text { Net Present } \\
\text { Value }(1991 \text { \$) }\end{array}$ \\
\hline $\begin{array}{l}\text { 34-W Eff. Magnetic } \\
40-W \text { Eff. Magnetic } \\
75-W \text { Eff. Magnetic }\end{array}$ & $\begin{array}{r}158,917 \\
3,944,494 \\
209,903\end{array}$ & $\begin{array}{l}0.0383 \\
0.0410 \\
0.0314\end{array}$ & $\begin{array}{r}36,992 \\
894,926 \\
52,103\end{array}$ \\
\hline $\begin{array}{l}34-W \text { Electronic } \\
40-W \text { Electronic } \\
75-W \text { Electronic }\end{array}$ & $\begin{array}{r}536,344 \\
13,312,666 \\
682,183\end{array}$ & $\begin{array}{l}0.0295 \\
0.0316 \\
0.0221\end{array}$ & $\begin{array}{r}135,386 \\
3,299,950 \\
183,524\end{array}$ \\
\hline $\begin{array}{l}34-W \text { Tunable } \\
40-W \text { Tunable } \\
75-W \text { Tunable }\end{array}$ & $\begin{array}{r}536,344 \\
13,312,666 \\
682,183\end{array}$ & $\begin{array}{l}0.0364 \\
0.0389 \\
0.0262\end{array}$ & $\begin{array}{r}127,228 \\
3,083,504 \\
177,217\end{array}$ \\
\hline
\end{tabular}


TABLE B.10. Number of Fixtures with Reflector Addition

Existing Fixture

\begin{tabular}{cc} 
Type & Reflectors Added \\
\hline $40-W$ & 121,123 \\
$34-W$ & 4,554 \\
$75-W$ & 3,515
\end{tabular}

basis. In the analysis, it is implicitly assumed that delamping and removal of fixtures can be accomplished on a perfectly continuous basis, to allow the final level of light to be equal to the current level. In practice this would be more difficult, as there would be locations where delamping/removal would not be feasible. An informal survey of suppliers gave a cost of $\$ 57.50$ per reflector, including installation. The results of the analysis are shown in Table B.11.

\section{B.3.3.4 Fluorescent Lighting Fixture Upgrade}

The sixth lighting conservation measure involves combining ballast replacement with parabolic reflector installation through complete replacement of the fixtures. The population of fixtures involved is the same as shown in Table B.10. The costs associated with this option are displayed in Table B.12. The results of the analysis are provided in Table B.13.

\section{B.3.3.5 ather Lighting Technologies}

Three more lighting technologies were considered in addition to the ballast replacements and reflector installations. One option was to replace fluorescent fixtures containing two 75-W lamps with 150-W high-pressure sodium (HPS) fixtures. Another option was to replace fluorescent fixtures containing

TABLE B.11. Fluorescent Lighting Fixture Reflector Analysis: Annual Energy Savings, Levelized Energy Cost, and Net Present Value

\begin{tabular}{|c|c|c|c|c|}
\hline Action & $\begin{array}{l}\text { Annual Energy } \\
\text { Savings (kWh) }\end{array}$ & $\begin{array}{l}\text { Levelized Energy } \\
\text { Cost }(\$ / \mathrm{kWh}) \\
\end{array}$ & $\begin{array}{c}\text { Net Present } \\
\text { Value }(1991 \text { \$) }\end{array}$ & $\begin{array}{c}\text { Initial } \\
\text { Capital } \\
\text { Cost (1991 S) } \\
\end{array}$ \\
\hline $\begin{array}{l}\text { Add } 34-W \text { Ref lector } \\
\text { Add } 49-W \text { Ref lector } \\
\text { Add } 75-W \text { Ref lector }\end{array}$ & $\begin{array}{r}620,648 \\
17.535,667 \\
890,526\end{array}$ & $\begin{array}{l}0.0270 \\
0.0257 \\
0.0131\end{array}$ & $\begin{array}{r}168.978 \\
4.740 .160 \\
276.817\end{array}$ & $\begin{array}{r}261,872 \\
6,964,545 \\
202,132\end{array}$ \\
\hline
\end{tabular}


TABLE B.12. Fluorescent Lighting Fixture Costs

\begin{tabular}{crccc} 
& \multicolumn{3}{c}{ Cost (1991 \$) } \\
\cline { 5 - 5 } Replacement Fixture & & Replacement & Existing & Different \\
\cline { 5 - 6 } Two-tube 34-W & & 90.00 & 35.00 & 55.00 \\
Two-tube 40-W & & 90.00 & 35.00 & 55.00 \\
Two-tube 75-W & 105.0 n & 42.50 & 62.50
\end{tabular}

TABLE B.13. Fluorescent Lighting Fixture Replacement Option: Energy Savings, Levelized Energy Cost, and Net Present Value

\begin{tabular}{|c|c|c|c|c|}
\hline Action & $\begin{array}{l}\text { Annual Energy } \\
\text { Savings (kWh) }\end{array}$ & $\begin{array}{l}\text { Levelized Energy } \\
\text { Cost }(\$ / k L h) \\
\end{array}$ & $\begin{array}{c}\text { Net Present } \\
\text { Value }(1991 \text { \$) }\end{array}$ & $\begin{array}{c}\text { Initial } \\
\text { Capital } \\
\text { Cost (1991 \$) }\end{array}$ \\
\hline $\begin{array}{l}\text { 34-W Fixture Replace } \\
\text { 46-W Fixture Replace } \\
75-W \text { Fixture Replace }\end{array}$ & $\begin{array}{r}957,409 \\
25,915,995 \\
1,318,273\end{array}$ & $\begin{array}{l}0.6167 \\
0.0166 \\
0.0698\end{array}$ & $\begin{array}{r}277.917 \\
7,454.913 \\
410,348\end{array}$ & $\begin{array}{r}250,486 \\
6,661,738 \\
219,769\end{array}$ \\
\hline
\end{tabular}

34-W and 40-W lamps with F-30 T-8 fixtures. The final option was to replace fluorescent fixtures containing two 75-W lamps with single-lamp, 8-ft, veryhigh-output (VHO) fixtures. The population of fixtures involved is shown in Table B.14. This last option actually resulted in increased energy consumption. For this reason, the reported levelized cost is negative; this indicates that a positive payment must be made to obtain a negative savings. Needless to say, this option does not compare well with the others. The costs of replacement with other lighting technologies are shown in Table B.15. The results of the analysis are provided in Table B.16.

The calculated financial values of replacing the 8 - $\mathrm{ft}$ fluorescent fixtures with HPS lamps are felt to be high, because lower expected 0\&M costs are not included. The lower 0\&M costs would result from reduced labor requirements to change bulbs, because the HPS bulbs have a longer life.

IABLE B.14. Number of Replacement Fixtures

\begin{tabular}{cc} 
Replacement Fixture Type & Replacement Fixtures \\
\hline 150-W HPS & 4,065 \\
$34-$ W F-30 T-8 & 4,244 \\
$40-$ W F-30 T-8 & 121,123 \\
VHO & 5,419
\end{tabular}


TABLE B.15. Other Lighting Technology Replacement Options and Cost

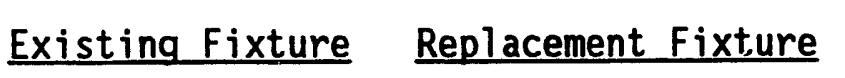

$\frac{\text { Cost (1991 \$) }}{\text { Replacement Existing Differential }}$

Two-tube 75-W

Two-tube 34-W

Two-tube 40-W

Two-tube 75-W

$150-W$ HPS
$34-W$ F -30 F-8
$40-W$ F-30 T-8
VHO

142.00

115.00

42.50

99.50

115.00

35.00

80.00

120.00

35.00

80.00

42.50

77.50

TABLE B.16. Other Lighting Technology Options: Energy Savings, Levelized Energy Cost, and Net Present Value

\begin{tabular}{|c|c|c|c|c|c|}
\hline Action & & $\begin{array}{l}\text { Annual Energy } \\
\text { Savings (kWh) }\end{array}$ & $\begin{array}{l}\text { Levelized Energy } \\
\text { Cost }(\$ / \mathrm{kWh}) \\
\end{array}$ & $\begin{array}{c}\text { Net Present } \\
\text { Value }(1991 \text { \$) }\end{array}$ & $\begin{array}{c}\text { Initial } \\
\text { Capita } 1 \\
\text { Cost }(1991 \text { S) } \\
\end{array}$ \\
\hline $\begin{array}{l}15 \theta-W \text { HPS } \\
34-W F-3 \theta \\
4 \theta-W F-30 \\
\text { VHO }\end{array}$ & $\begin{array}{l}T-8 \\
T-8\end{array}$ & $\begin{array}{r}770,736 \\
959,482 \\
28,399,233 \\
-529,129\end{array}$ & $\begin{array}{r}0.0527 \\
0.0245 \\
0.0245 \\
-0.0542\end{array}$ & $\begin{array}{r}288,862 \\
246,431 \\
7,059,222 \\
-240,089\end{array}$ & $\begin{array}{r}404,430 \\
339,502 \\
9,689,801 \\
420,011\end{array}$ \\
\hline
\end{tabular}

\section{B.4 REFERENCES}

National Appliance Energy Conservation Act of 1987. Public Law 100-12.

Northwest Power Planning Council. 1986. 1986 Northwest Conservation and Electric Power Plan. Fortland, Oregon. 


\section{APPENDIX C}

MOTOR BASELINE AND EFFICIENCY ASSESSMENT 
APPENDIX C

\section{MOTOR BASELINE AND EFFICIENCY ASSESSMENT}

The baseline electricity use and the efficiency improvement potential for motors used in the water supply and sewage treatment plants are described in this appendix. Section C.1 provides the assumptions used to estimate baseline energy use for water pump motors in the water supply system, along with results. Section C.2 presents the efficiency potential and levelized cost of replacing existing water pump motors in the supply system with high-efficiency models of similar horsepower. Sections $C .3$ and $C .4$ are similar to Sections C.1 and C.2, respectively, but are for the effluent pump motors used in the water treatment plant.

\section{C.1 WATER SUPPLY BASELINE ENERGY USE}

No metered electrical data were available for the water pump motors used in the water supply system at Fort Lewis. However, the following data were available from the Fort:

- average hours of operation per day for each well for each month of the year spanning October 1989 through September 1990

- total monthly pumping capacity in gallons of water for each well

- actual gallons per minute flow capacity for each of the one or more pump motors used at each we11

- motor horsepower (except for the irrigation pump motors used at Well 15, which were estimated based on flow capacities relative to others).

To estimate baseline electricity use for the water pump motors from the 7 imited data, it was necessary to make several assumptions. First, because cycling schedules of water pump motors were unknown--as were the number of days per month that they were operated--all motors associated with a given we $11 /$ pumping station were assumed to be in operation simultaneously at $75 \%$ of design load for the calculation of total monthly operating hours. Motor efficiencies used for the energy calculations were based on data for

C. 1 
Siemens-A1lis standard efficiency totally enciosed, fan-cooled (TEFC) motors operating at $75 \%$ of rated horsepower (see Table C.1, Column 1).

From the above assumptions and data, total baseline electricity use for all of the water pump motors was estimated to be about 3.6 million $\mathrm{kWh}$ annually. Baseline energy use for each well/pumping station in the water supply system at Fort Lewis is summarized in Table C.2.

\section{C.2 WATER SUPPLY EFFICIENCY POTENTIAL AND COST}

The energy conservation strategy chosen for the analysis of the water supply system was replacement of all existing (assumed) standard efficiency water pump motors with high-efficiency models and replacement of all pump motors upon failure. The upon-failure analysis makes no attempt to predict when the pump motors will fail: rather, it is assumed that they all fail at the start of the analysis. The only difference between the strategies, therefore, is that in the replacement option, the entire cost of a new efficient pump motor is used, while in the replace-upon-failure option the difference in cost between an efficient pump motor and a standard one is used. High-efficiency motor data were again obtained from Siemens-A1lis. The installation/replacement cost estimate was based on data from the 1990 version of Richardson's Process Plant Construction Estimating Standards - Volume 4.

Unit pricing in tiris reference is for Reliance Motors. Other costs considered when preparing this estimate include the following:

- Handling and Placing Labor - Richardson presents handling and placing man-hour estimates as a function of motor horsepower.

- Installation Materials and Labor - This category includes the materials and labor associated with foundations, structural steel, buildings, piping, instrumentation, insulation, electrical, and painting. For replacement electric motors, any foundations, structural steel, or buildings (enclosures) are presumed to already exist. Some replacement wiring and/or instrumentation may be required, however. Average values in the American Association of Cost Engineers (AACE) Recommended Practice are as follows: 


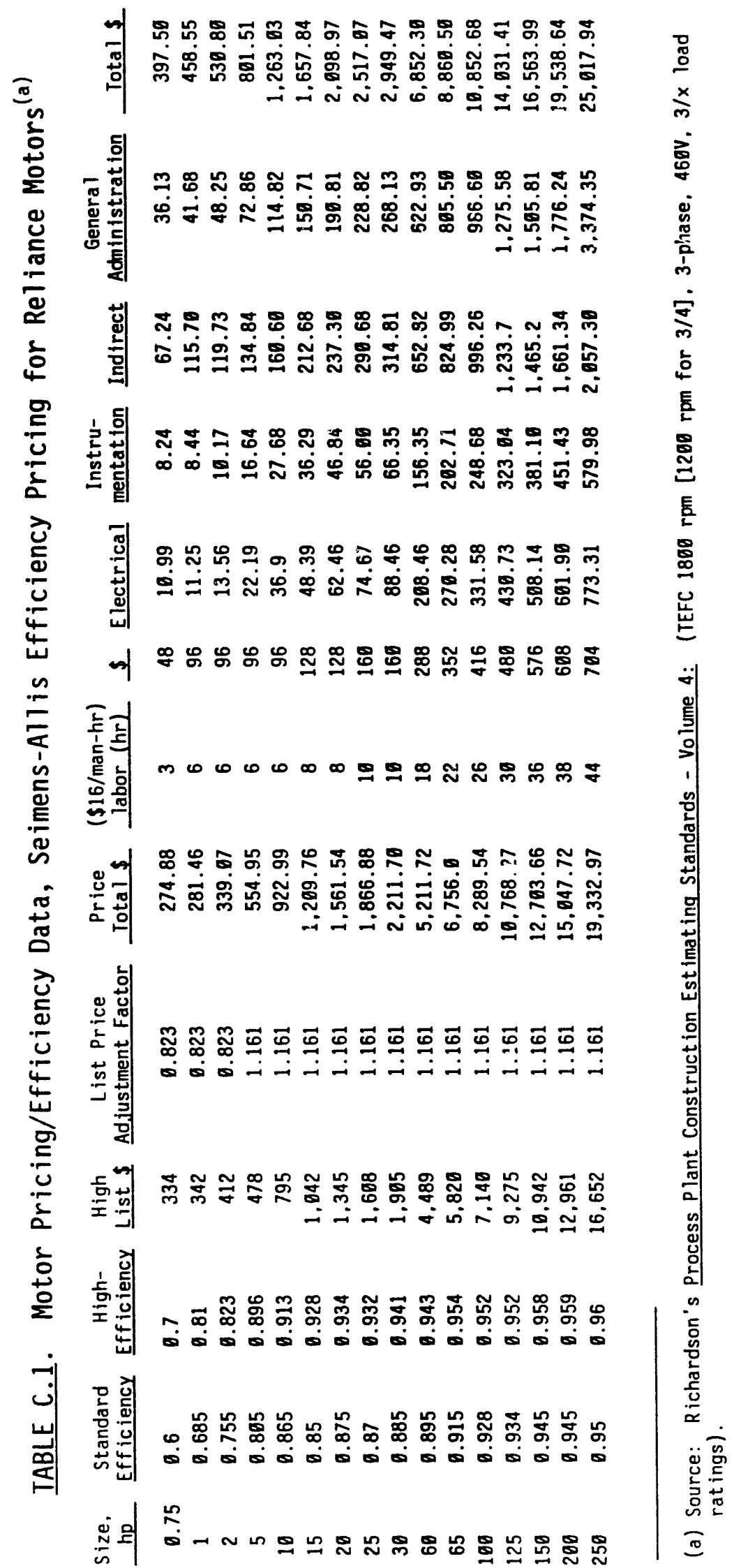

C. 3 
TABLE C.2. Summary of Water Supply Basel ine Energy Use and Conservation Potential

Wel1/Pumping Station
Sequal Spring (30250hp)
We11 \#9 (1025, 105hp)
We11 \#10 (102hp)
We11 \#12 (20150hp)
We11 \#13 (10100hp)
We11 \#14 (10125hp)
We11 \#15 (2060hp?)
We11 \#17 (10150hp)
We11 \#18 (1060hp)
We11 \#19 (1030,1060hp)

- Electrical Material

- Electrical Material Labor

- Instrumentation Material

- Instrumentation Material Labor

\begin{tabular}{|c|c|}
\hline $\begin{array}{l}\text { Annual kWh } \\
\text { Baseline }\end{array}$ & $\begin{array}{l}\text { Annual kWh } \\
\text { Savings }\end{array}$ \\
\hline $\begin{array}{r}2,174,463 \\
7,361 \\
383 \\
552,549 \\
113,798 \\
186,618 \\
136,645 \\
64,732 \\
271,314 \\
10 \varepsilon, 652\end{array}$ & $\begin{array}{r}24,573 \\
494 \\
32 \\
7,498 \\
2,869 \\
3,528 \\
6,955 \\
878 \\
13,810 \\
5,522\end{array}$ \\
\hline
\end{tabular}

$8 \%$ of purchased equipment cost $4 \%$ of purchased equipment cost $6 \%$ of purchased equipment cost $3 \%$ of purchased equipment cost

- Much of the wiring and instrumentation already in place may not need to be replaced. On the other hand, there is probably more wiring associated with electric motors than with process equipment in general. The above factors should, therefore, result in a conservative estimate.

- Indirect Field Costs - This cost category includes charges for indirect labor (e.g., supervision, engineering), craft labor fringe benefits, and miscelianeous construction supplies, tools, and equipment. Per AACE Recommended Practice, this was roughly estimated as $100 \%$ of the sum of handling, placing, and material installation labor (direct labor).

- General and Administrative (Overheads) - Based on AACE recommendations, $10 \%$ of the sum of al1 direct and indirect costs (the sum of all cost categories noted above) was included.

- Project Contingency - In general, project contingency covers the cost of additional equipment requirements that are typically identified when more detailed designs are prepared. Because the estimate assumed replacement of al1 motors in the water supply system and Richardson's guidelines are based on only a single motor, the uncertainty in equipment specification and installation material requirements that would normally call for a contingency was assumed to be offset. Thus, a contingency was not included.

The results of the analysis are displayed in Table C.3. 
TABLE C.3. Water Supply Analysis Results

\begin{tabular}{|c|c|c|c|}
\hline Action & $\begin{array}{c}\text { Annual } \\
\text { Energy } \\
\text { Savings } \\
\text { (kWh) }\end{array}$ & $\begin{array}{c}\text { Levelized } \\
\text { Energy } \\
\text { Cost } \\
\text { (\$/kiwh) }\end{array}$ & $\begin{array}{l}\text { Net Present } \\
\text { Value } \\
(1991 \$)\end{array}$ \\
\hline \multicolumn{4}{|l|}{$\begin{array}{l}\text { Complete } \\
\text { Rep Tacement }\end{array}$} \\
\hline $\begin{array}{l}\text { Sequal Spring } \\
\text { We11 \#9 } \\
\text { We11 } \# 10 \\
\text { We11 } \# 12 \\
\text { We11 } \# 13 \\
\text { We11 } \# 14 \\
\text { We11 } \# 15 \\
\text { We11 } \# 17 \\
\text { We11 } \# 18 \\
\text { We11 } \# 19\end{array}$ & $\begin{array}{r}24,573 \\
494 \\
32 \\
7,498 \\
2,869 \\
3,528 \\
6,955 \\
878 \\
13,810 \\
5,522\end{array}$ & $\begin{array}{l}0.2587 \\
0.4516 \\
1.1263 \\
0.2970 \\
0.2543 \\
0.2673 \\
0.1324 \\
1.2675 \\
0.0334 \\
0.1193\end{array}$ & $\begin{array}{r}-6,366 \\
-341 \\
-70 \\
-2,582 \\
-715 \\
-981 \\
158 \\
-2,205 \\
3,368 \\
288\end{array}$ \\
\hline \multicolumn{4}{|l|}{$\begin{array}{l}\text { Replace on } \\
\text { Failure }\end{array}$} \\
\hline $\begin{array}{l}\text { Sequal Spring } \\
\text { We11 \#9 } \\
\text { We11 \#10 } \\
\text { We11 \#12 } \\
\text { We11 \#13 } \\
\text { We11 \#14 } \\
\text { We11 \#15 } \\
\text { We11 \#17 } \\
\text { We11 \#18 } \\
\text { We11 \#19 }\end{array}$ & $\begin{array}{r}24,573 \\
494 \\
32 \\
7,498 \\
2,869 \\
3,528 \\
6,955 \\
878 \\
13,810 \\
5,522\end{array}$ & $\begin{array}{l}0.0562 \\
0.0165 \\
0.0363 \\
0.0613 \\
0.0567 \\
0.0612 \\
0.0263 \\
0.2614 \\
0.0066 \\
0.0251\end{array}$ & $\begin{array}{r}4,739 \\
29 \\
8 \\
1,362 \\
550 \\
641 \\
1,806 \\
-233 \\
4,192 \\
1,448\end{array}$ \\
\hline
\end{tabular}

\section{3 WATER TREATMENT BASELINE ENERGY USE}

The available data for the three water treatment effluent pumps (two at $125 \mathrm{hp}$, one at $75 \mathrm{hp}$ ) were both more and less complete than that available for the water supply' pump motors. Operation schedules and water capizities were unavailable. However, a set of metered electrical demand data (in kilowatts) for the time period between Juiy 5 and July 13, 1990, was taken by PNL for FORSCOM. From these data it was inferred that 24-hour-a-day operation of one of the 125-hp pumps and the 75-hp pump occurred, at about $80 \%$ of full-rated 
horsepower. Because no additional data were available for the effluent pumps, these data was extrapolated for 365 days/year to get a yearly total baseline energy consumption of 1.16 million $\mathrm{kWh}$.

Ho other breakdowns on baseline energy use were available for the water treatment plant, though it is known that a large number of small motors (3/4, 1,5 , and $10 \mathrm{hp}$ ) are also used in the facilities for various purposes.

\section{C.4 WATER TREATMENT EFFICIENCY POTENTIAL AND COST}

The assumptions to calculate capital and installation costs of the standard efficiency effluent pump motors with high-efficiency motors are essentially the same as those presented in Section C.3 for the water supply well pumps and thus are not repeated here.

The results of the analysis are shown in Table C.4.

TABLE C.4. Water Treatment Analysis Results

\begin{tabular}{|c|c|c|c|}
\hline Action & $\begin{array}{c}\text { Annual } \\
\text { Energy } \\
\text { Savings } \\
\text { (kWh) }\end{array}$ & $\begin{array}{c}\text { Levelized } \\
\text { Energy } \\
\text { Cost } \\
\text { (\$/kWh) } \\
\end{array}$ & $\begin{array}{c}\text { Net Present } \\
\text { Value } \\
(1991 \text { \$) } \\
\end{array}$ \\
\hline $\begin{array}{l}\text { Complete } \\
\text { Replacement }\end{array}$ & 30,747 & 0.0807 & 4,249 \\
\hline $\begin{array}{l}\text { Replace on } \\
\text { Failure }\end{array}$ & 30,747 & 0.0181 & 8,544 \\
\hline
\end{tabular}

\section{5 REFERENCE}

Richardson Engineering Services, Inc. 1990. Process Plant Construction Estimating Standards - Volume 4. Mesa, Arizona. 


\section{APPENDIX D}

TRANSFORMER LOSS AND VOLTAGE REGULATION EFFICIENCY ASSESSMENT 
APPENDIX D

\section{TRANSFORMER LOSS AND VOLTAGE REGULATION EFFICIENCY ASSESSMENT}

The conservation potential (loss reduction) achievable by replacing the Fort Lewis transformer stock with more efficient units and regulating the voltage for the electricity distribution system was assessed. Section D.1 describes the estimation of the magnitude of the conservation resource (annual kilowatt-hour savings) and the levelized energy cost $(\$ / \mathrm{kWh})$ that would result from improving transformer efficiencies. Section D.2 describes the potential that may exist through improved regulation of the distribution system voltage.

\section{D.1 TRANSFORMER EFFICIENCY IMPROVEMENT}

The overall approach involved assessing the losses of the existing Fort Lewis transformer stock and a hypothetical replacement stock of more efficient transformers. The difference in the aggregate losses of these two transformer stocks represents the loss reduction potential provided by the replacement units. The value of the resource was then developed by associating a levelized annual cost of replacing transformers with the annual loss reduction that would result.

\section{D.1.1 Approach}

An irventory list supplied by Fort Lewis was used to sort the existing transformer stock by number of units at each rated capacity (in kilovoltamperes [kVA]). This classification accounted for 2051 transformers from the current stock of 2080 units on the inventory 1 ist. The balance of 29 units was shown with a $0-k V A$ rating and could not be evaluated without more information.

Because no firm data were available on transformer losses in the Fort Lewis inventory, estimates were made using values found in the literature for typical transformer no-load (also called core or iron) losses and load (or copper) losses (Goenen 1986; Tepel, Callaway, and DeSteese 1987). Using a spreadsheet format, these estimated losses were associated with the existing

D.1 
transformer stock at each rated capacity. Units were assigned to the nearest capacity rating for which loss data were available. For example, as no specific loss information was found for 20-kVA or 28-kVA transformers, units of these sizes were grouped with and assigned the estimated losses of 25-kVA units. No data were found for typical losses of units between 750 kVA and $7500 \mathrm{kVA}$. As a result, losses for Fort Lewis transformers in the 1000-, 1500-, and 2500-kVA classes were extrapolated from data for smaller units.

A particularly valuable set of loss and cost data was obtained from Bonneville for transformers ranging in capacity from 25 kVA to 100 kVA. These data, traceable to experience of the General Electric Company, included loss and cost information for high-loss, medium-loss, and amorphous-core transformers. Consequently, estimated loss reduction potential and costs for transformers in this capacity range are considered to be the most reliable.

Corresponding load and no-load losses taken from the above sources were entered into the spreadsheet for replacement transformers at each capacity leve1. Loss data for amorphous-core units were used for transformers in the 25- to 100-kVA capacity range. Replacements at other rated capacities were assumed to have the loss characteristics of the higher-efficiency replacement transformers considered by Tepel, Callaway, and DeSteese (1987).

The loss reduction potential has two components: 1) the difference between the no-load losses of the existing and replacement stocks and 2) the corresponding difference in load losses. As transformer load losses are generally reported at rated capacity, the loss reduction represented by the difference in load losses was reduced, in each case, by a loss factor of 0.62 to account for losses under actual operating conditions. The loss factor (LF) was derived from the expression given by Goenen (1986):

$$
L F=0.3 L D+0.7 L D^{2}
$$

where LD is the load factor. In the absence of information on Fort Lewis load factors, a load factor of 0.75 was assumed for all transformers. Actual load

D.2 
factors may vary from unit to unit. Transformers with substantially lower load factors will have lower total losses, which would tend to increase the levelized energy cost of any loss reduction achieved.

The annual loss reduction (ALR) was calculated from the expression

$$
A L R=N(N L L+0.62 L L) \times 8.76(k W h)
$$

where $N$ is number of units in each transformer class

NLL is no-load reduction in watts/unit

$L L$ is the load loss reduction in watts/unit.

Replacement capital costs were obtained from Bonneville for transformers in the 25- to 100-kVA capacity range ard from other sources for all other capacities (Tepe1, Callaway, and DeSteese 1987; Westinghouse Electric Corporation 1986, 1987). The costs for transformers in the 10ru- to 2500-kVA range were extrapolated and are, therefore, the most tentativ's. Representative transformer installation costs were provided by a utility engineer.

The total investment for replacing transformers in each capacity grouping was estimated by multiplying the sum of the unit capital and installation cost by the number of units in each group.

\section{D.1.2 Loss Reduction Potential}

The levelized energy cost (LEC) of replacement transformers was calculated as described in Section 2.0. The life of replacement transformers was taken as 30 years for all units. No salvage value of the repiaced stock was considered in the assessment, and all capital investments were assumed to occur in the first year. Operation and maintenance costs for the new transformer stock were considered to be the same as those of the replaced stock and, therefore, can be neglected in the estimation of annual levelized cost.

Summary results of the transformer loss reduction analysis are shown in Table D.1. The results include considerable uncertainty because of the lack of information on the loss characteristics of the existing transformer stock and the cost of replacement units. However, an important indication of this analysis is that an annual loss reduction of about 2.2 million kWh may be

\section{3}


realized at Fort Lewis by replacing existing transformers in the 37.5- to 50-kVA range with amorphous-core units at a cost of less than $\$ 0.023 / \mathbf{k W h}$. An additional annual savings of about 1.6 million $\mathrm{kWh}$ (for a total of $3.8 \mathrm{mil}$ lion kWh) may be realized by replacing existing transformers in the 25- to 100-kVA range with amorphous-core units at a cost of less than $\$ 0.045 / \mathrm{kWh}$. Increasing the allowable LEC to $\$ 0.075 / \mathrm{kWh}$ makes 200-kVA high-efficiency transformers economically viable and increases the annual savings by 0.37 million $k W h$.

The results in Table D.1 show the expected trend: that it is uneconomic, as a conservation measure alone, to replace units at the low and high ends of the capacity range. Although most units below 25 kVA may have fairly high iosses per unit, the unit cost of replacement is essentially the same as that of a 25-kVA unit. The smaller aggregate loss reduction potential of these units divided into a disproportionately higher cost results in a higher LEC than that of 25-kVA units. At the upper end of the capacity range (200- to 750-kVA), unit costs increase steeply while the efficiency improvement potential of the replacement stock decreases with size. This tendency results in higher LECS for this group also.

TABLE D.1. Transformer Loss Reduction and Cost

\begin{tabular}{|c|c|c|c|c|}
\hline $\begin{array}{l}\text { Number } \\
\text { of Units }\end{array}$ & $\begin{array}{l}\text { Capacity } \\
\text { (kVA) }\end{array}$ & $\begin{array}{l}\text { Energy } \\
\text { Savings } \\
\text { (kWh) } \\
\end{array}$ & $\begin{array}{c}\text { Energy } \\
\text { Cost } \\
(\$ / \mathrm{kWh}) \\
\end{array}$ & $\begin{array}{c}\text { Net Present } \\
\text { Value } \\
(1991 \text { \$ }) \\
\end{array}$ \\
\hline $\begin{array}{r}21 \\
332 \\
350 \\
247 \\
470 \\
339 \\
43 \\
97 \\
50 \\
47 \\
30 \\
9 \\
14 \\
2\end{array}$ & $\begin{array}{c}5 \\
15 \\
25 \\
37.5 \\
50 \\
75 \\
100 \\
200 \\
300 \\
500 \\
750 \\
1000 \\
1500 \\
2500\end{array}$ & $\begin{array}{r}6,398 \\
205,211 \\
606,455 \\
699,314 \\
1,500,308 \\
865,947 \\
120,387 \\
374,132 \\
206,202 \\
208,314 \\
176,512 \\
196,785 \\
522,937 \\
123,621\end{array}$ & $\begin{array}{l}0.1564 \\
0.0771 \\
0.0275 \\
0.0228 \\
0.0210 \\
0.0335 \\
0.0373 \\
0.0605 \\
0.0800 \\
0.1180 \\
0.1333 \\
0.1410 \\
0.1419 \\
0.1582\end{array}$ & $\begin{array}{r}-338 \\
37,004 \\
197,780 \\
237,665 \\
517,748 \\
267,148 \\
35,792 \\
85,771 \\
35,395 \\
12,517 \\
2,672 \\
-405 \\
-953 \\
-876\end{array}$ \\
\hline
\end{tabular}


The LEC estimates for transformers larger than 1000 kVA are the least believable because of the need for extensive extrapolation to estimate losses and replacement costs. For a more accurate assessment, the economic replacement potential of these units should be considered separately on a case-bycase basis. However, in light of the general trend discussed above, it is unlikely that replacement of these units would prove to be cost-effective.

\section{D.2 CONSERVATION VOLTAGE REGULATION}

Conservation voltage regulation (CVR) is, in principle, the regulation of distribution feeder voltages so that the line loss is reduced and thus, the load farthest from the substation is maintained at the minimum acceptable voltage under all load conditions on the circuit. This practice can have the effect of reducing the average feeder voltage by several percent without any significant reduction in end-use load or appliance performance. Already required in several states, CVR is a cost-effective conservation and load management option applicable to many of the circuits in a typical utility distribution system. Energy conservation results because the energy consumption of many loads and appliances is reduced in some proportion to the reduction in voltage. Many CVR evaluations by U.S. utilities show, on average, that end-use energy consumption is reduced by approximately $0.7 \%$ for each $1 \%$ reduction in voltage. Similar reductions in peak loads have been demonstrated using CVR as a load management measure.

A study performed by PNL for Bonneville on the CVR potential of Pacific Northwest utilities showed cost-effective conservation between 170 average MW and 270 average MW at costs up to $\$ 0.05 / \mathrm{kWh}$, for the region as a whole (DeSteese et a1. 1987). The best opportunities for CVR were shown to exist in densely-populated urban areas where distribution feeders are less than 3 to 12 miles long. The Fort Lewis distribution system appears similar in layout to systems that showed the best CVR potential in the PNL study. Therefore, Fort Lewis is expected to be an ideal candidate for some level of CVR application.

The general indication of the PNL study for Bonneville showed that short, densely loaded feeders can be regulated to reduce average feeder 
voltages up to $5 \%$. This translates into an end-use energy savings potential between $1 \%$ arid $3.5 \%$. On systems with automatic regulation already in place, the implementation of CVR is generally a matter of relatively simple adjustments to existing equipment. In such cases, CVR can be implemented for a few hundred to a few thousand dollars per circuit. The PNL study showed that CVR achieved by simple system adjustment usually resulted in energy conservation costs less than $\$ 0.01 / \mathrm{kWh}$. In other cases, the study showed cost-effective CVR could be aciieved with higher-cost measures such as capacitor and regulator additions.

In this analysis, CVR applied to the Fort Lewis system is projected to provide a $1 \%$ reduction in total energy use at a cost of $\$ 0.01 / \mathrm{kWh}$. However, the value and practicality of CVR is highly system-specific; further study of the Fort Lewis distribution system would be necessary to evaluate its CVR potential in detail.

\section{D.3 REFERENCES}

DeSteese, J. G., S. B. Merrick, R. C. Tepel, and J. W. Callaway. 1987. Assessment of Conservation Voltage Reduction Applicable in the Bonnevilile Power Administration Service Area. D0E/BP 14031-1, Prepared by Pacific Northwest Laboratory for the Bonneville Power Administration, Portland, Oregon.

Goenen, T. 1986. Electric Power Distribution System Engineering. McGrawHill Book Company. New York.

Northwest Power Planning Council. 1986. 1986 Northwest Conservation and Electric Power Plan. Portland, Oregon.

Tepel, R. C., J. W. Callaway, and J. G. DeSteese. 1987. Customer System Efficiency Improvement Assessment: Supply Curves for Transmiss : on and Distribution Conservation Options. PNL-6076, Pacific Northwest Laboratory. Richland, Washington.

Westinghouse Electric Corporation. 1986. "Unit Substation Transformers." Price List 47-400. WEC Smal1 Power Transformer Division, South Boston, Virginia.

Westinghouse Electric Corporation. 1987. "Substation Transformers." Price List 43-300. WEC Small Power Transformers Division, South Boston, Virginia. 
APPENDIX E

EXTERIOR LIGHTING SECTOR BASELINE AND EFFICIENCY ASSESSMENT 


\section{APPENDIX E}

\section{EXTERIOR LIGHTING SECTOR BASELINE AND EFFICIENCY ASSESSMENT}

\section{E.1 ASSUMPTIONS}

The assumptions used to develop the baseline amount of exterior lighting energy are described in the following subsections.

\section{E.1.1 Residential Sector}

Each residential unit is served by two $60-W$ incandescent bulbs, of which $70 \%$ are operated 12 hours/day, 365 days/year. This provides for about $368 \mathrm{kWh}$ per residential living unit per year. When multiplied by 3505 living units, the total estimated annual consumption is 1290 MWh.

No HID lighting is assumed in this sector.

\section{E.1.2 All Other Building}

Building exterior and parking lot lighting is assumed equal to $2 \%$ of nonresidential building electricity usage of 122,666 MWh, providing an estimated annual consumption of 2453 MWh. This is shared between HID and incandescent by $80 \%$ and $20 \%$, respectively.

\section{E.1.3 Street Lighting}

Street lighting is assumed to be equal to $2 \%$ of total energy consumption of 200,000 MWh and to be $100 \%$ HID.

\section{E.2 ESTIMATED EXTERIOR LIGHTING BASELINE}

The exterior lighting baseline estimates are shown in Table E.l.

TABLE E.1. Estimated Exterior Lighting Baseline

\begin{tabular}{|c|c|c|}
\hline Sector & Incandescent & HID \\
\hline $\begin{array}{l}\text { Residential } \\
\text { Other Building Exterior } \\
\text { Street } \\
\text { Total }\end{array}$ & $\begin{array}{r}1,290 \\
491 \\
-- \\
1,781\end{array}$ & $\begin{array}{l}1,962 \\
4,000 \\
5,962\end{array}$ \\
\hline
\end{tabular}




\section{E.4 EFFICIENCY ASSESSMENT}

The only measure considered for this sector was the replacement of $100 \%$ of the existing incandescent lighting that is less than $200 \mathrm{~W}$ in residential applications with compact fluorescents. This assessment is contained in Appendix $B$, in the discussion on installing compact fluorescent lamps in place of incandescent bulbs.

Items that were not considered in the exterior lighting sector that may add to the efficiency resource potential are

- installation of new and replacement of faulty, photocells to reduce or eliminate exterior lighting during daylight hours

- replacement of existing low-efficiency HID with lighting with highefficiency units

- replacement of incandescent lighting that is greater than $200 \mathrm{~W}$ with HID or other suitable high-efficiency al ternative. 


\section{DISTRIBUTION}

No. of

Copies

OFFSITE

12 DOE/Office of Scientific and Technical Communication

5 A. Gillespie

FORSCOM

Attn: FCEN-RDF

Fort McPherson, GA 30330-6000

5 L. Harris, CE-44

U.S. Department of Energy Federal Energy Management Administration 1000 Independence Avenue Washington, DC 20585

5 D. Moore

Tacoma Piblic Utilities

P.0. Box 11007

Tacoma, WA 98411

5 N. G. Flood

I Corps \& Fort Lewis

Attn: AFZH-DEU

Fort Lewis, WA 98433-5000

5 R. W. Jamieson

Bonneville Power

Administration

MS: RCMB

P.0. Box 3621

Portland, OR 97208

2 G. W. Schanche

U.S. Army Corps of Engineers

Construction Engineering

Research Laboratory

P.0. Box 4005

Champaign, IL 61820-1305
No. of

Copies

\section{OFFSITE}

2 H. Goradia

Enyineering \& Housing Support Center CEHSC-FUM, Kingman Blvd.

Ft. Belvoir, VA 22060-5516

2 A. Fanning

Army COE - Huntsville Division Attn: ZEHND-ED-ME

P.0. Box 1600

Huntsville, AL 35807-4301

J. Richmond

Energy Management Coordinator

Alameda Bureau of Electricity 2000 Grand Street

Alameda, CA 94501

\section{ONSITE}

DOE Field Office, Richland

D. R. Segna

110 Pacific Northwest Laboratory

J. W. Currie

J. G. DeSteese

J. A. Dirks

T. J. Marseille

B. L. Mohler

G. B. Parker (75)

R. W. Reilly

E. E. Richman

T. J. Secrest (20)

S. A. Shankle

J. L. Stoops

Publishing Coordination

Technical Report Files (5) 

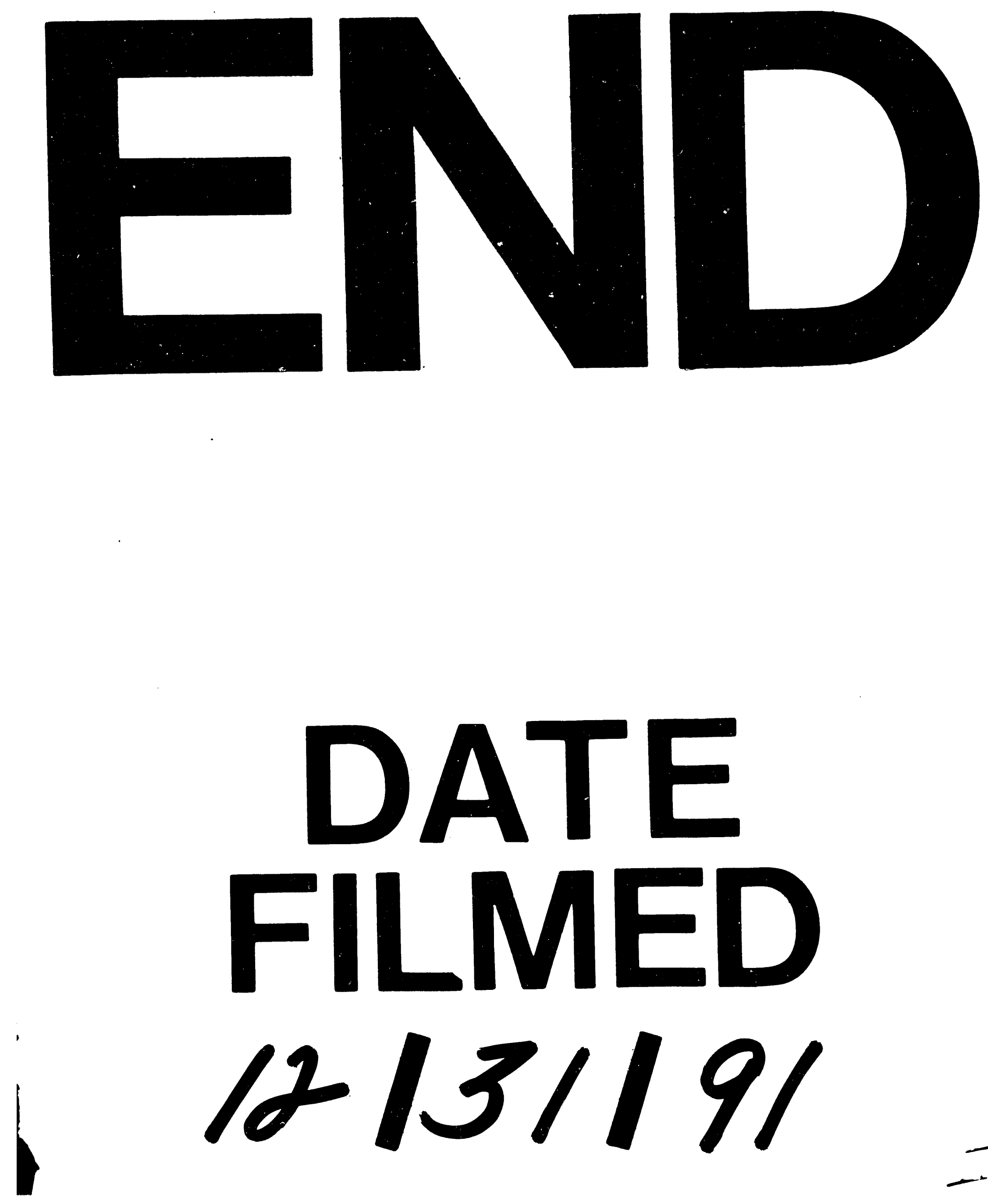